\title{
MORFOMETRIA DE POPULAÇÕES DE Heterodera glycines ICHINOHE, 1952 (NEMATA: HETERODERIDAE) E EFEITO DE PLANTAS HOSPEDEIRAS SOBRE A MORFOMETRIA DE UMA POPULAÇÃO
}

\author{
CARLOS EDUARDO ROSSI \\ Engenheiro Agrônomo
}

Orientador: Prof. Dr. LUIZ CARLOS C. B. FERRAZ

\begin{abstract}
Dissertação apresentada à Escola Superior de Agricultura "Luiz de Queiroz", Universidade de São Paulo, para obtenção do título de Mestre em Ciências, Área de Concentração: Entomologia.
\end{abstract}

P I R A C I C A B A

Estado de São Paulo - Brasil

Novembro de 1997 
Dados Internacionais de Catalogação na Publicação (CIP) DIVISÃo DE BIBLIOTECA E DOCUMENTAÇÃo - Campus "Luiz de Queiroz"/USP

Rossi, Carlos Eduardo

Morfometria de populaçōes de Heterodera glycines Ichinohe, 1952 (Nemata: Heteroderidae) e efeito de plantas hospedeiras sobre a morfometria de uma população / Carlos Eduardo Rossi. - - Piracicaba, 1997.

$86 \mathrm{p}$.

Dissertação (mestrado) - - Escola Superior de Agricultura Luiz de Queiroz, 1997. Bibliografia.

1. Morfometria animal 2. Nematóide-de-cisto-da-soja 3. Nematóide parasito de planta 4. Planta hospedeira 5. População animal I. Título 


\section{MORFOMETRIA DE POPULAÇÕES DE Heterodera glycines ICHINOHE, 1952 (NEMATA: HETERODERIDAE) E EFEITO DE PLANTAS HOSPEDEIRAS SOBRE A MORFOMETRIA DE UMA POPULAÇÃO}

CARLOS EDUARDO ROSSI

Aprovada em: 19.12.1997

Comissão julgadora:

Prof. Dr. Luiz Carlos Camargo Barbosa Ferraz

ESALQ/USP

$\mathrm{Dr}^{2}$. Leila Lucí Dinardo-Miranda

IAC/Piracicaba

Prof ${ }^{\natural}$. Dr ${ }^{\mathrm{a}}$. Marineide Mendonça Aguillera

UFSCar/Araras

Prof. Luiz Carlos Camargo Barbosa Ferraz

Orientador 
$\grave{A}$ minha esposa Sandra, que abnegadamente me estimulou e auxiliou com o mais nobre dos sentimentos:

o amor verdadeiro,

DEDYCO

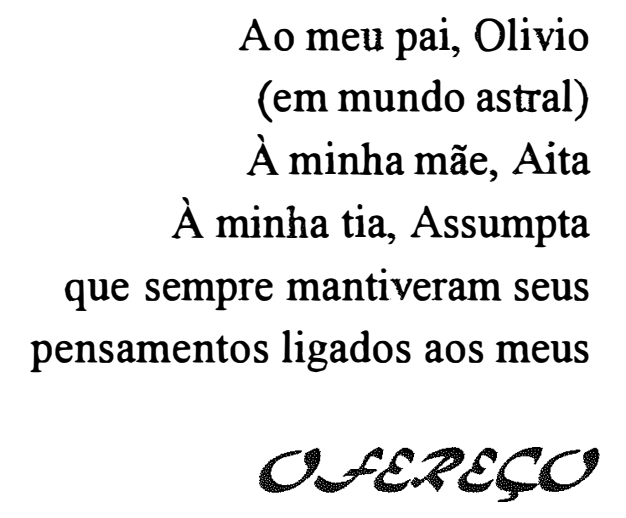




\section{AGRADECIMENTOS}

Quero deixar registrado os meus mais sinceros agradecimentos às pessoas e instituições que participaram comigo deste trabalho:

Ao Prof. Dr. Luiz Carlos Camargo Barbosa Ferraz, pela orientação, confiança, ensinamentos e amizade;

Ao Prof. Dr. Ailton Rocha Monteiro, pelas sugestões, permissão de uso de seus equipamentos e amizade;

Ao CNPq e CAPES, pelo apoio financeiro;

Aos Engenheiros Agrônomos João Flávio Veloso Silva, Antonio Carnielli, Daniel Cassetari Neto, pela remessa de amostras de solo infestado;

À Seção de Leguminosas (IAC) e Piraí Sementes, pela cessão de sementes;

Aos professores dos Departamentos de Zoologia e Entomologia, pelos ensinamentos e facilidades oferecidas;

Aos amigos Ana Cristina, Ana Maria, Anibal, Antonio Lofego (Tonhão), Fabrício, Marco, Miguel, Pimentel, Silvia Renata, Reginaldo, Sonia, Vera e Zacharias pelo companheirismo;

À bibliotecária Kátia M. de A. Ferraz, pela correção das referências bibliográficas. 


\section{SUMÁRIO}

\section{Página}

LISTA DE TABELAS ..................................................................... vii

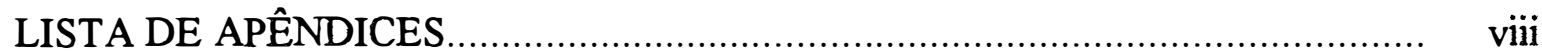

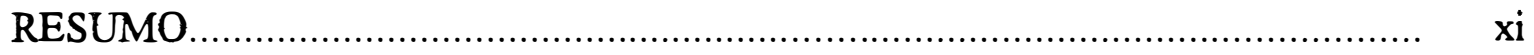

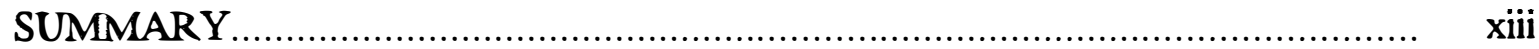

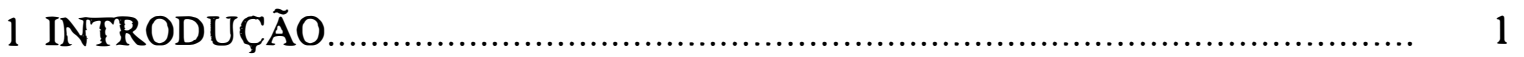

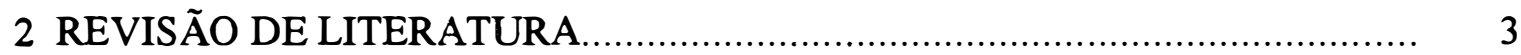

2.1 Variações morfométricas em Heterodera glycines .................................. 3

2.2 Plantas hospedeiras de Heterodera glycines.......................................... 6

2.3 Efeito de espécies vegetais com diferentes graus de eficiência hospedeira sobre a morfometria de Heterodera glycines........................................

3 MATERIAL E MÉTODOS .............................................................. 11

3.1 Morfometria de populações brasileiras de Heterodera glycines.................. 11

3.1.1 Local.................................................................................. $\quad 11$

3.1.2 Origem e manutenção das populações........................................ 11

3.1.3 Determinação das raças das populações....................................... 12

3.1.4 Obtenção de juvenis de segundo estádio .................................... 12

3.1.5 Formação das plantas ...................................................... 13

3.1.6 Inoculação e condução do experimento........................................ 13

3.1.7 Delineamento experimental.............................................. 14 


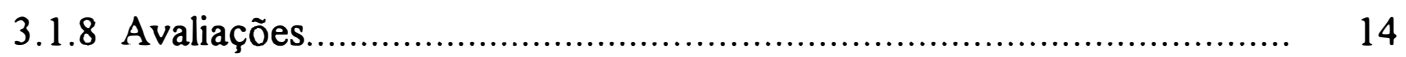

3.1.9 Preparação e montagem dos juvenis, machos e cistos para morfometria..

3.2 Efeito de espécies vegetais com diferentes graus de eficiência hospedeira na morfometria de Heterodera glycines.

4 RESULTADOS E DISCUSSÃO

4.1 Morfometria de populações de Heterodera glycines......

4.1.1 Juvenis de segundo estádio

4.1.2 Machos.

4.1.3 Cistos

4.1.4 Ovos

4.2 Morfometria de Heterodera glycines extraídos de espécies vegetais com diferentes graus de eficiência hospedeira.

4.2.1 Juvenis de segundo estádio

4.2.2 Machos.

4.2.3 Cistos.

4.2.4 Ovos.

5 CONCLUSÕES 


\section{LISTA DE TABELAS}

Página

01 Raças de Heterodera glycines identificadas, nas populações utilizadas no estudo, em função dos índices de parasitismo (I.P.).

02 Caracteres morfométricos mensurados em juvenis de segundo estádio (J), machos (M), cistos (C) e ovos (O) de Heterodera glycines e respectivas siglas.

03 Número de cistos de Heterodera glycines extraídos de soja 'FT Cristalina' de cada população, após 45 dias da inoculação de 1.000 juvenis de segundo estádio.

04 Valores médios de morfometria de 20 juvenis de segundo estádio de oito populações de Heterodera glycines extraídos aos 45 dias de soja 'FT Cristalina

05 Valores médios de morfometria de 20 machos de oito populações de Heterodera glycines extraídos aos 45 dias de soja 'FT Cristalina'.

06 Valores médios de morfometria de 12 cistos e 60 ovos de oito populações de Heterodera glycines extraídos aos 45 dias de soja 'FT Cristalina'

07 Número de cistos de Heterodera glycines, índice de parasitismo (I.P.) e reação das plantas hospedeiras, segundo Schmitt \& Shannon(1992)........

08 Valores médios de morfometria de 20 juvenis de segundo estádio de Heterodera glycines raça 3 (população SP2) extraídos aos 45 dias de cinco espécies vegetais com diferentes graus de eficiência hospedeira

09 Valores médios de morfometria de 20 machos de Heterodera glycines raça 3 (população SP2) extraídos aos 45 dias de cinco espécies vegetais com diferentes graus de eficiência hospedeira.

10 Valores médios de morfometria de 12 cistos e 60 ovos de Heterodera glycines raça 3 (população SP2) extraídos aos 45 dias de cinco espécies vegetais com diferentes graus de eficiência hospedeira. 


\section{LISTA DE APÊNDICES}

Página

01 Valores de morfometria de 20 juvenis de segundo estádio de Heterodera glycines população MT extraídos de soja 'FT Cristalina'

02 Valores de morfometria de 20 juvenis de segundo estádio de Heterodera glycines população SP1 extraídos de soja 'FT Cristalina'

03 Valores de morfometria de 20 juvenis de segundo estádio de Heterodera glycines população SP2 extraídos de soja 'FT Cristalina'.

04 Valores de morfometria de 20 juvenis de segundo estádio de Heterodera glycines população MS extraídos de soja 'FT Cristalina'.

05 Valores de morfometria de 20 juvenis de segundo estádio de Heterodera glycines população GO1 extraídos de soja 'FT Cristalina'...

06 Valores de morfometria de 20 juvenis de segundo estádio de Heterodera glycines população GO2 extraídos de soja 'FT Cristalina'

07 Valores de morfometria de 20 juvenis de segundo estádio de Heterodera glycines população PR extraídos de soja 'FT Cristalina'

08 Valores de morfometria de 20 juvenis de segundo estádio de Heterodera glycines população MG extraídos de soja 'FT Cristalina'.

09 Valores de morfometria de 20 machos de Heterodera glycines população MT extraídos de soja 'FT Cristalina'

10 Valores de morfometria de 20 machos de Heterodera glycines população SPl extraídos de soja 'FT Cristalina'.

11 Valores de morfometria de 20 machos de Heterodera glycines população SP2 extraídos de soja 'FT Cristalina'.

12 Valores de morfometria de 20 machos de Heterodera glycines população MS extraídos de soja 'FT Cristalina'.

13 Valores de morfometria de 20 machos de Heterodera glycines população GO1 extraídos de soja 'FT Cristalina'

14 Valores de morfometria de 20 machos de Heterodera glycines população GO2 extraídos de soja 'FT Cristalina' 
15 Valores de morfometria de 20 machos de Heterodera glycines população PR extraídos de soja 'FT Cristalina'.

16 Valores de morfometria de 20 machos de Heterodera glycines população MG extraídos de soja 'FT Cristalina'.

17 Valores de morfometria de 12 cistos e 60 ovos de Heterodera glycines população MT extraídos de soja 'FT Cristalina'

18 Valores de morfometria de 12 cistos e 60 ovos de Heterodera glycines população SP1 extraídos de soja 'FT Cristalina'.

19 Valores de morfometria de 12 cistos e 60 ovos de Heterodera glycines população SP2 extraídos de soja 'FT Cristalina'......

20 Valores de morfometria de 12 cistos e 60 ovos de Heterodera glycines população MS extraídos de soja 'FT Cristalina'

21 Valores de morfometria de 12 cistos e 60 ovos de Heterodera glycines população GO1 extraídos de soja 'FT Cristalina'...

22 Valores de morfometria de 12 cistos e 60 ovos de Heterodera glycines população GO2 extraídos de soja 'FT Cristalina'

23 Valores de morfometria de 12 cistos e 60 ovos de Heterodera glycines população PR extraídos de soja 'FT Cristalina'.

24 Valores de morfometria de 12 cistos e 60 ovos de Heterodera glycines população MG extraídos de soja 'FT Cristalina'.

25 Valores de morfometria de 20 juvenis de segundo estádio de Heterodera glycines população SP2 extraídos de soja 'FT Cristalina'.

26 Valores de morfometria de 20 juvenis de segundo estádio de Heterodera glycines população SP2 extraídos de feijão comum 'IAC Carioca'..

27 Valores de morfometria de juvenis de segundo estádio de Heterodera glycines população SP2 extraídos de crotalária cv. IAC 1-2 e chícharo.....

28 Valores de morfometria de 20 juvenis de segundo estádio de Heterodera glycines população SP2 extraídos de feijão azuki vermelho 'AL-9'.

29 Valores de morfometria de 20 juvenis de segundo estádio de Heterodera glycines população SP2 extraídos de feijão mungo 'M-80'. 
30 Valores de morfométricos de 20 juvenis de segundo estádio de Heterodera glycines população SP2 extraídos de tremoço branco.

31 Valores de morfometria de 20 machos de Heterodera glycines população SP2 extraídos de soja 'FT Cristalina'.

32 Valores de morfometria de 20 machos de Heterodera glycines população SP2 extraídos de feijão comum 'IAC Carioca'.....

33 Valores de morfometria de 20 machos de Heterodera glycines população SP2 extraídos de feijão azuki vermelho 'AL-9'

34 Valores de morfometria de 20 machos de Heterodera glycines população SP2 extraídos de feijão mungo 'M-80'

35 Valores de morfometria de 20 machos de Heterodera glycines população SP2 extraídos de tremoço branco.

36 Valores de morfometria de 12 cistos e 60 ovos de Heterodera glycines população SP2 extraídos de soja 'FT Cristalina'.

37 Valores de morfometria de 12 cistos e 60 ovos de Heterodera glycines população SP2 extraídos de feijão comum 'IAC Carioca'..

38 Valores de morfometria de 7 cistos de Heterodera glycines população SP2 extraídos de chícharo.

39 Valores de morfometria de 12 cistos e 60 ovos de Heterodera glycines população SP2 extraídos de feijão azuki vermelho 'AL-9'

40 Valores de morfometria de 12 cistos e 60 ovos de Heterodera glycines população SP2 extraídos de feijão mungo 'M-80'.

41 Valores de morfometria de 12 cistos e 60 ovos de Heterodera glycines população SP2 extraídos de tremoço branco 


\title{
MORFOMETRIA DE POPULAÇŌES DE Heterodera glycines ICHINOHE, 1952 (NEMATA: HETERODERIDAE) E EFEITO DE PLANTAS HOSPEDEIRAS SOBRE A MORFOMETRIA DE UMA POPULAÇÃO
}

\author{
Autor: Carlos Eduardo Rossi \\ Orientador: Prof. Dr. Luiz Carlos C.B. Ferraz
}

\section{RESUMO}

Realizaram-se dois experimentos, em casa de vegetação, para verificar as variações que ocorrem na morfometria de populações brasileiras de Heterodera glycines Ichinohe, 1952 e o efeito de espécies vegetais com diferentes graus de eficiência hospedeira sobre a morfometria de uma população do nematóide. No primeiro, utilizaram-se oito populações procedentes dos Estados de Mato Grosso (MT), São Paulo (SP1 e SP2), Mato Grosso do Sul (MS), Goiás (GO1 e GO2), Paraná (PR) e Minas Gerais (MG). Cada planta foi inoculada com 1000 juvenis de segundo estádio, em 20 repetições para cada população, sendo a parcela representada por uma planta de soja 'FT Cristalina'. Após 45 dias, foram extraídos os juvenis de segundo estádio, machos e cistos. Os ovos foram extraídos dos cistos. Estudaramse 23 caracteres relativos a juvenis, 19 a machos, 12 a cistos e 2 a ovos. Os resultados do primeiro estudo confirmaram que as populações apresentam as características da espécie $H$. glycines. Apesar disso, foram verificadas diferenças significativas entre as populações, não sendo possível caracterizar uma ou mais populações por causa da sobreposição dos valores numéricos. Entretanto, as populações GO1 e GO2, no caso dos juvenis, e GO2, no caso dos machos, mostraram valores significativamente superiores aos das demais para determinados caracteres. Por outro lado, para juvenis, MG, MS e SP1, e para machos, MG, foram as populações que mostraram valores significativamente menores que os das demais para 
determinados caracteres. Para cistos e ovos, não foi possível verificar alguma população que se destacasse das demais com caracteres apresentando diferenças significativas. Na segunda parte do estudo, inoculou-se cada planta de soja 'FT Cristalina', feijão comum 'IAC Carioca', ervilha 'Maria', chícharo, crotalária (Crotalaria juncea L.) 'IAC 1-2', feijão azuki vermelho 'AL-9', feijão mungo verde 'M-80' e tremoço branco com 1000 juvenis de segundo estádio, num total de 20 repetições para cada espécie vegetal. A partir daí, os procedimentos adotados foram semelhantes aos do primeiro estudo. Verificou-se que a ervilha, a crotálaria e o chícharo foram hospedeiras altamente desfavoráveis ao nematóide, obtendo-se a partir delas número insuficiente de espécimes para o estudo morfométrico comparativo com as demais hospedeiras, não sendo possível, inclusive, analisar estatisticamente os seus dados. Para os feijões comum, mungo e azuki e para o tremoço branco, considerados moderadamente resistentes, verificaram-se poucos caracteres com diferenças significativas em comparação à soja, não permitindo evidenciar efeitos negativos dessas hospedeiras sobre a morfometria do parasito. 


\title{
MORPHOMETRY OF Heterodera glycines ICHINOHE, 1952 (NEMATA: HETERODERIDAE) POPULATIONS AND EFFECT OF HOST PLANTS ON THE MORPHOMETRY OF A POPULATION
}

\author{
Author: Carlos Eduardo Rossi \\ Adviser: Prof. Dr. Luiz Carlos C.B. Ferraz
}

\section{SUMMARY}

Two trials were carried out, under greenhouse conditions, to assess the morphometric variations occurring among brazilian populations of Heterodera glycines Ichinohe, 1952 as well as the effect of plant species with different host suitability degrees on the morphometry of one population of the nematode. In the first one, eight populations proceeding from the States of Mato Grosso (MT), São Paulo (SP1 and SP2), Mato Grosso do Sul (MS), Goiás (GO1 and GO2), Paraná (PR) and Minas Gerais (MG) were used. Each soybean 'FT-Cristalina' plant was inoculated with 1,000 second-stage juveniles, in 20 repetitions for each population. The juveniles, males and cysts were extracted after 45 days of the inoculations. The eggs were subsequently extracted from the cysts. The study comprised 23 characters regarding to juveniles, 19 to males, 12 to cysts and 2 to eggs. The results confirmed that all the populations featured characteristics of the species $H$. glycines. Even so, significant differences occurred between the populations with regard to some characters, but it was not possible to properly characterize one or more populations because of the frequent overlapping of the numerical values observed. It should be noticed that the populations $\mathrm{GO} 1$ and $\mathrm{GO} 2$, for juveniles, and $\mathrm{GO} 2$, for males, showed significantly higher values for some characters than all other populations. Otherwise, MG, MS and SP1, for juveniles, and MG, for males, showed significantly lower values for some characters than all other populations. For cysts and eggs, no significant differences were observed among the population used in this study. In the second trial, each plant of the tested hosts (soybean 'FT- 
Cristalina', common bean 'IAC-Carioca', pea 'Maria', chickpea, sunn hemp 'IAC 1-2', adzuki bean 'AL-9', mung bean 'M-80' and white lupin) was inoculated with 1,000 second-stage juveniles, with 20 repetitions. The other procedures were similar to those adopted in the first trial. Pea, sunn hemp and chickpea showed to be very poor/unfavourable hosts not allowing to the formation of nematode specimens in their roots in sufficient numbers to make possible a comparative study together with the other tested host plants. For common bean, adzuki bean, mung bean and white lupin, rated as moderately resistant hosts, significant differences occurred for some characters in relation to soybean data, but no evidence of negative effects of these plant species on the morphometry of the nematode could be noticed. 


\section{INTRODUÇÃO}

O nematóide de cisto da soja [Glycine max (L.) Merr.], Heterodera glycines Ichinohe, 1952, tem causado grandes prejuízos à sojicultura mundial. Sua ocorrência no Brasil foi relatada na safra 91/92, infestando pelo menos 10.000 hectares da cultura nos Estados de Mato Grosso (Lordello et al., 1992), Mato Grosso do Sul (Monteiro \& Morais, 1992) e Minas Gerais (Lima et al., 1992). Atualmente, ocorre também em mais quatro Estados: Goiás (Mendes \& Dickson, 1993), São Paulo (Rossi et al., 1995), Rio Grande do Sul (Carneiro \& Almeida, 1995) e Paraná (Embrapa, 1996) e a estimativa de área infestada ultrapassa 1.500 .000 hectares (Silva, J.F.V. et al., 1997).

Essa rápida expansão, além de evidenciar uma alta capacidade de disseminação, indica que a espécie foi introduzida em solo brasileiro. Corrobora essa hipótese, o fato de seis raças diferentes do parasito terem sido detectadas em um levantamento realizado no ano de 1993 (Noel et al., 1994). Atualmente, estão relatadas nove raças no Brasil (Silva, J.F.V. et al., 1997). Como, à época do aparecimento da espécie no país, não existiam cultivares resistentes que pudessem exercer pressão de seleção nas populações, acreditase que houve várias introduções do nematóide no país.

As raças são populações de campo que, diferindo na freqüência de genes, mostram habilidade distinta de parasitar uma série de hospedeiras consideradas diferenciais. Dentro de uma população, é possível ocorrer uma mistura de genótipos e, conseqüentemente, de raças. Aliado a isso, $H$. glycines é espécie anfimítica e o acasalamento de uma fêmea com vários machos é comum, o que pode gerar hibridações entre raças. Isso resulta em uma enorme variabilidade genética dentro das populações desse nematóide (Opperman, 1995).

A conseqüência prática disso é o surgimento de problemas no desenvolvimento de cultivares resistentes. Assim, para que a utilização da técnica de rotação de culturas, incluindo cultivares resistentes de soja na seqüência de cultivos, não seja fadada ao 
fracasso após poucos anos de uso, torna-se necessário um acompanhamento efetivo das características genéticas das populações dentro dos programas de melhoramento.

Heterodera glycines é de ocorrência recente em condições brasileiras e como estão sendo desenvolvidas muitas pesquisas relativas ao controle, principalmente por resistência genética de plantas, considera-se importante conhecer os aspectos biológicos, comportamentais, fisiológicos e morfológicos do nematóide.

Para isso, o estudo da morfometria é uma ferramenta que orienta a identificação de espécies e proporciona meios de se conhecer as importantes variações intraespecíficas.

Os objetivos deste trabalho foram:

a) caracterizar, por morfometria, oito populações brasileiras de $H$. glycines geograficamente isoladas e observar as possíveis variações e diferenças ocorrentes entre elas;

b) verificar os efeitos que espécies vegetais com diferentes graus de eficiência hospedeira ocasionam sobre a morfometria de uma determinada população. 


\section{REVISÃO DE LITERATURA}

A revisão apresentada a seguir reúne trabalhos relacionados à morfometria de populações de $H$. glycines, às plantas hospedeiras do nematóide, com ênfase às espécies vegetais usadas no trabalho, e ao efeito que as mesmas podem causar à morfometria do parasito.

\subsection{Variações morfométricas em Heterodera glycines}

A ocorrência de um nematóide de cisto em soja foi relatada pela primeira vez no Japão por Hori' citado por Ichinohe (1952), sendo, naquela ocasião, identificado como Heterodera schachtii Schmidt, 1871. Fujita \& Miura (1934) avaliaram as reações de diferentes espécies vegetais a esse nematóide e, pelo fato de não infectar quenopodiáceas, hospedeiras eficientes de $H$. schachtii, passou a ser referido como uma raça biológica de $H$. schachtii. Ichinohe (1952) comparou espécimes desse nematóide com os de outras espécies de Heterodera e em função de diferenças observadas nas características das pontuações da cutícula do cisto, na razão comprimento/largura do cisto, na cor da fêmea, no comprimento do estilete do macho e no círculo de hospedeiras decidiu por considerála como espécie nova à ciência, descrevendo-a como $H$. glycines. Anos depois, esse mesmo autor (Ichinohe, 1959) complementou a descrição original, comentando mais detalhadamente aspectos da morfologia e biologia da espécie.

Atualmente, a identificação específica de Heterodera é baseada principalmente no estudo das estruturas do cone vulvar do cisto e na morfometria de juvenis de segundo estádio e de machos, além do conhecimento do círculo de hospedeiras (Mulvey, 1972 e Baldwin \& Mundo-Ocampo, 1991).

\footnotetext{
${ }^{1}$ HORI, S. Phytopathological notes. 5. Sick soil of soy bean caused by a nematode. Journal of Plant Protection, v. 2, p. 927-930, 1915.
} 
Sabe-se que $H$. glycines, $H$. schachtii e $H$. trifolii Goffart, 1932 são espécies muito próximas morfologicamente (Graney \& Miller, 1982 e Riggs et al., 1982), havendo sobreposição de plantas hospedeiras e coexistência em mesmo local. Entretanto, existem caracteres considerados mais eficientes para a diferenciação interespecífica (Hirschmann, 1956; Graney \& Miller, 1982 e Mulvey \& Golden, 1983).

Dez anos após a descrição de $H$. glycines e oito depois do relato inicial de ocorrência nos Estados Unidos (Winstead et al., 1955), surgiu a primeira referência a diferenças fisiológicas entre populações (Ross, 1962). Esse autor estudou a reprodução de uma população do Estado da Carolina do Norte em uma linhagem de soja resistente à população do Estado de Tennessee. A partir dessa primeira observação, outros estudos começaram a surgir, identificando diferenças entre e dentro de populações geográficas .

Golden et al. (1970), em vista das muitas variações observadas nos resultados obtidos nas pesquisas envolvendo o nematóide nos Estados Unidos, propuseram um primeiro esquema de identificação de raças de $H$. glycines baseado nas reações apresentadas pelas diferentes populações quando inoculadas em três cultivares (Peking, Pickett e Lee) e duas introduções (PI 88788 e PI 90763) tidas como "padrões". Por esse sistema de identificação, podiam ser reconhecidas quatro raças.

Riggs (1988) revisou os trabalhos relativos às variações fisiológicas observadas entre diferentes populações dos Estados Unidos, o que permitiu a expansão do esquema de caracterização de raças proposto inicialmente por Golden et al. (1970), possibilitando a caracterização de 16 possíveis raças de H. glycines (Riggs \& Schmitt, 1988).

Outras variações foram encontradas entre populações com relação à sintomatologia causada. Algumas áreas, apesar do alto nível de infestação, não apresentavam sintomas de amarelecimento nas folhas. Esse sintoma foi associado à supressão de nodulação pela bactéria Bradyrhizobium (Epps \& Golden, 1967). Esses autores também observaram diferenças morfológicas entre as populações estudadas.

Variações nos valores morfométricos estão bem documentadas para populações do Japão e principalmente dos Estados Unidos. Ichinohe (1961) e Ohshima et al. ${ }^{2}$, citados por Burrows \& Stone (1985), fizeram estudos morfométricos com populações obtidas no Japão.

\footnotetext{
${ }^{2}$ OHSHIMA, Y.; MOMOTA, Y.; SHIMIZU, K. Additional information of some morphological characteristics of Heterodera glycines Ichinohe, 1952. Japanese Journal of Nematology, v. 10, p. 52$53,1981$.
} 
A separação de populações é feita com base em um ou em vários caracteres. Golden \& Epps (1965) afirmaram que o comprimento da cauda e a forma e o comprimento da região hialina da cauda de juvenis de segundo estádio permitiram a distinção entre seis isolados geográficos (cinco dos Estados Unidos e um do Japão), permitindo a formação de três grupos: o primeiro com a cauda e a região hialina da cauda curtas (42 e $22 \mu \mathrm{m})$, o segundo com a cauda e a região hialina da cauda longa (50 e $26 \mu \mathrm{m})$ e um terceiro grupo intermediário com cauda e região hialina da cauda com 45 e $23 \mu \mathrm{m}$, respectivamente.

Koliopanos \& Triantaphyllou (1971) também observaram diferenças nos comprimentos do corpo, da cauda e da região hialina da cauda de juvenis oriundos de quatro populações. A média do comprimento do corpo separou as populações em dois grupos significativamente diferentes, o comprimento da cauda em três grupos e o comprimento da região hialina da cauda mostrou-se significativamente diferente entre as quatro populações. Da mesma forma, Miller \& Duke (1967) encontraram diferenças significativas para caracteres de juvenis, machos, cistos e ovos oriundos de 11 locais dos Estados Unidos, porém como ocorreu sobreposição nos valores, não foi possível a esses autores definir caracteres realmente úteis à distinção entre as populações estudadas.

Taylor (1974), procurando viabilizar a identificação de $H$. glycines para serviço de quarentena, definiu, por morfometria, os intervalos de variação dos principais caracteres dos diferentes estádios do nematóide.

Trabalhando com 35 populações de $H$. glycines e 15 de outras espécies de Heterodera, Globodera e Punctodera, Riggs et al. (1982) verificaram uma grande variação nas mensurações morfométricas intra e interespecíficas e encontraram uma população tetraplóide de $H$. glycines com as dimensões do corpo consideravelmente maiores. Se não houvesse sobreposição nas mensurações morfométricas, o que ocorreu nesse estudo para populações de $H$. glycines, poder-se-ia descrever subespécies do nematóide.

Faghihi et al. (1986b) trabalharam com morfometria de juvenis, machos, cistos e ovos de cinco populações de $H$. glycines do Estado de Indiana (EUA) com o objetivo de diferenciar populações do norte e do sul. Observaram-se algumas diferenças nas médias, porém, houve sobreposição nos valores. A morfometria de juvenis de segundo estádio mostrou-se mais útil na diferenciação do que a de outros estádios de desenvolvimento. Entretanto, não se encontraram caracteres que pudessem diferenciar as populações do norte com as do sul, nem similaridades entre as diferenças morfométricas das populações 
com as respostas das mesmas em relação à reprodução em certas linhagens e cultivares de soja (Faghihi, 1986a).

No Brasil, Lima et al. (1992) mensuraram alguns caracteres de exemplares de um nematóide de cisto detectado em lavoura de soja no Estado de Minas Gerais, concluindo que a espécie pertencia ao gênero Heterodera e ao grupo schachtii. Posteriormente, Ferraz $^{3}$ confirmou tratar-se de $H$. glycines.

Tihohod (1996) estudou populações de $H$. glycines oriundas de Iraí de Minas (MG), Chapadão do Céu (GO) e Costa Rica (MS) e uma população de $H$. fici Kirjanova, 1954 de Valinhos (SP) do ponto de vista da morfometria e bioquímica. Os resultados obtidos do estudo morfométrico permitiram a caracterização e identificação das populações, bem como das espécies estudadas, com eficiência, já que ambas as espécies pertencem ao grupo schachtii e, conseqüentemente, são muito semelhantes. Os caracteres dos juvenis de segundo estádio tiveram menor variabilidade do que os de cistos, sendo considerados de maior utilidade na caracterização e identificação das espécies de Heterodera.

\subsection{Plantas hospedeiras de Heterodera glycines}

Uma planta é considerada hospedeira se pelo menos uma fêmea completa o ciclo e produz ovos férteis (Riggs \& Hamblen, 1966).

Uma das características do gênero Heterodera, que auxilia muito na identificação específica, é o restrito número de hospedeiras. Entretanto, $H$. glycines tem ampla gama de plantas hospedeiras, incluindo, principalmente, representantes da família Fabaceae, mas também de outras famílias (Riggs, 1992).

O primeiro estudo sobre a gama de plantas hospedeiras desse nematóide foi feito por Fujita \& Miura (1934), considerando soja, feijão azuki [Vigna angularis (Willd.) Ohwi \& Ohashi], feijão comum (Phaseolus vulgaris L.) e feijão multiflora (Phaseolus coccineus L.) passíveis de serem parasitadas. Hoje sabe-se que este último não é planta hospedeira (Riggs, 1992).

\footnotetext{
${ }^{3}$ FERRAZ, S. (Universidade Federal de Viçosa, Viçosa-MG). Comunicação pessoal, 1994.
} 
Skotland et al. ${ }^{4}$, citados por Ichinohe (1961), relataram como hospedeiras as espécies vegetais lespedeza anual (Lespedeza stipulacea Maxim.), ervilhaca comum (Vicia sativa L.) e feijão comum (Phaseolus vulgaris L.).

Skotland (1957), avaliando a hospedabilidade de 45 espécies vegetais, que incluíam representantes de 28 gêneros e nove famílias, adicionou à lista de hospedeiras as espécies Glycine gracilis Skvortz., ervilhaca peluda, Vicia villosa Roth., lespedeza comum, Lespedeza striata (Thunb. ex Murr.) Hook., e lespedeza chinesa, L. cuneata (Dum.-Cours.) G.Don.

Epps \& Chambers $(1958 ; 1959)$ adicionaram outras quatro espécies vegetais como hospedeiras, a saber: Sesbania macrocarpa Mühlenb.; o tremoço branco, Lupinus albus L.; Lamium amplexicaule L.; e feijão mungo, Phaseolus aureus Roxb., atualmente conhecida como Vigna radiata (L.) Wilczek.

Riggs \& Hamblen (1962) avaliaram as reações de dezenas de espécies vegetais frente a uma população obtida do Estado de Arkansas, sob condições de casa de vegetação. Como era de se esperar, as plantas hospedeiras foram principalmente leguminosas (= fabáceas). Espécies vegetais filiadas a outras famílias botânicas foram, no geral, não hospedeiras. Entre as hospedeiras confirmadas como suscetíveis incluíam-se o feijão comum, o feijão mungo, o feijão azuki e o tremoço branco. Em relação ao chícharo (Lathyrus sativus L.), quatro introduções mostraram-se resistentes e uma suscetível. Para a Crotalaria juncea L., a introdução estudada revelou-se resistente. Finalmente, as cultivares de ervilha (Pisum sativum L.) testadas foram predominantemente resistentes.

Smart (1964) verificou, pela primeira vez, a existência de plantas hospedeiras dentro das famílias Caryophyllaceae e Scrophulariaceae, além de duas espécies de leguminosas.

Riggs \& Hamblen (1966) deram continuidade ao estudo anterior publicado em 1962, avaliando a hospedabilidade de algumas espécies de leguminosas ainda não testadas e de representantes de outras 50 famílias botânicas.

Finalmente, Riggs (1992) sintetizou toda a pesquisa desenvolvida nesse sentido e classificou as hospedeiras em duas categorias: eficientes ("efficient") ou desfavoráveis

\footnotetext{
${ }^{4}$ SKOTLAND, C.B.; SASSER, J.N.; WINSTEAD, N.N. Preliminary reports of results of research on the soybean cyst nematode in North Carolina. Ann. Rept. Soybean Cyst Nema. Control., Pl. Pest Control. Branch, U.S.D.A. p. 19-25, 1956.
} 
("poor hosts"), entendendo-se como desfavoráveis aquelas nas quais poucas fềmeas são formadas.

No Brasil, Iunes (1995), trabalhando com plantas cultivadas, genótipos de soja e plantas daninhas, confirmou, entre outros resultados, a suscetibilidade do feijão azuki e observou variabilidade na reação de espécies de crotalárias e cultivares de feijão comum. Becker et al. (1995) também encontraram diferentes reações de cultivares e linhagens de feijão comum frente a uma população de $H$. glycines oriunda de Minas Gerais.

Carnielli (1995), em experimento realizado em campo, observou fêmeas nas raizes de ervilha, ervilhaca peluda, feijão comum e feijão fava (Vicia faba L.), além de soja. Entretanto, em estudo com 196 introduções de ervilha, Riggs \& Hamblen (1962) verificaram variabilidade na reação de ervilha, obtendo respostas de imunidade (nenhuma fềmea encontrada nas raízes e no solo) até suscetibilidade (mais de 10 cistos encontrados). Contradizendo o trabalho anterior, Riggs (1992) qualifica todas as cultivares de ervilha como hospedeiras eficientes para a reprodução de $H$. glycines.

Valle (1996) verificou que feijão azuki 'AL-9', feijão mungo 'M-124', Crotalaria juncea cv. IAC 1 e guandu [Cajanus cajan (L.) Millsp.] 'IAC Fava Larga' permitiram a reprodução de uma população de $H$. glycines raça 3.

Silva, M.A. et al. (1997) observaram que ervilha 'XPC-88', caupi [Vigna unguiculata (L.) Walp.] 'IT-835-899' e grão de bico (Cicer arietinum L.) 'ICCV-3' e 'IAC India-4' não foram hospedeiras de $H$. glycines raça 3, mas feijão comum '2293', feijão azuki 'M-127' e feijão arroz [Vigna umbellata (Thunb.) Ohwi \& Ohashi] 'USA' apresentaram-se como hospedeiras, com indice de parasitismo superior a $10 \%$ do encontrado em soja.

Dias et al. (1995), trabalhando com plantas daninhas, testaram 17 espécies vegetais, não encontrando nenhuma que tivesse hospedado o nematóide.

Estudando a reação de nove espécies de leguminosas usadas como cobertura do solo e adubação verde, Valle et al. (1997) verificaram que apenas em soja, galáxia [Galactia striata (Jacq.) Urb.] e Crotalaria ochroleuca G. Don encontraram-se fêmeas do nematóide nas raízes. 


\subsection{Efeito de espécies vegetais com diferentes graus de eficiência hospedeira sobre a morfometria de Heterodera glycines}

Os trabalhos relativos a plantas hospedeiras referem-se, na maioria das vezes, à reprodução do nematóide. Trabalhos tratando de diferenças morfométricas originadas a partir do parasitismo em plantas com diferentes graus de eficiência hospedeira são escassos na literatura.

Tarte \& Mai (1976) citaram que aspectos do comportamento, bem como mudanças ocorridas durante o desenvolvimento, estão associados a variações nos caracteres morfológicos. A indução de variabilidade tem sido considerada em relação à densidade populacional, ao método de preparação dos nematóides para observação microscópica, aos fatores do ambiente, às espécies de plantas hospedeiras e, também, à fisiologia dessas plantas hospedeiras. Diferenças relacionadas com a localização geográfica têm sido sugeridas em alguns casos.

Trudgill et al. (1970) observaram, em machos de Globodera rostochiensis (Wollenweber, 1923) Behrens, 1975 (antes Heterodera rostochiensis) desenvolvidos em cultivares de batata resistentes, que o comprimento do corpo e, conseqüentemente, o comprimento do estilete, eram menores do que os desenvolvidos em batatas suscetíveis, concluindo que as primeiras são nutricionalmente menos favoráveis ao desenvolvimento dos juvenis que formariam machos. O mesmo fato foi relatado por Williams \& Siddiqi (1972) com relação a Heterodera avenae Wollenweber, 1924, cujos machos eram bem menores quando extraídos de cereais resistentes.

Pant et al. (1985) verificaram que fêmeas de Meloidogyne incognita (Kofoid \& White, 1919) Chitwood, 1949, quando desenvolvidas em plantas hospedeiras resistentes, têm as dimensões do corpo reduzidas. Esses mesmos autores consideraram que esse fato poderia estar relacionado às características morfológicas da raiz, como por exemplo, ao decréscimo no número e tamanho de células de transferência formadas como resultado do parasitismo, ou pela presença de certas substâncias nematóxicas formadas a partir da interação entre a planta hospedeira e o nematóide.

Para H. glycines, Ichinohe (1961) apresentou quadro comparativo de medidas obtidas de fềmeas formadas em raízes de soja, feijão comum e feijão azuki, extraídas aos 18 e 30 dias das inoculações. Miller (1968) observou que o comprimento de cistos, o comprimento e a largura de ovos e o comprimento de juvenis obtidos de raizes de boca de leão (Antirrhinum majus L.) foram significativamente menores do que os obtidos em 
soja. Da mesma forma, fêmeas formadas em tomate (Lycopersicon esculentum Mill.) 'Pearson A-1' foram menores que as de soja 'Lee' (Miller, 1975). Por outro lado, Abawi \& Jacobsen (1984) não observaram diferenças na largura de juvenis e fềmeas desenvolvidas em feijão comum 'California Light Red Kidney'ou em soja 'Amsoy 71'. 


\section{MATERIAL E MÉTODOS}

\subsection{Morfometria de populações brasileiras de Heterodera glycines}

\subsubsection{Local}

O estudo foi realizado sob condições de casa de vegetação no Departamento de Zoologia da ESALQ/USP, localizado no município de Piracicaba, SP, latitude $22^{\circ} 42^{\prime}$ 30 " $\mathrm{S}$.

\subsubsection{Origem e manutenção das populações}

Amostras de solo da rizosfera de soja coletadas em áreas infestadas com $H$. glycines dos Estados de Mato Grosso [município de Primavera do Leste (MT)], São Paulo [Tarumã (SP1) e Florínea (SP2)], Mato Grosso do Sul [Costa Rica (MS)], Goiás [Jataí (GO1) e Chapadão do Céu (GO2)], Paraná [Sertaneja (PR)] e Minas Gerais [Uberaba (MG)], foram misturadas a substrato composto por solo e areia (2:1), previamente esterilizado por brometo de metila $\left(150 \mathrm{~cm}^{3} / \mathrm{m}^{3}\right)$ e colocadas em recipientes plásticos de $535 \mathrm{~cm}^{3}$ de capacidade, perfazendo volume de $500 \mathrm{~cm}^{3}$. Em cada recipiente foi transplantada uma plântula de soja 'FT Cristalina' em estádio VE (Fehr \& Caviness, 1977). Os recipientes, contendo solo da mesma área, foram mantidos agrupados, mas devidamente separados entre si, no interior de vasos de barro com capacidade para 7 litros, preenchidos $1 / 3$ de sua capacidade com pedra britada. 


\subsubsection{Determinação das raças das populações}

As populações MS, GOl e PR foram obtidas junto ao CNPSo/EMBRAPA, Londrina, PR já com as raças identificadas. As populações GO2 e MT foram obtidas do CPAO/EMBRAPA, Dourados - MS e Universidade Federal do Mato Grosso, Cuiabá MT, respectivamente, também já identificadas. As demais populações foram coletadas nos locais citados.

Todas as populações foram caracterizadas segundo método proposto por Riggs \& Schmitt (1988), tido hoje como de rotina, adotando-se a soja 'FT Cristalina' como o padrão de suscetibilidade (Tabela 01).

Tabela 01. Raças de Heterodera glycines identificadas, nas populações utilizadas no estudo, em função dos índices de parasitismo (I.P.)*.

\begin{tabular}{ccccccc}
\hline \multirow{2}{*}{ População } & \multicolumn{5}{c}{ Indices de Parasitismo e Reação nas Plantas Diferenciais } & \multirow{2}{*}{ Raça } \\
\cline { 2 - 6 } & \multicolumn{2}{c}{ Pickett } & Peking & PI 88788 & PI 90763 & FT Cristalina \\
\hline MT & $2,3(-) * *$ & $0,3(-)$ & $11,7(+)$ & $0,1(-)$ & $100(+)$ & 1 \\
MS & $74,0(+)$ & $17,2(+)$ & $0(-)$ & $14,9(+)$ & $100(+)$ & 14 \\
GO1 & $43,2(+)$ & $40,1(+)$ & $0(-)$ & $11,7(+)$ & $100(+)$ & 14 \\
GO2 & $53,4(+)$ & $18,3(+)$ & $2,2(-)$ & $18,6(+)$ & $100(+)$ & 14 \\
MG & $0(-)$ & $0(-)$ & $0(-)$ & $0(-)$ & $100(+)$ & 3 \\
PR & $0(-)$ & $0(-)$ & $0(-)$ & $0(-)$ & $100(+)$ & 3 \\
SP1 & $0(-)$ & $0(-)$ & $0(-)$ & $0(-)$ & $100(+)$ & 3 \\
SP2 & $0(-)$ & $0(-)$ & $0(-)$ & $0(-)$ & $100(+)$ & 3 \\
\hline
\end{tabular}

*Segundo Riggs \& Schmitt (1988).

**(+) I.P. $\geq 10 \%$ e (-) I.P. $<10 \%$.

\subsubsection{Obtenção de juvenis de segundo estádio}

Após 35 dias do transplantio da soja em solo infestado, retiraram-se as plantas dos recipientes e extraíram-se as fêmeas brancas do nematóide dos sistemas radiculares. Para tanto, as raizes foram mergulhadas em água contida em balde para eliminar o solo aderente e, em seguida, colocadas sobre peneira $n^{\circ} 20$ (malha de 0,850mm). As fêmeas foram removidas submetendo-se as raizes a jato forte de água por 30 segundos e recolhendo-as em peneira $n^{\circ} 60$ (malha de $0,250 \mathrm{~mm}$ ) subposta à $n^{\circ} 20$. Colocaram-se 
então as fêmeas em câmaras de eclosão, formadas mediante o método do Baermann modificado para recipiente raso, descrito em Southey (1970), com temperatura variando de 24 a $27^{\circ} \mathrm{C}$, de modo a se obter juvenis de segundo estádio. Os juvenis foram recolhidos diariamente mediante passagem da suspensão por peneira $n^{\circ} 500$ (malha de $0,025 \mathrm{~mm}$ ), sendo transferidos para béqueres de $50 \mathrm{~cm}^{3}$ de capacidade, tampados com papel alumínio e mantidos em câmara tipo $\mathrm{BOD}$, a $16^{\circ} \mathrm{C}$. O número de juvenis por $\mathrm{cm}^{3}$ foi estimado em lâmina de Peters ao microscópio, calibrando-se para 500 juvenis por $\mathrm{cm}^{3} \mathrm{da}$ suspensão-inóculo.

\subsubsection{Formação das plantas}

Concomitantemente à obtenção dos juvenis, sementes de soja 'FT Cristalina' procedentes da Seção de Leguminosas do Instituto Agronômico de Campinas (IAC) foram selecionadas para maior uniformidade, tratadas com hipoclorito de sódio a $0,25 \%$, por 5 minutos, para a desinfecção superficial e, em seguida, lavadas com água destilada (Abawi \& Jacobsen, 1984). A seguir, foram colocadas para germinar em placas de Petri, com papel de filtro umedecido no fundo. As sementes pré-germinadas foram transplantadas para recipientes plásticos com capacidade para $535 \mathrm{~cm}^{3}$, contendo $500 \mathrm{~cm}^{3}$ do mesmo substrato esterilizado do item 3.1.2. Quando se apresentaram no estádio V1 (Fehr \& Caviness, 1977), foram selecionadas plântulas de tamanho uniforme para serem inoculadas.

\subsubsection{Inoculação e condução do experimento}

Procedeu-se a inoculação das plantas com pipetador automático, liberando-se $2 \mathrm{~cm}^{3}$ da suspensão-inóculo, contendo aproximadamente 1.000 juvenis, em dois orifícios previamente preparados junto ao caule de cada plântula, cobertos, em seguida, com pequena quantidade de substrato.

As plantas foram mantidas por 45 dias após a inoculação com temperatura do ar variando de 18 a $32^{\circ} \mathrm{C}$ e com os tratos convencionais para a cultura. As regas foram, no geral, realizadas diariamente. 


\subsubsection{Delineamento experimental}

Os recipientes foram arranjados em bancada na casa de vegetação, seguindo um delineamento inteiramente casualizado, com 8 tratamentos (populações) e 20 repetições, sendo a parcela representada por um recipiente contendo uma planta.

Utilizou-se a soja 'FT Cristalina' por ter sido a mais adotada em experimentos com esse nematóide no Brasil e também porque as sementes disponíveis da cultivar Lee (padrão de suscetibilidade recomendado por Golden et al., 1970) junto ao banco de germoplasma de soja da EMBRAPA apresentavam-se com desuniformidade genética (Hiromoto, 1996).

\subsubsection{Avaliações}

Aos 45 dias da inoculação, 10 plantas de cada população foram retiradas e do número total de cistos extraídos das raizes obtiveram-se os juvenis e machos (idem item 3.1.4) para as mensurações, os quais foram mortos pelo calor $\left(55^{\circ} \mathrm{C}\right)$ e fixados em formalina $4 \%$.

O restante das repetições foi usado para a extração dos cistos, que foram fixados diretamente em formalina $4 \%$. Todos os cistos das 20 repetições foram contados.

\subsubsection{Preparação e montagem dos juvenis, machos e cistos para morfometria}

Montaram-se lâminas temporárias em formalina $4 \%$ com juvenis e machos coletados ao acaso das amostras fixadas. Em cada lâmina, foram dispostos 10 juvenis ou 5 machos. Foram feitos desenhos com auxílio de câmara clara acoplada a microscópio nos aumentos de $200 x$ para o comprimento do corpo e $1.000 x$ para os demais caracteres, totalizando 20 exemplares de cada estádio para cada população.

Os cistos foram colocados, individualmente, em lâminas escavadas, em gota de formalina $4 \%$, desenhando-se a linha que limitava externamente o corpo no aumento de 100x e mensurando-se conforme descrito em Faghihi et al. (1986b). Após isso, cada cisto foi cortado ao meio, separados os ovos e estes montados em lâminas temporárias em formalina $4 \%$ e desenhados no aumento de $200 x$, perfazendo 5 ovos por cisto. A porção posterior do cisto foi montada em lâmina, pelo método de Hooper (1970), para observação e mensuração das estruturas do cone vulvar, totalizando 12 cistos por 
população. Cada cisto foi numerado de forma que as mensurações do cone vulvar fossem feitas nos mesmos exemplares em que foram feitas as mensurações relativas ao corpo.

Os caracteres escolhidos para as mensurações foram os apresentados na Tabela 02 .

Tabela 02. Caracteres morfométricos mensurados em juvenis de segundo estádio $(J)$, machos (M), cistos (C) e ovos (O) de Heterodera glycines e respectivas siglas.

\begin{tabular}{|c|c|c|}
\hline Caracteres & Siglas. & Estádio \\
\hline Comprimento do corpo & $\mathrm{L}$ & $\mathrm{J}, \mathrm{M}, \mathrm{C}$ \\
\hline Comprimento do corpo sem o pescoço & $\mathrm{Ls} / \mathrm{p}$ & $\mathrm{C}$ \\
\hline Maior largura do corpo & bw & $\mathrm{J}, \mathrm{M}, \mathrm{C}$ \\
\hline Largura do corpo ao nível dos bulbos basais do estilete & stbw & $\mathrm{J}, \mathbf{M}$ \\
\hline Comprimento da região cefálica & lcef & $\mathrm{J}, \mathbf{M}$ \\
\hline Largura da região cefálica & wcef & $\mathrm{J}, \mathbf{M}$ \\
\hline Comprimento do estilete & St & $\mathrm{J}, \mathrm{M}$ \\
\hline Comprimento da haste e bulbos basais do estilete & 1 hbst & $\mathrm{J}, \mathbf{M}$ \\
\hline Comprimento dos bulbos basais do estilete & lbst & $\mathrm{J}, \mathbf{M}$ \\
\hline Largura dos bulbos basais do estilete & wbst & $\mathrm{J}, \mathrm{M}$ \\
\hline Distância da extremidade anterior do corpo à base do estilete & Ebst & $\mathrm{J}, \mathrm{M}$ \\
\hline $\begin{array}{l}\text { Distância da abertura do canal da glândula esofagiana dors } \\
\text { base do estilete }\end{array}$ & DGO & $\mathrm{J}, \mathrm{M}$ \\
\hline $\begin{array}{l}\text { Distância da extremidade anterior do corpo à extremi } \\
\text { posterior das glândulas esofagianas }\end{array}$ & Oes' & $\mathbf{M}$ \\
\hline Comprimento do testículo & ltt & $\mathbf{M}$ \\
\hline Comprimento do cone vulvar & lc & C \\
\hline Largura do cone vulvar & wc & $\mathrm{C}$ \\
\hline Comprimento do pescoço & lp & C \\
\hline Largura do pescoço & wp & C \\
\hline Comprimento da fenda vulvar & ly & C \\
\hline Largura da ponte vulvar & wv & C \\
\hline Comprimento da semifenestra & lsf & C \\
\hline
\end{tabular}


Cont. Tabela 2

\begin{tabular}{|c|c|c|}
\hline Caracteres & Siglas & Estádio \\
\hline Comprimento da fenestra & If & $\mathrm{C}$ \\
\hline Distância da extremidade anterior do corpo ao poro excretor & EP & $\mathrm{J}, \mathbf{M}$ \\
\hline Largura do corpo ao nível do poro excretor & Pbw & $\mathrm{J}, \mathbf{M}$ \\
\hline Comprimento da cauda & $\mathrm{t}$ & $\mathrm{J}$ \\
\hline Largura do corpo ao nível do ânus & abw & $\mathbf{J}$ \\
\hline Maior largura da região hialina da cauda & wh & $\mathrm{J}$ \\
\hline Comprimento da região hialina da cauda & $\mathbf{h}$ & $\mathbf{J}$ \\
\hline Comprimento do ovo & 10 & $\mathrm{O}$ \\
\hline Largura do ovo & wo & $\mathrm{O}$ \\
\hline Comprimento do corpo/maior largura do corpo & a & $\mathrm{J}, \mathrm{M}, \mathrm{C}$ \\
\hline \multicolumn{3}{|l|}{ Comprimento do corpo/distância da extremidade anterior do corpo } \\
\hline à extremidade posterior das glândulas esofagianas & $\mathbf{b}^{\prime}$ & $\mathbf{M}$ \\
\hline Comprimento do corpo/comprimento da cauda & c & $\mathrm{J}$ \\
\hline Comprimento da cauda/largura do corpo ao nível do ânus & $c^{\prime}$ & $\mathbf{J}$ \\
\hline \multicolumn{3}{|l|}{ Comprimento da região hialina da cauda/maior largura da região } \\
\hline hialina da cauda & $\mathrm{h} / \mathrm{wh}$ & $\mathbf{J}$ \\
\hline $\begin{array}{l}\text { (Distância da extremidade anterior da cabeça ao poro } \\
\text { excretor/comprimento do corpo) } \times 100\end{array}$ & $P$ & $\mathrm{~J}, \mathbf{M}$ \\
\hline (Comprimento do testículo/ comprimento do corpo) x 100 & $\mathrm{~T}$ & $\mathbf{M}$ \\
\hline (Comprimento da haste e bulbos basais do estilete/comprimento do & & \\
\hline estilete) $\times 100$ & lhbst/St & $\mathrm{J}$ \\
\hline
\end{tabular}

Cada valor obtido foi multiplicado pelo fator de correção da objetiva usada e submetido à análise estatística, aplicando-se o Teste $\mathrm{F}$ na análise da variância e, quando ocorreram diferenças significativas, aplicou-se o Teste de Duncan ao nível de $5 \%$ de probabilidade, utilizando-se o programa ANOVA (SAS Institute, 1988). 


\subsection{Efeito de espécies vegetais com diferentes graus de eficiência hospedeira na morfometria de Heterodera glycines}

Nesse experimento, utilizou-se metodologia semelhante a do anterior, sendo adotados os mesmos procedimentos dos itens 3.1.1, 3.1.4, 3.1.5, 3.1.6, 3.1.8 e 3.1.9.

As plantas utilizadas nesse estudo foram cedidas pela empresa Piraí Sementes (Piracicaba/SP) e pela Seção de Leguminosas do IAC.

Os nematóides utilizados nas inoculações das plantas originaram-se de uma população de $H$. glycines raça 3 (SP2), por ser esta considerada a raça de maior ocorrência no país (Noel et al., 1994), multiplicados em soja 'FT Cristalina'.

As plantas hospedeiras utilizadas foram:

a) Soja [Glycine max (L.) Merr.] 'FT Cristalina' (hospedeira eficiente);

b) Feijão comum (Phaseolus vulgaris L.) 'IAC Carioca' (hospedeira eficiente);

c) Ervilha (Pisum sativum L.) 'Maria' (hospedeira ineficiente);

d) Chícharo (Lathyrus sativus L.) (hospedeira ineficiente);

e) Crotalária (Crotalaria juncea L.) 'IAC 1-2' (hospedeira ineficiente);

f) Feijão azuki [Vigna angularis (Willd.) Ohwi \& Ohashi] 'AL-9' (hospedeira eficiente);

g) Feijão mungo [Vigna radiata (L.) Wilczek] 'M-80' (hospedeira eficiente); e

h) Tremoço branco (Lupinus albus L.) (hospedeira eficiente).

Adotou-se um delineamento inteiramente casualizado com 8 tratamentos (espécies vegetais) e 20 repetições.

Para as espécies vegetais que, após as avaliações foram efetivamente consideradas ineficientes, todos os cistos obtidos das 20 repetições foram contados e submetidos à câmara de eclosão para extração dos juvenis de segundo estádio e machos eventualmente formados e, posteriormente, os poucos exemplares de cistos, juvenis e machos foram submetidos às mensurações. 


\section{RESULTADOS E DISCUSSÃO}

\subsection{Morfometria de populações de Heterodera glycines}

As populações multiplicaram-se eficientemente em soja 'FT Cristalina', não se observando diferenças significativas no número médio de cistos entre as populações (Tabela 03). Houve uma variação de 80,17 cistos para a população SPl até 138,83 para MG.

Tabela 03. Número de cistos de Heterodera glycines extraídos de soja 'FT Cristalina' de cada população, após 45 dias da inoculação de 1.000 juvenis de segundo estádio.

\begin{tabular}{cc}
\hline População & Número de cistos* \\
\hline MG & $138,83 \mathrm{~ns}^{* *}$ \\
PR & 126,00 \\
GO1 & 120,33 \\
GO2 & 118,83 \\
MT & 116,33 \\
SP2 & 113,50 \\
MS & 88,17 \\
SP1 & 80,17 \\
\hline C.V. & $54,82 \%$ \\
\hline
\end{tabular}

*Valores médios de 20 repetições.

**Não significativo.

Os resultados a seguir foram discutidos confrontando-se os caracteres de cada população estudada com os verificados por outros autores em estudos afins. 


\subsubsection{Juvenis de segundo estádio}

Com relação à morfometria de juvenis (Tabela 04 e Apêndices 01 a 08), observou-se que a maioria dos valores obtidos encontrava-se no intervalo de variação, em consonância com os resultados relatados por outros autores (Hirschmann, 1956; Ichinohe, 1959; Miller \& Duke, 1967; Koliopanos \& Triantaphyllou, 1971; Taylor, 1974; Ohshima et al. citados por Burrows \& Stone, 1985; Faghihi et al., 1986b; Lima et al., 1992 e Tihohod, 1996).

A largura do corpo dos juvenis estudados mostrou-se maior que a obtida por Ichinohe (1959), mas o comprimento do corpo foi menor. Em relação às três populações brasileiras estudadas por Tihohod (1996), os presentes valores de largura do corpo foram sempre inferiores, ao passo que o comprimento do corpo, se considerada a média das oito populações $(413,27 \mu \mathrm{m})$ aproximou-se do $(424,50 \mu \mathrm{m})$ obtido por aquele autor. $\mathrm{Da}$ mesma forma, também os valores da largura do corpo ao nível do poro excretor encontrados por Tihohod (1996) foram sempre maiores que os obtidos neste estudo. Relativamente à população de Nova Ponte (MG), estudada por Lima et al. (1992), na qual os valores máximo e mínimo de comprimento do corpo obtidos foram 360,29 e $383,66 \mu \mathrm{m}$, o comprimento médio do corpo das populações aqui tratadas foi sempre superior $(386,47-426,55 \mu \mathrm{m})$.

A partir da análise da variância foi possivel verificar diferenças significativas entre as populações nas médias de alguns caracteres (Tabela 04), embora, com freqüência, ocorresse sobreposição entre as faixas de variação dos valores numéricos obtidas para essas populações. Considerando-se apenas os caracteres que envolvem medidas de distâncias, expressas em micrômetros, em número de 17, verificou-se que as populações procedentes do sudoeste de Goiás, GO1 (Jataí) e GO2 (Chapadão do Céu), foram as que mais se destacaram. A população GO2 diferiu significativamente de todas as demais para dois caracteres (comprimento da região cefálica e maior largura da região hialina da cauda) e, para outros 14 caracteres, seus valores ou foram numericamente os mais elevados ou não diferiram estatisticamente dos mais altos observados. GO1 não foi significativamente diferente de todas as restantes para nenhum caráter, mas, para 14 deles, seus valores ou foram numericamente os mais elevados ou não diferiram estatisticamente dos mais altos observados. Semelhante observação pode ser verificada no trabalho de Tihohod (1996), embora o autor não tivesse destacado tal aspecto e não houvesse feito análise estatística, tendo obtido valores de comprimento e largura do 


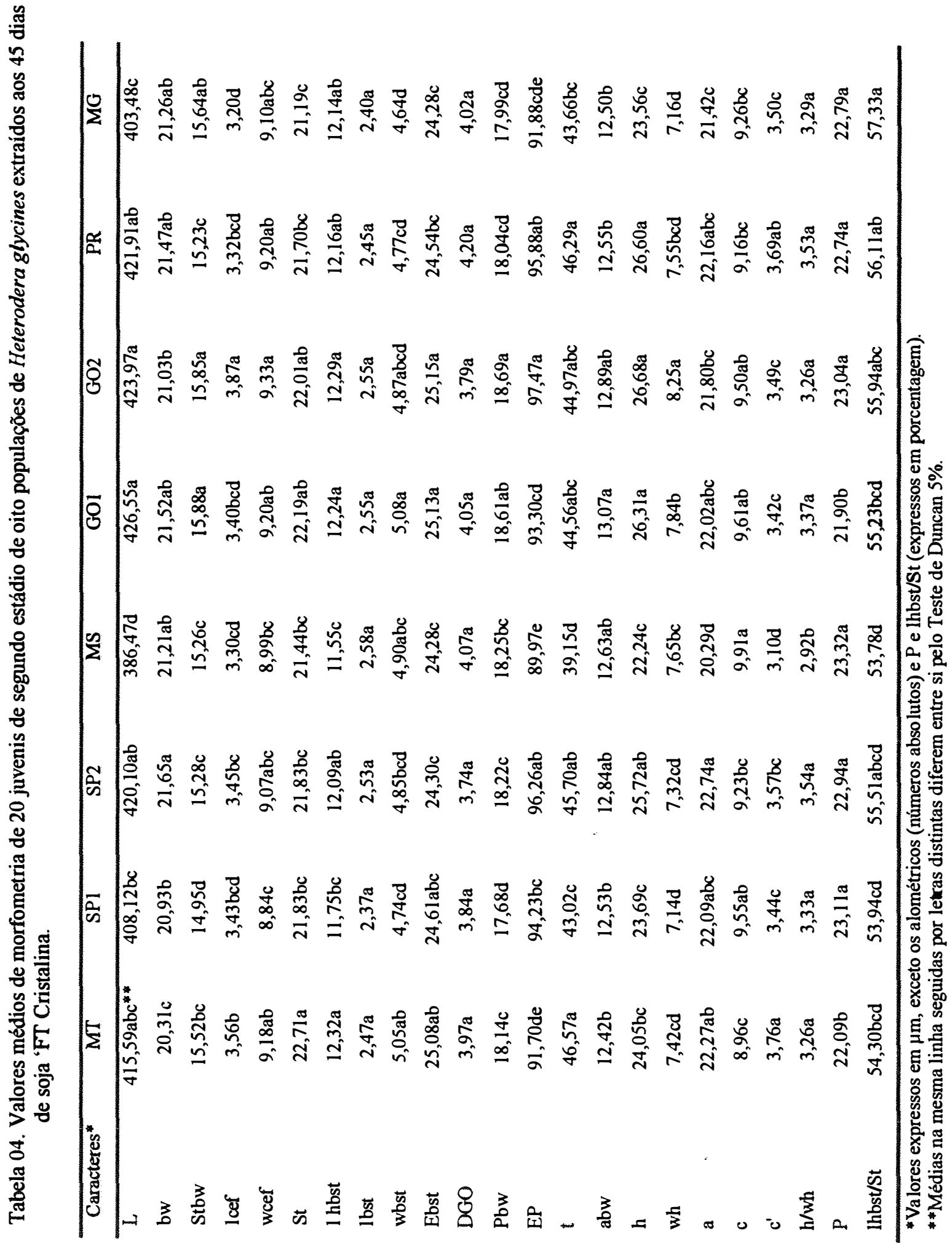


corpo, largura do corpo ao nível dos bulbos basais do estilete, largura da região cefálica, comprimento do estilete, distâncias da extremidade anterior do corpo à base do estilete e ao poro excretor, comprimento de cauda, largura do corpo ao nível do ânus, comprimento e maior largura da região hialina da cauda maiores para a população goiana oriunda de Chapadão do Céu do que para as populações de Iraí de Minas (MG) e Costa Rica (MS).

As populações MS, MG e SP1 apresentaram os maiores números de caracteres com valores significativamente inferiores aos das demais populações. As demais populações apresentaram valores intermediários.

Confirmaram a utilidade de alguns dos caracteres ora utilizados os resultados de Miller \& Duke (1967), que evidenciaram diferenças entre populações dos Estados Unidos com base nos valores do comprimento e largura do corpo, comprimento do estilete e da parte posterior (haste e bulbos basais) do estilete, distância da extremidade anterior do corpo ao poro excretor, comprimento da cauda e da região hialina da cauda, maior largura da região hialina da cauda e distância da abertura do canal da glândula esofagiana dorsal à base do estilete. Koliopanos \& Triantaphyllou (1971) puderam verificar diferenças no comprimento do corpo, da cauda e da região hialina da cauda entre quatro populações dos Estados Unidos, sendo que a população de Arkansas tinha maior comprimento do corpo e a da Carolina do Norte tinha maior comprimento da cauda e da região hialina da cauda. Semelhante resultado obtiveram Faghihi et al. (1986b) com esses caracteres e também para comprimento do estilete e distância da extremidade anterior do corpo ao poro excretor, evidenciando diferenças entre populações do Estado de Indiana.

As populações SP1, SP2 e PR são muito próximas geograficamente e da mesma raça, sugerindo que a mesma população teria se disseminado de uma área para a outra. Nos resultados obtidos, porém, verificaram-se diferenças entre elas, ilustrando a diversidade genética que existe nas populações desse nematóide, mesmo entre as geograficamente próximas.

Os mais altos coeficientes de variação foram os determinados para o comprimento da região cefálica, comprimento e largura dos bulbos basais do estilete, comprimento da região hialina da cauda, distância da abertura do canal da glândula esofagiana dorsal à base do estilete e comprimento da região hialina da cauda/maior largura da região hialina da cauda. Da mesma forma, os coeficientes de variação mais baixos foram os encontrados para comprimento do corpo, comprimento do estilete, distância da extremidade anterior do corpo ao poro excretor, distância da extremidade anterior do corpo à base do estilete. 
Essas observações revelaram-se concordantes com as de Tihohod (1996), embora esse autor tivesse trabalhado com um número menor de populações. Por outro lado, ocorreram discrepâncias para os caracteres largura do corpo, largura do corpo ao nível do poro excretor e largura do corpo ao nível do ânus, sendo os valores dos coeficientes de variação ora obtidos mais baixos que os apresentados por Tihohod (1996).

\subsubsection{Machos}

No estudo relativo à morfometria de machos (Tabela 05 e Apêndices 9 a 16), repetiu-se o observado com os juvenis, situando-se os valores no intervalo de variação citados por Hirschmann (1956), Ichinohe (1959), Miller \& Duke (1967) e Faghihi et al. (1986b).

Apenas os valores de comprimento do corpo, comprimento e largura da região cefálica, e distância da extremidade anterior do corpo ao poro excretor estão pouco abaixo do intervalo citado por Ichinohe (1959). O valor obtido para comprimento do corpo também mostrou-se menor que o observado por Hirschmann (1956).

Os caracteres largura do corpo ao nível dos bulbos basais do estilete, comprimento da haste e bulbos basais do estilete, comprimento e largura dos bulbos basais do estilete, distância da extremidade anterior do corpo à base do estilete, largura do corpo ao nível do poro excretor, comprimento do testículo e distância da extremidade anterior do corpo ao poro excretor/comprimento do corpo $\mathrm{x} 100$ foram pela primeira vez mensurados em machos de $H$. glycines.

Quanto às diferenças entre as populações, observou-se que a GO2 voltou a se destacar, como ocorrera no caso dos juvenis, diferenciando-se de todas as demais para o caráter largura do corpo e, para 12 dos 15 caracteres relativos a distâncias, seus valores ou foram numericamente os mais elevados ou não diferiram estatisticamente dos mais altos observados. Em contrapartida, a população MG, como também já ocorrera para juvenis, apresentou, no geral, os mais baixos valores observados. Assim, para cinco caracteres, a saber, comprimento e largura do corpo, largura dos bulbos basais do estilete, distância da extremidade anterior do corpo à base do estilete e comprimento do testículo, seus valores diferiram significativamente daqueles obtidos para as demais populações.

Miller \& Duke (1967) também detectaram diferenças entre populações nos Estados Unidos relativamente ao comprimento e largura do corpo, comprimento do 


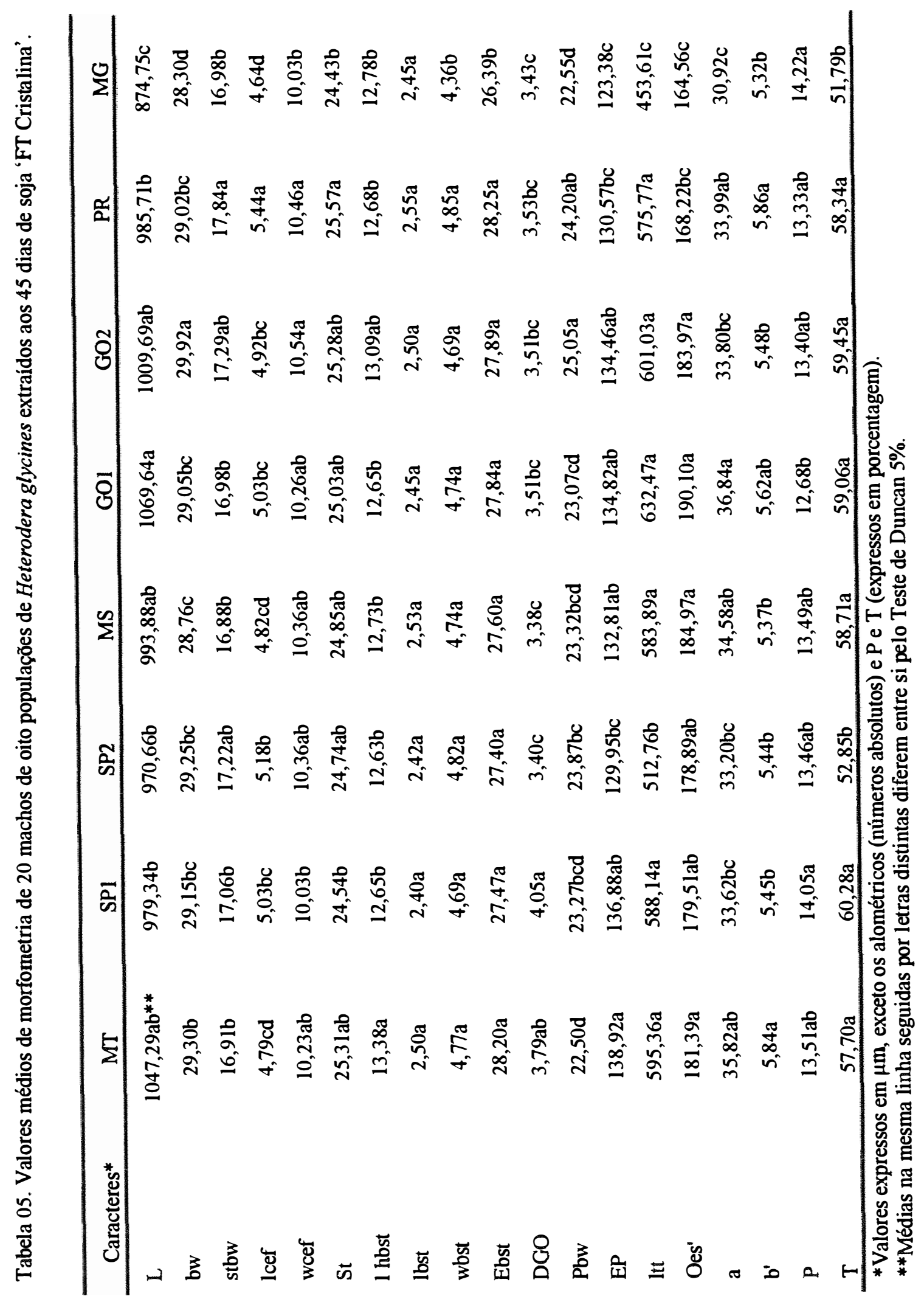


estilete e distância da abertura do canal da glândula esofagiana dorsal à base do estilete. Do mesmo modo, o comprimento do estilete, o comprimento do esôfago e a distância da extremidade anterior do corpo ao poro excretor foram alguns dos caracteres usados por Faghihi et al. (1986b) para diferenciar populações em Indiana, EUA.

Os menores coeficientes de variação foram os referentes à largura do corpo, à largura do corpo ao nível dos bulbos basais do estilete, à largura de região cefálica e ao comprimento do estilete.

\subsubsection{Cistos}

Da mensuração dos caracteres dos cistos (Tabela 06 e Apêndices 17 a 24) resultaram valores semelhantes aos de Hirschmann (1956), Ichinohe (1959), Miller \& Duke (1967), Mulvey (1972), Taylor (1974), Graney \& Miller (1982), Faghihi et al. (1986b) e Tihohod (1996), à exceção dos obtidos para comprimento do corpo, comprimento de corpo sem o pescoço e largura do corpo, que se apresentaram maiores que os de Ichinohe (1959) e Tihohod (1996).

Não houve nenhuma população que se destacou por apresentar um número de caracteres, com valores menores ou maiores, superior às demais. Para quatro caracteres analisados não ocorreram diferenças significativas entre os tratamentos.

Em sua maioria, os caracteres tiveram coeficientes de variação altos, confirmando o que Tihohod (1996) afirmou em seu trabalho, de que os caracteres de cistos tiveram maior variabilidade do que os de juvenis de segundo estádio.

\subsubsection{Ovos}

Para a morfometria de ovos (Tabela 06 e Apêndices 17 a 24), verificou-se que os valores foram semelhantes aos de Hirschmann (1956), Miller \& Duke (1967), Taylor (1974) e Faghihi et al. (1986b).

A população MS apresentou o comprimento do ovo significativamente menor que as populações SP1, GO1, PR e MG, porém teve a largura do ovo maior que as demais, exceto a GO2.

Ambos os caracteres apresentaram coeficientes de variação baixos. 


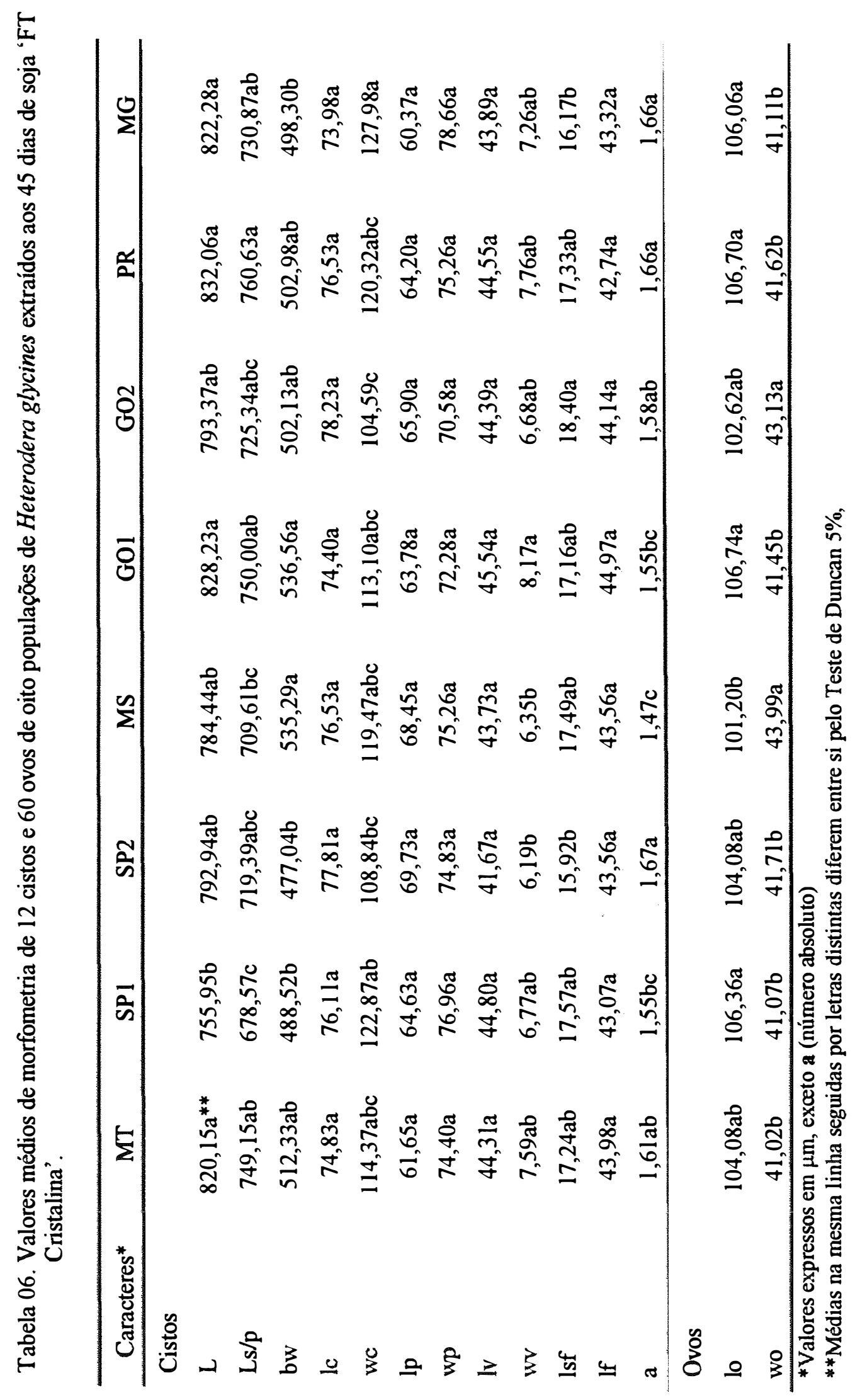




\subsection{Morfometria de Heterodera glycines extraídos de espécies vegetais com diferentes graus de eficiência hospedeira}

O número de cistos extraídos das diferentes plantas testadas variou amplamente (Tabela 07).

Como era de se esperar, a soja foi a espécie vegetal da qual se obteve o maior número de cistos, enquadrando-se como suscetível, segundo escala proposta por Schmitt \& Shannon (1992). O tremoço branco foi, após a soja, a espécie vegetal na qual se encontrou maior número de cistos, confirmando o observado por Epps \& Chambers, (1958; 1959 e 1966), diferindo das demais, exceto do feijão mungo. Um terceiro grupo foi formado pelo feijões comum e azuki, que nos estudos de Fujita \& Miura (1934), Riggs \& Hamblen (1962), Valle (1996) e Silva, M.A. et al. (1997) também foram classificados como hospedeiras do nematóide. As espécies vegetais desse terceiro grupo foram consideradas moderadamente resistentes. $\mathrm{O}$ último grupo foi formado pela ervilha, chícharo e crotalária, que foram consideradas resistentes e permitiram o desenvolvimento de pouquíssimos nematóides. Na ervilha, não foi encontrado nenhum cisto. Entretanto, para a espécie de crotalária empregada, ao contrário do que observou Iunes (1995), que não encontrou nenhuma fêmea, detectaram-se umas poucas fêmeas nas raízes.

Tabela 07. Número de cistos de Heterodera glycines, índice de parasitismo (I.P.) e reação das plantas hospedeiras, segundo Schmitt \& Shannon(1992).

\begin{tabular}{lccc}
\hline \multicolumn{1}{c}{ Espécie Vegetal } & $\mathrm{N}^{0}$ de cistos* & I.P. & Reação*** \\
\hline Soja & $158,10 \mathrm{a}^{* *}$ & 100 & $\mathrm{~S}$ \\
Feijão Comum & $28,20 \mathrm{c}$ & 17,8 & $\mathrm{MR}$ \\
Ervilha & $0 \mathrm{~d}$ & 0 & $\mathrm{R}$ \\
Chícharo & $0,35 \mathrm{~d}$ & 0 & $\mathrm{R}$ \\
Crotalária & $0,05 \mathrm{~d}$ & 0 & $\mathrm{R}$ \\
Feijão azuki & $28,10 \mathrm{c}$ & 17,8 & $\mathrm{MR}$ \\
Feijão mungo & $36,90 \mathrm{bc}$ & 23,3 & $\mathrm{MR}$ \\
Tremoço branco & $46,78 \mathrm{~b}$ & 29,6 & $\mathrm{MR}$ \\
\hline C.V. & $37,94 \%$ & & \\
\hline * Os valores apresentados são médias originais de 20 repetições, sendo utilizados os valores médios \\
transformados em $\sqrt{\mathrm{x}+0,5}$ para análise estatística. \\
$* *$ Médias seguidas por letras distintas, diferem ao nível de $5 \%$ de probabilidade pelo Teste de Duncan \\
**S = suscetível; MR = moderadamente resistente; $\mathrm{R}=$ resistente.
\end{tabular}


Carnielli (1995) verificou fêmeas nas raizes de ervilha e Riggs (1992) citou que todas as cultivares de ervilha são suscetiveis ao nematóide. Porém, neste estudo, não se encontraram cistos ou juvenis nas raizes, o que concorda com Skotland (1957), Riggs \& Hamblen (1962 e 1966) e Silva, M.A. et al. (1997). Já Ichinohe (1959) verificou que muitos juvenis penetraram nas raizes de ervilha, porém não se desenvolveram.

Essas variações nos resultados podem estar associadas a diferenças nos genótipos das hospedeiras e entre raças do nematóide usadas nos respectivos estudos.

\subsubsection{Juvenis de segundo estádio}

Com relação à morfometria de juvenis, não foi possivel a inclusão dos dados relativos à ervilha, ao chícharo e à crotalária na análise estatística (Tabela 08) pelo fato de que apenas dois exemplares foram obtidos em crotalária, um em chícharo e nenhum em ervilha. Nos casos de espécimes obtidos de crotalária e chícharo, os valores obtidos das mensurações estão apresentados no Apêndice 27. Para as demais espécies vegetais, os valores morfométricos originais obtidos para os juvenis estão apresentados nos Apêndices 25, 26, 28, 29 e 30.

A ausência ou presença em números extremamente baixos de juvenis nas raízes de ervilha, chícharo e crotalária evidenciou muito bem que essas espécies vegetais são hospedeiras altamente desfavoráveis ao nematóide, a ponto de sequer possibilitar, como era um dos objetivos do presente trabalho, a obtenção de um número mínimo de exemplares necessário a uma adequada comparação entre os valores morfométricos do parasito. $\mathrm{Na}$ análise envolvendo a soja e as espécies vegetais identificadas como moderadamente resistentes (Tabela 08), verificou-se que muitos caracteres dos juvenis, inclusive aqueles tidos como úteis e usuais na diferenciação das populações, mostraramse não significativos. Apenas para o feijão mungo e o tremoço branco observaram-se diferenças significativas relativamente às demais espécies vegetais com referência a alguns caracteres, encontrando-se valores inferiores, por exemplo, para o comprimento da haste e bulbos basais do estilete nas duas hospedeiras, comprimento da cauda e da região hialina da cauda para feijão mungo e distância da abertura do canal da glândula esofagiana dorsal à base do estilete e c para o tremoço branco.

Os coeficientes de variação tidos como mais altos foram os determinados para o comprimento da região cefálica, comprimento dos bulbos basais do estilete, comprimento 


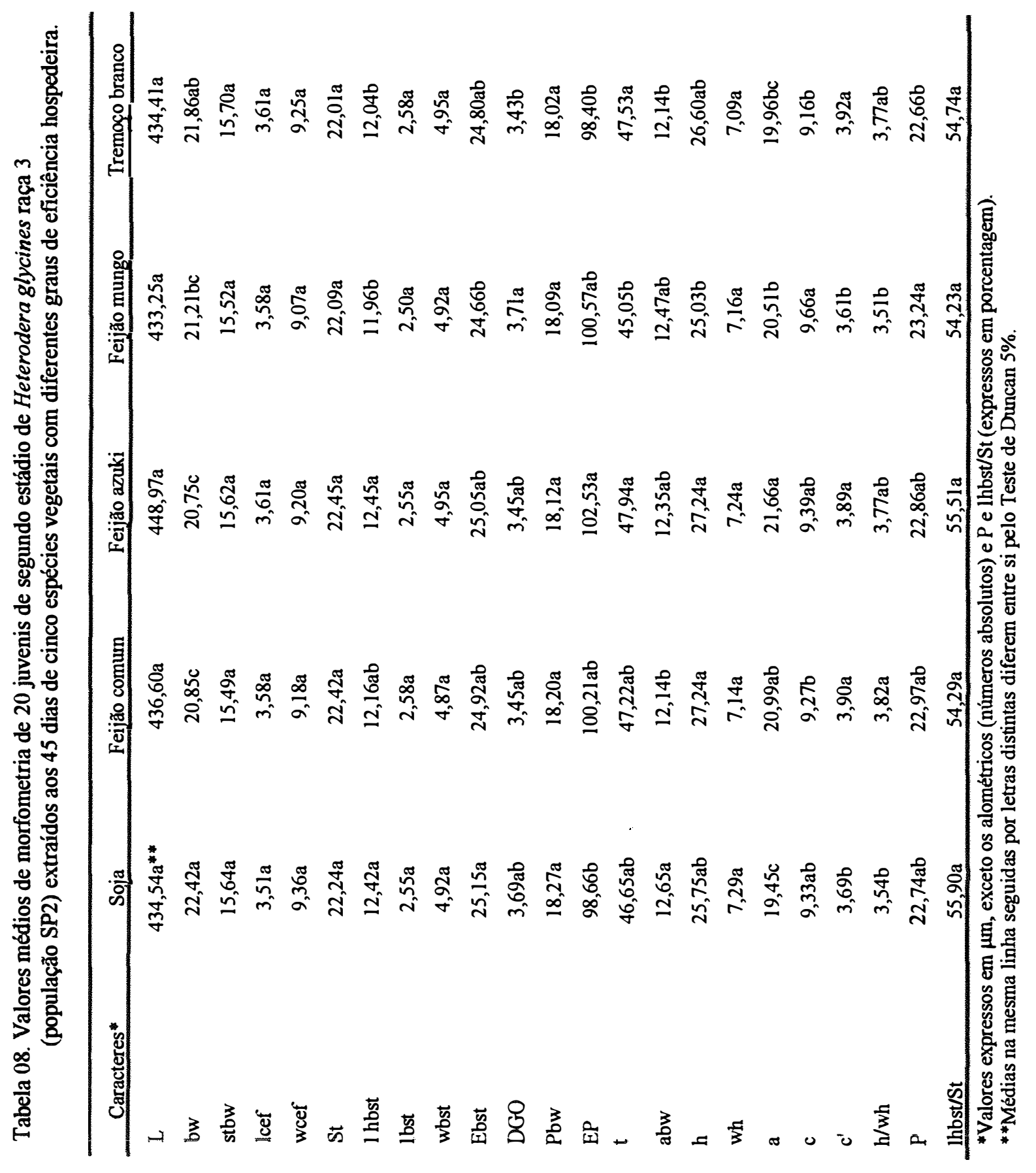


da região hialina da cauda, distância da abertura do canal da glândula esofagiana dorsal à base do estilete, comprimento da região hialina da cauda/maior largura da região hialina da cauda, confirmando as observações realizadas na primeira parte do estudo.

Os valores obtidos para a população utilizada nesta segunda parte do trabalho, desenvolvida em diferentes plantas hospedeiras, aproximaram-se bastante dos obtidos para as oito populações empregadas na primeira fase do estudo.

\subsubsection{Machos}

Os resultados referentes aos machos estão apresentados na Tabela 09 e nos Apêndices 31 a 35 .

Em relação à soja, obtiveram-se valores significativamente menores em quatro caracteres para o feijão comum, cinco para o mungo, seis para o tremoço e apenas um para o azuki. No entanto, tão somente para um único caráter, a largura do corpo, todos foram inferiores à soja. De outra parte, em uns poucos casos, obtiveram-se valores significativamente maiores para certos caracteres nos espécimes formados em mungo e azuki que na própria soja. Portanto, embora tenham sido obtidos para a soja valores numericamente superiores aos das demais espécies vegetais em 10 dos 19 caracteres estudados, verificou-se que não foi possível definir-se um grupo de caracteres em que isso ocorresse para todas as espécies vegetais ao mesmo tempo e que possibilitasse afirmar existir uma diferenciação morfométrica devida a melhores ou piores condições de desenvolvimento em plantas hospedeiras distintas.

Infelizmente, não foram obtidos machos a partir de ervilha, chícharo e crotalária, evidenciando mais uma vez, como observado para os juvenis, que estas espécies vegetais são muito desfavoráveis ao nematóide. Se exemplares tivessem sido formados nessas espécies vegetais e pudessem ser incluídos no estudo comparativo, junto às demais plantas hospedeiras, possivelmente se pudesse verificar melhor a ocorrência de efeitos negativos sobre o desenvolvimento do parasito e o impacto destes sobre a morfometria dos machos.

Trudgill et al. (1970) observaram menor comprimento do corpo e de estilete de machos de Globodera rostochiensis oriundos de cultivares resistentes de batata. Esses autores associaram tal fato às condições nutricionalmente desfavoráveis que os juvenis sofreram, antes da emergência como machos. No presente trabalho, as espécies vegetais 


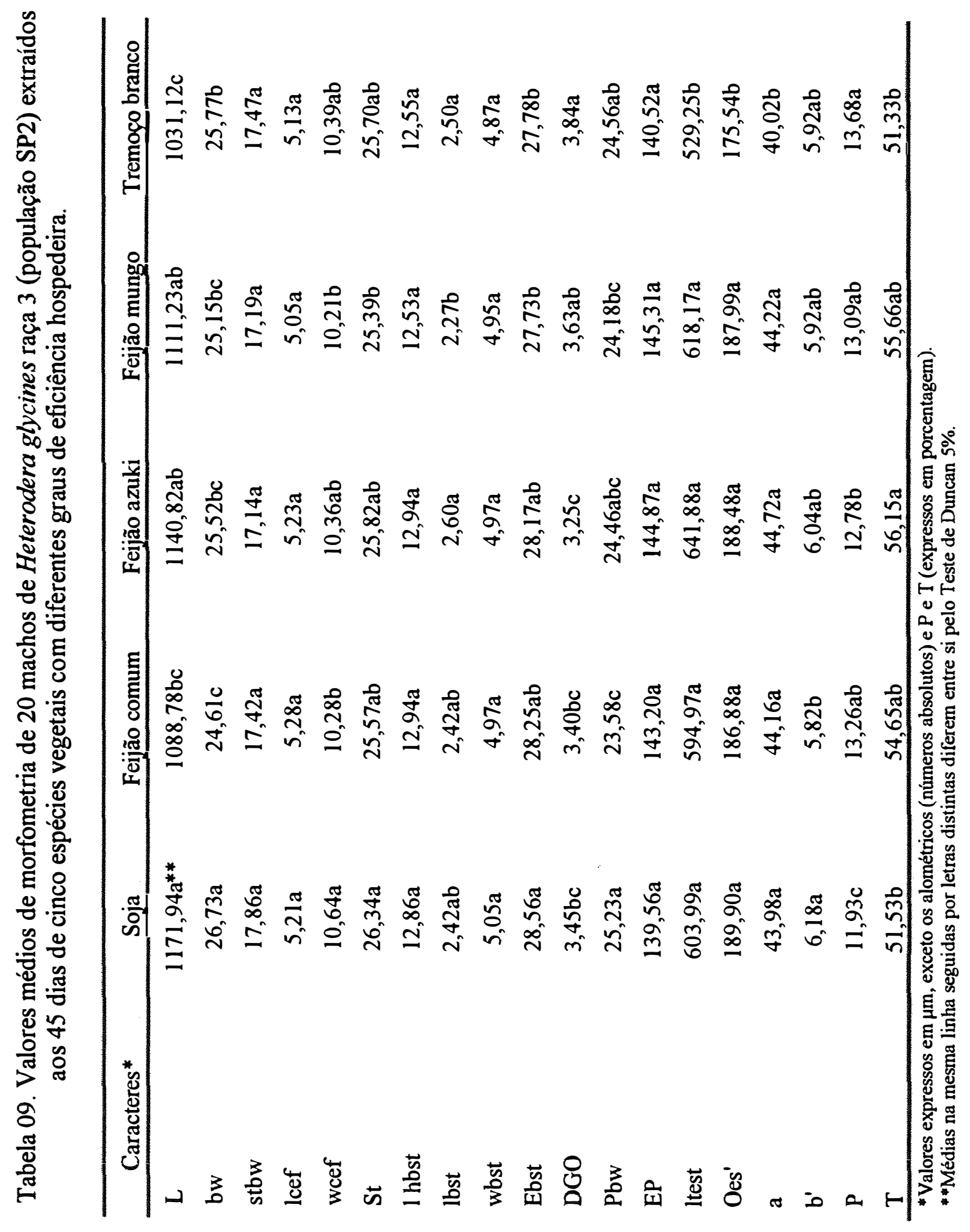


que se mostraram resistentes (ervilha, chícharo e crotalária) não permitiram a obtenção de quaisquer espécimes machos e, nos casos das hospedeiras consideradas moderadamente resistentes (feijões comum, azuki e mungo e tremoço branco), diferentemente do relatado por Trudgill et al., praticamente não ocorreram diferenças significativas relativamente ao comprimento do corpo e do estilete em relação aos valores encontrados para a soja, o padrão suscetível.

Os coeficientes de variação (Apêndices 31 a 35) mais altos foram os obtidos para o comprimento dos bulbos basais do estilete, comprimento do testículo, distância da abertura do canal da glândula esofagiana dorsal à base do estilete e comprimento do testículo/comprimento do corpo x 100, ao passo que os mais baixos foram os referentes ao comprimento do estilete e à distância da extremidade anterior do corpo aos bulbos basais do estilete. Lamentavelmente, como no trabalho de Tihohod (1996) não foram estudados os dados morfométricos relativos aos machos, não houve possibilidade de se estabelecer confronto com os presentes resultados.

\subsubsection{Cistos}

Da mesma forma que para os demais estádios, não se obteve nenhum cisto em ervilha e apenas um em crotalária e sete em chícharo, estando os resultados relativos a essa última espécie vegetal apresentados no Apêndice 38. Os valores obtidos do único cisto extraído de crotalária foram: $(\mathrm{em} \mu \mathrm{m}) \mathrm{L}=862,24 ; \mathrm{Ls} / \mathrm{p}=760,20$; bw $=464,29$; lc $=$ 102,$04 ; w c=153,06 ; \mathrm{lp}=102,04 ; \mathrm{wp}=102,04 ;$ (em número absoluto) $a=1,86 . \mathrm{Em}$ chícharo e crotalária não foram mensuradas as estruturas do cone vulvar. Pelo baixo número de cistos disponiveis, os valores referentes a estes não foram analisados estatisticamente.

Para a soja, hospedeira sabidamente suscetível, e os feijões comum, azuki e mungo e o tremoço branco, hospedeiros tidos como moderadamente resistentes, os dados obtidos estão apresentados na Tabela 10. Pelo fato dos caracteres apresentarem, em sua maioria, altos valores de coeficiente de variação (Apêndices 36 a 41) e por se constatar que para seis de 12 caracteres não ocorreram diferenças significativas entre os tratamentos, não foi possível verificar nenhum efeito sobre a morfometria de cistos extraídos dessas espécies vegetais. Miller (1968), sobre o assunto, havia relatado que os 


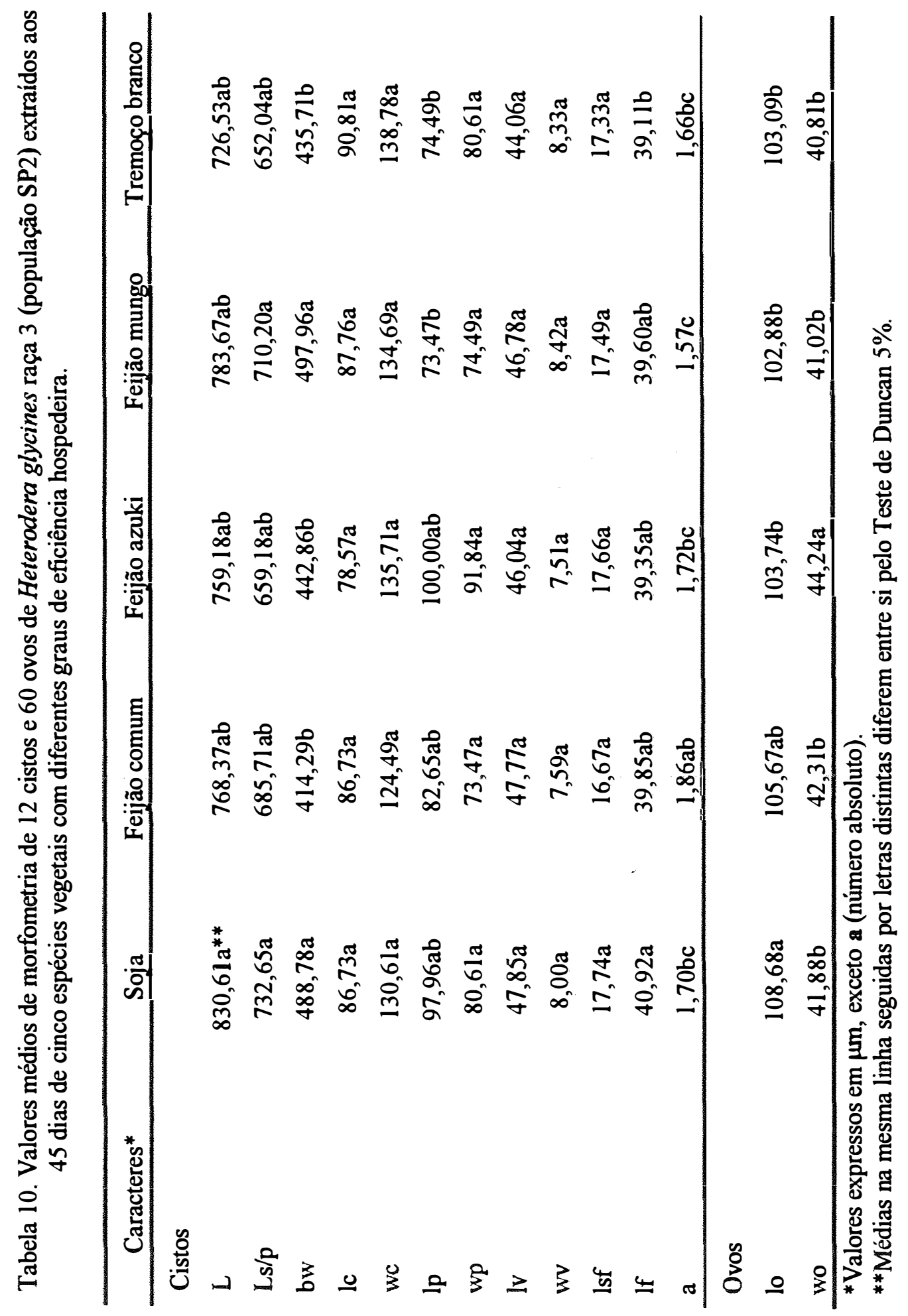


valores obtidos para o comprimento de cistos de $H$. glycines formados em raízes de boca de leão haviam sido significativamente menores que os referentes a plantas de soja.

\subsubsection{Ovos}

Não se dispôs de ovos em raízes de ervilha, chícharo e crotalária para mensurações porque os poucos formados foram colocados em câmaras de eclosão visando a obtenção de juvenis.

Quanto às outras espécies vegetais (Tabela 10 e Apêndices 36 a 41), observou-se que os extraídos de cistos em soja diferiram dos de azuki, mungo e tremoço para o comprimento do ovo, não diferindo do feijão comum. A largura foi maior nos ovos de azuki, diferindo das demais plantas.

Da mesma forma que para o estudo relativo às populações, os coeficientes de variação foram baixos.

\subsection{Considerações finais}

As populações de $H$. glycines obtidas em diferentes locais do Brasil apresentaram características semelhantes, do ponto de vista da morfometria, às encontradas nos Estados Unidos e Japão. Entretanto, diferenças significativas entre as populações estudadas foram observadas para alguns caracteres, não sendo possível separá-las pelo fato de existirem sobreposições entre os valores numéricos obtidos. Esse fato foi observado por Miller \& Duke (1967), Koliopanos \& Triantaphyllou (1971), Riggs et al. (1982), Faghihi et al. (1986b) e Tihohod (1996) que também estudaram variações entre populações.

Recentes estudos sobre as condições edáficas, como pH (Garcia et al., 1997 e Pereira et al., 1997), níveis de cálcio, magnésio, fósforo, potássio e saturação de bases (Pereira et al., 1997; Sologuren \& Santos, 1997 e Machado et al., 1997) e até diferentes

classes de solo (Machado et al., 1997) mostraram que essas variáveis podem modificar os níveis populacionais de $H$. glycines. Esse fato pode explicar, em parte, as diferenças 
encontradas entre as populações, já que esses fatores também influenciam a qualidade do alimento para o nematóide, bem como níveis populacionais altos podem causar uma competição maior por sítios de parasitismo, conseqüentemente afetando o desenvolvimento do parasito e sua morfometria. Mais estudos relativos a esses fatores capazes de influenciar a morfometria das diferentes populações são necessários para se entender melhor as causas de tais variações.

Quanto ao estudo do efeito das espécies vegetais (segunda fase), esperava-se verificar variações na morfometria determinadas pelas diferentes hospedeiras testadas, já que Mayr (1969) citou que esse efeito pode acarretar um erro taxonômico e permitir confusão com raças microgeográficas ou com espécies simpátricas. Segundo o autor, esse fenômeno é comumente expressado em diferenças de tamanho, mas pode envolver outros caracteres morfológicos ou fisiológicos. No entanto, o que se observou no presente estudo foi um efeito tão desfavorável, nos casos das espécies vegetais consideradas resistentes, que não se conseguiu obter a partir delas os números mínimos de exemplares para a adequada realização do estudo morfométrico previsto. 


\section{CONCLUSÕES}

Com base nos resultados obtidos, foi possível concluir que:

a) Do ponto de vista da morfometria, as populações estudadas apresentaram características de Heterodera glycines;

b) Houve diferenças significativas para alguns caracteres, porém não foi possível caracterizar uma ou mais populações, com base na morfometria, devido à freqüente sobreposição dos valores numéricos referentes aos caracteres analisados;

c) Não se verificou efeito de espécies vegetais com diferentes graus de eficiência hospedeira na morfometria do nematóide. 


\section{REFERÊNCIAS BIBLIOGRÁFICAS}

ABAWI, G.S.; JACOBSEN, B.J. Effect of initial inoculum densities of Heterodera glycines on growth of soybean and kidney bean and their efficiency as hosts under greenhouse conditions. Phytopathology, v. 74, n. 12, p. 1470-1474, 1984.

BALDWIN, J.G.; MUNDO-OCAMPO, M. Heteroderinae, cyst and non-cyst-forming nematodes. In: NICKLE, R. (Ed.). Manual of agricultural nematology. New York: Marcel Dekker, 1991. p. 275-362.

BECKER, W.F.; DIAS, W.P.; FERRAZ, S. Hospedabilidade do feijão comum (Phaseolus vulgaris) ao nematóide de cisto da soja (Heterodera glycines). In: CONGRESSO BRASILEIRO DE FITOPATOLOGIA, 28., Ilhéus, 1995. Resumo. Fitopatologia Brasileira, v. 20, p. 357, 1995.

BURROWS, P.R.; STONE, A.R. Heterodera glycines. St. Albans: CAB, 1985. 4p. (C.I.H. Descriptions of Plant-Parasitic Nematodes, 8).

CARNEIRO, R.M.D.G.; ALMEIDA, M.R.A. Deteç̧ão de Heterodera glycines em soja no Rio Grande do Sul. In: CONGRESSO INTERNACIONAL DE NEMATOLOGIA TROPICAL, Rio Quente, 1995. Programa e anais. Rio Quente: Sociedade Brasileira de Nematologia/Organização dos Nematologistas da América Tropical, 1995. p.73. 
CARNIELLI, A. Reação de culturas utilizadas em rotação e sucessão à soja ao nematóide Heterodera glycines. In: CONGRESSO INTERNACIONAL DE NEMATOLOGIA TROPICAL, Rio Quente, 1995. Programa e anais. Rio Quente: Sociedade Brasileira de Nematologia/Organização dos Nematologistas da América Tropical, 1995. p.35.

DIAS, W.P.; FERRAZ, S.; SILVA, A.A.; LIMA, R.D.; VALLE, L.A.C. Hospedabilidade de algumas ervas daninhas ao nematóide de cisto da soja (Heterodera glycines Ichinohe). In: CONGRESSO INTERNACIONAL DE NEMATOLOGIA TROPICAL, Rio Quente, 1995. Programa e anais. Rio Quente: Sociedade Brasileira de Nematologia/Organização dos Nematologistas da América Tropical, 1995. p.36

EMPRESA BRASILEIRA DE PESQUISA AGROPECUÁRIA - Centro Nacional de Pesquisa de Soja. Recomendações técnicas para a cultura da soja na Região Central do Brasil 1996/1997. Londrina, 1996. 164p.

EPPS, J.M.; CHAMBERS, A.Y. New host records for Heterodera glycines, including one host in the Labiatae. Plant Disease Reporter, v. 42, n. 2, p. 194, 1958.

EPPS, J.M.; CHAMBERS, A.Y. Mung bean (Phaseolus aureus), a host of the soybean cyst nematode (Heterodera glycines). Plant Disease Reporter, v. 43, n. 9, p. 981982, 1959.

EPPS, J.M.; CHAMBERS, A.Y. Comparative rates of reproduction of Heterodera glycines on 12 host plants. Plant Disease Reporter, v. 50, n. 8, p. 608-610, 1966.

EPPS, J.M.; GOLDEN, A.M. Biological differences in populations of the soybean-cyst nematode, Heterodera glycines. In: ANNUAL MEETING OF THE SOCIETY OF NEMATOLOGISTS, 5, Daytona Beach, 1966. Abstracts. Nematologica, v. 13, n. 1, p. 141, 1967. 
FAGHIHI, J.; FERRIS, J.M.; FERRIS, V.R. Heterodera glycines in Indiana: I. Reproduction of geographical isolates on soybean differentials. Journal of Nematology, v. 18, n. 2, p. 169-172, 1986 a.

FAGHIHI, J.; FERRIS, J.M.; FERRIS, V.R. Heterodera glycines in Indiana: II. morphology of geographical isolates. Journal of Nematology, v. 18, n. 2, p. 173 $177,1986 b$.

FEHR, W.R.; CAVINESS, C.E. Stages of soybean development. Ames: Iowa State University of Science and Technology, 1977. $11 \mathrm{p}$.

FUJTA, K.; MIURA, O. On the parasitism of Heterodera schachtii Schmidt on beans. Tran. Sapporo Nat. Hist. Soc., v. 13, p. 359-364, 1934.

GARCIA, A.; SILVA, J.F.V.; PEREIRA, J.E.; LANTMANN, A.F. Interação entre a população de Heterodera glycines e o $\mathrm{pH}$ do solo. In: CONGRESSO BRASILEIRO DE NEMATOLOGIA, 20., Gramado, 1997. Resumos. Gramado: Sociedade Brasileira de Nematologia, 1997. p. 60.

GOLDEN, A.M.; EPPS, J.M. Morphological variations in the soybean-cyst nematode. In: ANNUAL MEETING OF THE SOCIETY OF NEMATOLOGISTS, 3, Boulder, 1964. Abstracts. Nematologica, v. 11, n. 1, p. 38, 1965.

GOLDEN, A.M.; EPPS, J.M.; RIGGS, R.D.; DUCLOS, L.A.; FOX, J.A.; BERNARD, R.L. Terminology and identity of infraspecific forms of soybean cyst nematode (Heterodera glycines). Plant Disease Reporter, v. 54, n. 7, p. 544-546, 1970.

GRANEY, L.S.O.; MLLER, L.I. Comparative morphological studies of Heterodera schachtii and $H$. glycines. In: RIGGS, R.D. (Ed.) Nematology in the Southern Region of the United States. Fayetteville: Arkansas Agricultural Experiment Station, 1982. p. 96-107. (Southern Cooperative Series Bulletin, 276). 
HIROMOTO, D.M. Seleção de genótipos de soja para performance agronômica e resistência a Heterodera glycines Ichinohe e Diaporthe phaseolorum f.sp. meridionalis Morgan-Jones. Piracicaba, 1996. 84p. Tese (Doutorado) - Escola Superior de Agricultura "Luiz de Queiroz", Universidade de São Paulo.

HIRSCHMANN, H. Comparative morphological studies on the soybean cyst nematode, Heterodera glycines and the clover cyst nematode, $H$. trifolii (Nematoda: Heteroderidae). Proceedings of the Helminthological Society, v. 23, n. 2, p. 140$151,1956$.

HOOPER, D.J. Preserving and staining nematodes in plant tissues. In: SOUTHEY, J.F., (Ed.) Laboratory methods for work with plant and soil nematodes. London: Ministry of Agriculture, Fisheries and Food, 1970. p. 55-58.

ICHINOHE, M. On the soy bean nematode, Heterodera glycines n. sp., from Japan. Magazine of Applied Zoology, v. 17, n. 1/2, p. 1-4, 1952.

ICHINOHE, M. Studies on the soybean cyst nematode, Heterodera glycines and its injury to soybean plants in Japan. Plant Disease Reporter, Supplement, n. 260, p. 239-248, 1959.

ICHINOHE, M. Studies on the soybean cyst nematode Heterodera glycines. Hokkaido Nat. Agric., Exp. Stn. Rep., v. 56, p. 1-80, 1961.

IUNES, C.A. Reações de diferentes plantas cultivadas e daninhas ao nematóide de cisto da soja Heterodera glycines, Ichinohe, 1952. Jaboticabal, 1995. 73p. Dissertação (Mestrado) - Faculdade de Ciências Agrárias e Veterinárias, Universidade Estadual Paulista "Julio de Mesquita Filho".

KOLIOPANOS, C.N.; TRIANTAPHYLLOU, A.C. Host specificity and morphometrics of four populations of Heterodera glycines (Nematoda: Heteroderidae). Journal of Nematology, v. 3, n. 4, p. 364-368, 1971. 
LIMA, R.D.; FERRAZ, S.; SANTOS, J.M. dos. Ocorrência de Heterodera sp. em soja no triângulo mineiro. In: CONGRESSO BRASILEIRO DE NEMATOLOGIA, 16, Lavras, 1992. Resumos. Nematologia Brasileira, v. 16, n. 1/2, p. 101-102, 1992.

LORDELLO, A.I.L.; LORDELLO, R.R.A.; QUAGGIO, J.A. Heterodera sp. reduz produção de soja no Brasil. In: CONGRESSO BRASILEIRO DE NEMATOLOGIA, 16, Lavras, 1992. Resumos. Nematologia Brasileira, v. 16, n. 1/2, p. 101, 1992.

MACHADO, E.; GOULART FILHO, L.R.; SANTOS, M.A. dos; CORRÊA, G.F. Influência de dois níveis de saturação de bases em diferentes classes de latossolo no desenvolvimento de Heterodera glycines. In: CONGRESSO BRASILEIRO DE NEMATOLOGIA, 20., Gramado, 1997. Resumos. Gramado: Sociedade Brasileira de Nematologia, 1997. p. 63.

MAYR, E. Principles of systematic zoology. New York: McGraw-Hill, 1969. 428p.

MENDES, M.L.; DICKSON, D.W. Detection of Heterodera glycines on soybean in Brazil. Plant Disease, v. 77, n. 5, p. 499-500, 1993.

MILLER, L.I. Pathogenicity and development of the Tenn. 1 isolate of Heterodera glycines on Antirrhinum majus. In: ANNUAL MEETING OF THE SOCIETY OF NEMATOLOGISTS, 6, Washington, 1967. Abstracts. Nematologica, v. 14, n. 1, p. $10,1968$.

MILLER, L.I. Suscetibility of tomato (Lycopersicon esculentum) to certain isolates of the soybean cyst nematode (Heterodera glycines). Proceedings of the American Phytopathological Society, v.2, p. 125, 1975.

MILLER, L.I.; DUKE, P.L. Morphological variation of eleven isolates of Heterodera glycines in the United States. In: ANNUAL MEETING OF THE SOCIETY OF NEMATOLOGISTS, 5, Daytona Beach, 1966. Abstracts. Nematologica, v. 13, n. 1, p. $156,1967$. 
MONTEIRO, A.R.; MORAIS, S.R.A.C. de. Ocorrência do nematóide de cisto da soja, Heterodera glycines Ichinohe, 1952, prejudicando a cultura em Mato Grosso do Sul. In: CONGRESSO BRASILEIRO DE NEMATOLOGIA, 16, Lavras, 1992. Resumos. Nematologia Brasileira, v. 16, n. 1/2, p. 101, 1992.

MULVEY, R.H. Identification of Heterodera cysts by terminal and cone top structures. Canadian Journal of Zoology, v. 50, n. 10, p. 1277-1292, 1972.

MULVEY, R.H.; GOLDEN, A.M. An illustrated key to the cyst-forming genera and species of Heteroderidae in the western hemisphere with species morphometrics and distribution. Journal of Nematology, v. 15, n. 1, p. 1-59, 1983.

NOEL, G.R.; MENDES, M.L.; MACHADO, C.C. Distribution of Heterodera glycines races in Brazil. Nematropica, v. 24, n. 1, p. 63-68, 1994.

OPPERMAN, C.H. Genetic analysis of Heterodera glycines parasitism. In: CONGRESSO INTERNACIONAL DE NEMATOLOGIA TROPICAL, Rio Quente, 1995. Programa e anais. Rio Quente: Sociedade Brasileira de Nematologia/Organização dos Nematologistas da América Tropical, 1995. p.111119.

PANT, V.; SINGH, S.P.; HAKIM, S.; SAXENA, S.K. Reaction of different vegetables to root-knot nematode Meloidogyne incognita and their effect on the morphometrics of nematode. Indian Journal of Nematology, v. 15, n. 1, p. 33-35, 1985.

PEREIRA, J.E.; SILVA, J.F.V.; GARCIA, A.; LANTMANN, A.F. Análise multivariada na seleção de fatores químicos do solo e sua relação com a densidade populacional do nematóide de cisto e rendimento da cultura da soja. In: CONGRESSO BRASILEIRO DE NEMATOLOGIA, 20., Gramado, 1997. Resumos. Gramado: Sociedade Brasileira de Nematologia, 1997. p. 61.

RIGGS, R.D. Races of Heterodera glycines. Nematropica, v.18, n. 2, p. 163-170, 1988. 
RIGGS, R.D. Host range. In: RIGGS, R.D.; WRATHER, A. (Ed.) Biology and management of the soybean cyst nematode. St. Paul: APS Press, 1992. p. 107-114.

RIGGS, R.D.; HAMBLEN, M.L. Soybean-cyst nematode host studies in the family Leguminosae. Fayetteville: Agricultural Experiment Station, 1962. 19p. (Report Series, 110).

RIGGS, R.D.; HAMBLEN, M.L. Further studies on the host range of the soybeancyst nematode. Fayetteville: Agricultural Experiment Station, 1966. 19p. (Bulletin, 718).

RIGGS, R.D.; SCHMITT, D.P. Complete characterization of the race scheme for Heterodera glycines. Journal of Nematology, v. 20, n. 3, p. 392-395, 1988.

RIGGS, R.D.; HAMBLEN, M.L.; RAKES, L. Morphometric and serologic comparisons of a number of populations of cyst nematodes. Journal of Nematology, v. 14, n. 2, p. 188-199, 1982.

ROSS, J.P. Physiological strains of Heterodera glycines. Plant Disease Reporter, v. 46, n. 11, p. 766-769, 1962.

ROSSI, C.E.; MONTEIRO, A.R.; RAMIRO, Z.A. Ocorrência do nematóide de cisto, Heterodera glycines Ichinohe, 1952, em cultura de soja, no estado de São Paulo. Revista de Agricultura, v. 70, n. 1, p. 37-39, 1995.

SAS INSTITUTE S/A. SAS/STAT: user's guide: release 6.03 ed. Cary, 1988. 1028p.

SCHMITT, D.P.; SHANNON, G. Differentiating soybean responses to Heterodera glycines races. Crop Science, v. 32, n. 1, p. 275-277, 1992.

SILVA, J.F.V.; GARCIA, A.; SILVA, E.A. da; DIAS, V.P. Situação atual do nematóide de cisto da soja (NCS) no Brasil. In: CONGRESSO BRASILEIRO DE NEMATOLOGIA, 20., Gramado, 1997. Resumos. Gramado: Sociedade Brasileira de Nematologia, 1997. p. 20-22. 
SILVA, M.A.; HANADA, R.E.; SILVA, H.S.A. LIMA, R.D.; VIEIRA, R.F. Reprodução de Heterodera glycines em algumas leguminosas. In: CONGRESSO BRASILEIRO DE FITOPATOLOGIA, 30., Poços de Caldas, 1997. Fitopatologia Brasileira, v. 22, p. 324, 1997.

SKOTLAND, C.B. Biological studies of the soybean cyst nematode. Phytopathology, v. 47 , n. 10 , p. $623-625,1957$.

SMART, G.C. Additional hosts of the soybean cyst nematode, Heterodera glycines, including hosts in two additional plant families. Plant Disease Reporter, v. 48, n. 5 , p. 388-389, 1964.

SOLOGUREN, L.J.; SANTOS, M.A. dos Estudo de características químicas de solo em reboleiras de soja com Heterodera glycines. In: CONGRESSO BRASILEIRO DE FITOPATOLOGIA, 30., Poços de Caldas, 1997. Fitopatologia Brasileira, v. 22, p. 329, 1997.

SOUTHEY, J.F. Laboratory methods for work with plant and soil nematodes. London: Ministry of Agriculture, Fisheries and Food, 1970. 148p.

TARTE, R.; MAI, W.F. Morphological variation in Pratylenchus penetrans. Journal of Nematology, v. 8, n. 3, p. 185-195, 1976.

TAYLOR, A.L. Identification of soybean cyst nematodes for regulatory purposes. Soil and Crop Science Society of Florida Proceedings, v. 34, p. 200-206, 1974.

TIHOHOD, D. Caracterização morfobiométrica e bioquímica de populações brasileiras de Heterodera glycines Ichinohe, 1952 e H. fici Kirjanova, 1954. Jaboticabal, 1996. 110p. Tese (Livre docência) - Faculdade de Ciências Agrárias e Veterinárias, Universidade Estadual Paulista "Julio de Mesquita Filho".

TRUDGILL, D.L.; PARROTT, D.M.; STONE, A.R. Morphometrics of males and larvae of ten Heterodera rostochiensis populations and the influence of resistant hosts. Nematologica, v. 16, n. 3, p. 410-416, 1970. 
VALLE, L.A.C. do Controle do nematóide de cisto da soja, Heterodera glycines Ichinohe, com leguminosas e gramíneas forrageiras. Viçosa, $1996.74 \mathrm{p}$. Dissertação (M.S.) - Universidade Federal de Viçosa.

VALLE, L.A.C. do; SANCHES, J. de B.; MIZOBUTSI, E.H.; FERRAZ, S. Reação de leguminosas utilizadas como cobertura do solo e adubação verde ao nematóide de cisto da soja, Heterodera glycines. In: CONGRESSO BRASILEIRO DE FITOPATOLOGIA, 30., Poços de Caldas, 1997. Fitopatologia Brasileira, v. 22, p. 330, 1997.

WILLIAMS, T.D.; SIDDIQI, M.R. Heterodera avenae. St. Albans: CAB, 1972. 4p. (C.I.H. Descriptions of Plant-Parasitic Nematodes, 1).

WINSTEAD, N.N.; SKOTLAND, C.B.; SASSER, J.N. Soybean cyst nematode in North Carolina. Plant Disease Reporter, v. 39, p. 9-11, 1955. 


\section{APÊEDICE}


Apêndice 01 . Valores de morfometria de 20 juvenis de segundo estádio de Heterodera glycines população MT extraídos de soja 'FT Cristalina'.

\begin{tabular}{|c|c|c|c|c|c|c|}
\hline Caracteres* & Min. & Max. & Média & E. P. Média & E.P. & C.V. (\%) \\
\hline $\mathrm{L}$ & 360,82 & 443,30 & 415,59 & 17,14 & 21,45 & 5,16 \\
\hline bw & 17,53 & 20,10 & 18,69 & 0,39 & 0,55 & 2,95 \\
\hline stbw & 14,95 & 16,49 & 15,52 & 0,24 & 0,37 & 2,39 \\
\hline lcef & 3,09 & 4,12 & 3,56 & 0,32 & 0,41 & 11,42 \\
\hline wcef & 8,76 & 9,79 & 9,18 & 0,21 & 0,27 & 2,94 \\
\hline St & 21,13 & 24,74 & 22,71 & 0,75 & 0,97 & 4,26 \\
\hline $1 \mathrm{hbst}$ & 11,34 & 13,92 & 12,32 & 0,47 & 0,65 & 5,24 \\
\hline lbst & 2,06 & 3,09 & 2,47 & 0,25 & 0,32 & 12,82 \\
\hline wbst & 4,64 & 5,67 & 5,05 & 0,21 & 0,27 & 5,34 \\
\hline Ebst & 23,71 & 26,29 & 25,08 & 0,56 & 0,67 & 2,69 \\
\hline DGO & 3,09 & 5,45 & 3,97 & 0,59 & 0,65 & 16,37 \\
\hline Pbw & 16,49 & 19,07 & 18,14 & 0,47 & 0,64 & 3,52 \\
\hline EP & 85,05 & 96,39 & 91,70 & 2,59 & 3,29 & 3,58 \\
\hline $\mathrm{t}$ & 39,18 & 53,09 & 46,57 & 2,78 & 3,72 & 7,98 \\
\hline abw & 10,82 & 13,92 & 12,42 & 0,58 & 0,80 & 6,44 \\
\hline $\mathrm{h}$ & 19,59 & 27,84 & 24,05 & 1,90 & 2,30 & 9,57 \\
\hline wh & 6,19 & 8,25 & 7,42 & 0,48 & 0,59 & 7,93 \\
\hline a & 17,95 & 24,12 & 22,27 & 1,14 & 1,49 & 6,67 \\
\hline c & 8,04 & 10,33 & 8,96 & 0,44 & 0,59 & 6,55 \\
\hline$c^{\prime}$ & 3,15 & 4,25 & 3,76 & 0,26 & 0,32 & 8,58 \\
\hline $\mathrm{h} / \mathrm{wh}$ & 2,50 & 4,08 & 3,26 & 0,32 & 0,43 & 13,10 \\
\hline$P$ & 20,95 & 23,57 & 22,09 & 0,57 & 0,72 & 3,26 \\
\hline lhbst/St & 48,89 & 59,52 & 54,30 & 2,18 & 2,76 & 5,09 \\
\hline
\end{tabular}

*Valores expressos em $\mu \mathrm{m}$, exceto os alométricos (números absolutos) e P e lhbst/St (expressos em porcentagem) 
Apêndice 02. Valores de morfometria de 20 juvenis de segundo estádio de Heterodera glycines população SP1 extraídos de soja 'FT Cristalina'.

\begin{tabular}{|c|c|c|c|c|c|c|}
\hline Caracteres* & Min. & Max. & Média & E. P. Média & E.P. & C.V. $(\%)$ \\
\hline L & 373,71 & 458,76 & 408,12 & 16,03 & 21,49 & 5,26 \\
\hline bw & 20,62 & 22,68 & 20,93 & 0,37 & 0,51 & 2,45 \\
\hline stbw & 13,92 & 15,46 & 14,95 & 0,36 & 0,47 & 3,16 \\
\hline lcef & 3,09 & 4,12 & 3,43 & 0,30 & 0,35 & 10,09 \\
\hline wcef & 8,25 & 9,28 & 8,84 & 0,31 & 0,38 & 4,34 \\
\hline St & 20,10 & 23,71 & 21,83 & 1,02 & 1,17 & 5,38 \\
\hline $1 \mathrm{hbst}$ & 11,34 & 12,89 & 11,75 & 0,37 & 0,49 & 4,17 \\
\hline lbst & 2,06 & 3,61 & 2,37 & 0,31 & 0,39 & 16,39 \\
\hline wbst & 4,12 & 5,15 & 4,74 & 0,29 & 0,36 & 7,56 \\
\hline Ebst & 22,68 & 30,41 & 24,61 & 0,97 & 1,60 & 6,51 \\
\hline DGO & 3,09 & 5,67 & 3,84 & 0,51 & 0,66 & 17,13 \\
\hline Pbw & 17,01 & 19,7 & 17,68 & 0,46 & 0,58 & 3,29 \\
\hline EP & 84,02 & 100,00 & 94,23 & 3,46 & 4,27 & 4,53 \\
\hline $\mathrm{t}$ & 32,99 & 51,55 & 43,02 & 2,84 & 4,06 & 9,44 \\
\hline abw & 11,34 & 13,40 & 12,53 & 0,53 & 0,65 & 5,19 \\
\hline h & 15,46 & 28,35 & 23,69 & 2,45 & 3,16 & 13,35 \\
\hline wh & 5,67 & 8,25 & 7,14 & 0,47 & 0,63 & 8,85 \\
\hline a & 19,47 & 24,05 & 22,09 & 0,70 & 1,00 & 4,53 \\
\hline c & 8,39 & 11,56 & 9,55 & 0,63 & 0,80 & 8,38 \\
\hline$c^{\prime}$ & 2,67 & 3,96 & 3,44 & 0,18 & 0,28 & 8,22 \\
\hline $\mathrm{h} / \mathrm{wh}$ & 2,14 & 4,00 & 3,33 & 0,33 & 0,45 & 13,40 \\
\hline$P$ & 21,80 & 24,84 & 23,11 & 0,67 & 0,87 & 3,77 \\
\hline lhbst/St & 47,83 & 58,97 & 53,94 & 2,24 & 2,77 & 5,13 \\
\hline
\end{tabular}

*Valores expressos em $\mu \mathrm{m}$, exceto os alométricos (números absolutos) e $\mathrm{Pe} \mathrm{lhbst/St} \mathrm{(expressos} \mathrm{em} \mathrm{por-}$ centagem) 
Apêndice 03 . Valores de morfometria de 20 juvenis de segundo estádio de Heterodera glycines população SP2 extraidos de soja 'FT Cristalina'.

\begin{tabular}{|c|c|c|c|c|c|c|}
\hline Caracteres* & Min. & Max. & Média & E. P. Média & E.P. & C.V. $(\%)$ \\
\hline $\mathrm{L}$ & 394,33 & 463,92 & 420,10 & 16,24 & 20,10 & 4,79 \\
\hline bw & 20,10 & 23,71 & 21,65 & 0,82 & 1,03 & 4,76 \\
\hline stbw & 13,92 & 15,98 & 15,28 & 0,34 & 0,45 & 2,95 \\
\hline lcef & 3,09 & 4,12 & 3,45 & 0,32 & 0,38 & 10,94 \\
\hline wcef & 8,76 & 9,79 & 9,07 & 0,28 & 0,31 & 3,40 \\
\hline St & 19,59 & 24,74 & 21,83 & 1,23 & 1,46 & 6,69 \\
\hline $1 \mathrm{hbst}$ & 11,34 & 13,92 & 12,09 & 0,54 & 0,70 & 5,78 \\
\hline lbst & 2,06 & 3,09 & 2,53 & 0,19 & 0,28 & 11,28 \\
\hline wbst & 4,12 & 5,15 & 4,85 & 0,28 & 0,31 & 6,36 \\
\hline Ebst & 23,20 & 25,77 & 24,30 & 0,47 & 0,63 & 2,60 \\
\hline DGO & 3,09 & 5,15 & 3,74 & 0,39 & 0,53 & 14,06 \\
\hline $\mathrm{Pbw}$ & 17,01 & 19,07 & 18,22 & 0,37 & 0,48 & 2,64 \\
\hline $\mathrm{EP}$ & 87,63 & 102,58 & 96,26 & 2,67 & 3,56 & 3,69 \\
\hline $\mathrm{t}$ & 41,24 & 56,70 & 45,70 & 3,03 & 4,10 & 8,97 \\
\hline abw & 11,34 & 14,43 & 12,84 & 0,53 & 0,75 & 5,81 \\
\hline $\mathrm{h}$ & 21,65 & 34,54 & 25,72 & 2,22 & 3,07 & 11,95 \\
\hline wh & 5,67 & 9,28 & 7,32 & 0,48 & 0,72 & 9,85 \\
\hline a & 20,95 & 25,00 & 22,74 & 0,76 & 1,06 & 4,67 \\
\hline c & 8,18 & 10,12 & 9,23 & 0,36 & 0,47 & 5,12 \\
\hline$c^{\prime}$ & 3,26 & 4,40 & 3,57 & 0,23 & 0,31 & 8,82 \\
\hline $\mathrm{h} / \mathrm{wh}$ & 2,56 & 4,47 & 3,54 & 0,38 & 0,48 & 13,67 \\
\hline$P$ & 20,89 & 24,13 & 22,94 & 0,59 & 0,80 & 3,47 \\
\hline lhbst/St & 50,00 & 62,79 & 55,51 & 2,89 & 3,47 & 6,24 \\
\hline
\end{tabular}

*Valores expressos em $\mu \mathrm{m}$, exceto os alométricos (números absolutos) e P e lhbst/St (expressos em porcentagem) 
Apêndice 04 . Valores de morfometria de 20 juvenis de segundo estádio de Heterodera glycines população MS extraídos de soja 'FT Cristalina'.

\begin{tabular}{|c|c|c|c|c|c|c|}
\hline Caracteres* & Min. & Max. & Média & E. P. Média & E.P. & C.V. $(\%)$ \\
\hline $\mathrm{L}$ & 332,47 & 427,84 & 386,47 & 18,21 & 24,02 & 6,22 \\
\hline bw & 20,62 & 22,68 & 21,21 & 0,56 & 0,70 & 3,28 \\
\hline stbw & 14,43 & 15,98 & 15,26 & 0,32 & 0,39 & 2,55 \\
\hline lcef & 3,09 & 4,12 & 3,30 & 0,27 & 0,31 & 9,35 \\
\hline wcef & 8,25 & 9,28 & 8,99 & 0,37 & 0,43 & 4,73 \\
\hline St & 18,04 & 24,74 & 21,44 & 1,16 & 1,48 & 6,91 \\
\hline $1 \mathrm{hbst}$ & 7,22 & 13,40 & 11,55 & 0,80 & 1,26 & 10,88 \\
\hline lbst & 2,06 & 3,61 & 2,58 & 0,26 & 0,41 & 15,89 \\
\hline wbst & 4,64 & 5,15 & 4,90 & 0,26 & 0,26 & 5,40 \\
\hline Ebst & 22,68 & 26,80 & 24,28 & 0,58 & 0,87 & 3,57 \\
\hline DGO & 3,09 & 5,67 & 4,07 & 0,66 & 0,78 & 19,22 \\
\hline Pbw & 17,01 & 19,07 & 18,25 & 0,49 & 0,59 & 3,23 \\
\hline $\mathrm{EP}$ & 82,99 & 95,88 & 89,97 & 3,60 & 4,22 & 4,69 \\
\hline $\mathrm{t}$ & 33,51 & 44,33 & 39,15 & 2,60 & 3,20 & 8,18 \\
\hline abw & 10,31 & 13,92 & 12,63 & 0,57 & 0,79 & 6,28 \\
\hline $\mathrm{h}$ & 12,89 & 25,77 & 22,24 & 1,99 & 2,82 & 12,70 \\
\hline wh & 6,70 & 8,25 & 7,65 & 0,45 & 0,54 & 7,00 \\
\hline a & 18,47 & 21,84 & 20,29 & 0,86 & 1,02 & 5,03 \\
\hline c & 8,57 & 11,92 & 9,91 & 0,48 & 0,70 & 7,07 \\
\hline$c^{\prime}$ & 2,71 & 3,38 & 3,10 & 0,16 & 0,20 & 6,42 \\
\hline $\mathrm{h} / \mathrm{wh}$ & 1,67 & 3,85 & 2,92 & 0,24 & 0,40 & 13,77 \\
\hline$P$ & 21,30 & 25,12 & 23,32 & 0,69 & 0,91 & 3,89 \\
\hline lhbst/St & 40,00 & 58,97 & 53,78 & 2,86 & 4,20 & 7,82 \\
\hline
\end{tabular}

*Valores expressos em $\mu \mathrm{m}$, exceto os alométricos (números absolutos) e $\mathrm{P}$ e lhbst/St (expressos em porcentagem) 
Apêndice 05 . Valores de morfometria de 20 juvenis de segundo estádio de Heterodera glycines população GOl extraídos de soja 'FT Cristalina'.

\begin{tabular}{|c|c|c|c|c|c|c|}
\hline Caracteres* & Min. & Max. & Média & E. P. Média & E.P. & C.V. $(\%)$ \\
\hline $\mathrm{L}$ & 399,48 & 458,76 & 426,55 & 15,21 & 17,31 & 4,06 \\
\hline bw & 19,59 & 24,74 & 21,52 & 0,95 & 1,17 & 5,43 \\
\hline stbw & 14,95 & 16,49 & 15,88 & 0,38 & 0,46 & 2,90 \\
\hline Icef & 3,09 & 4,12 & 3,40 & 0,31 & 0,35 & 10,31 \\
\hline wcef & 8,25 & 9,79 & 9,20 & 0,27 & 0,38 & 4,17 \\
\hline St & 20,62 & 24,23 & 22,19 & 0,91 & 1,10 & 4,97 \\
\hline $1 \mathrm{hbst}$ & 11,34 & 12,89 & 12,24 & 0,43 & 0,53 & 4,29 \\
\hline lbst & 2,06 & 3,09 & 2,55 & 0,29 & 0,39 & 15,34 \\
\hline wbst & 4,12 & 6,19 & 5,08 & 0,27 & 0,42 & 8,25 \\
\hline Ebst & 23,71 & 26,80 & 25,13 & 0,55 & 0,73 & 2,89 \\
\hline DGO & 3,09 & 5,67 & 4,05 & 0,80 & 0,89 & 21,98 \\
\hline Pbw & 17,01 & 19,59 & 18,61 & 0,43 & 0,65 & 3,47 \\
\hline EP & 86,08 & 98,97 & 93,30 & 2,84 & 3,47 & 3,72 \\
\hline $\mathrm{t}$ & 39,18 & 50,52 & 44,56 & 2,47 & 3,14 & 7,06 \\
\hline abw & 11,86 & 13,92 & 13,07 & 0,54 & 0,65 & 5,00 \\
\hline $\mathrm{h}$ & 21,13 & 31,96 & 26,31 & 2,09 & 2,65 & 10,08 \\
\hline wh & 6,70 & 9,28 & 7,84 & 0,40 & 0,57 & 7,27 \\
\hline $\mathbf{a}$ & 20,66 & 24,05 & 22,02 & 0,81 & 0,96 & 4,37 \\
\hline c & 8,62 & 11,03 & 9,61 & 0,51 & 0,62 & 6,50 \\
\hline$c^{\prime}$ & 2,92 & 4,09 & 3,42 & 0,21 & 0,27 & 7,88 \\
\hline $\mathrm{h} / \mathrm{wh}$ & 2,69 & 4,13 & 3,37 & 0,28 & 0,35 & 10,33 \\
\hline $\mathrm{P}$ & 20,12 & 24,77 & 21,90 & 0,67 & 1,02 & 4,68 \\
\hline lhbst/St & 51,06 & 59.52 & 55,23 & 2,00 & 2,39 & 4,33 \\
\hline
\end{tabular}

*Valores expressos em $\mu \mathrm{m}$, exceto os alométricos (números absolutos) e P e lhbst/St (expressos em porcentagem) 
Apêndice 06. Valores de morfometria de 20 juvenis de segundo estádio de Heterodera glycines população GO2 extraídos de soja 'FT Cristalina'.

\begin{tabular}{|c|c|c|c|c|c|c|}
\hline Caracteres* & Min. & Max. & Média & E. P. Média & E.P. & C.V. $(\%)$ \\
\hline $\mathrm{L}$ & 378,87 & 474,23 & 423,97 & 19,97 & 25,89 & 6,11 \\
\hline bw & 20,10 & 22,68 & 21,03 & 0,51 & 0,64 & 3,04 \\
\hline stbw & 15,46 & 16,49 & 15,85 & 0,35 & 0,41 & 2,56 \\
\hline lcef & 3,09 & 4,64 & 3,87 & 0,36 & 0,43 & 11,03 \\
\hline wcef & 8,76 & 10,31 & 9,33 & 0,34 & 0,47 & 5,04 \\
\hline St & 20,10 & 24,74 & 22,01 & 1,00 & 1,25 & 5,69 \\
\hline $1 \mathrm{hbst}$ & 11,34 & 13,40 & 12,29 & 0,37 & 0,51 & 4,14 \\
\hline lbst & 2,06 & 3,61 & 2,55 & 0,24 & 0,39 & 15,34 \\
\hline wbst & 4,12 & 5,15 & 4,87 & 0,28 & 0,31 & 6,40 \\
\hline Ebst & 23,71 & 26,29 & 25,15 & 0,46 & 0,66 & 2,63 \\
\hline DGO & 3,09 & 5,15 & 3,79 & 0,39 & 0,51 & 13,44 \\
\hline Pbw & 17,53 & 19,59 & 18,69 & 0,44 & 0,58 & 3,08 \\
\hline EP & 90,72 & 105,15 & 97,47 & 2,89 & 3,58 & 3,68 \\
\hline$t$ & 36,08 & 52,58 & 44,97 & 4,38 & 5,10 & 11,33 \\
\hline abw & 11,86 & 13,92 & 12,89 & 0,46 & 0,60 & 4,68 \\
\hline $\mathrm{h}$ & 16,49 & 31,96 & 26,68 & 3,09 & 3,86 & 14,46 \\
\hline wh & 7,22 & 9,79 & 8,25 & 0,52 & 0,67 & 8,11 \\
\hline a & 19,34 & 24,21 & 21,80 & 0,97 & 1,25 & 5,75 \\
\hline c & 8,45 & 11,43 & 9,50 & 0,62 & 0,78 & 8,18 \\
\hline$c^{\prime}$ & 2,74 & 4,08 & 3,49 & 0,34 & 0,40 & 11,36 \\
\hline $\mathrm{h} / \mathrm{wh}$ & 1,68 & 4,21 & 3,26 & 0,41 & 0,56 & 17,16 \\
\hline $\mathrm{P}$ & 21,30 & 25,17 & 23,04 & 0,74 & 0,98 & 4,24 \\
\hline lhbst/St & 52,08 & 60,98 & 55.94 & 1,86 & 2,40 & 4,29 \\
\hline
\end{tabular}

*Valores expressos em $\mu \mathrm{m}$, exceto os alométricos (números absolutos) e $\mathrm{P}$ e lhbst/St (expressos em porcentagem) 
Apêndice 07. Valores de morfometria de 20 juvenis de segundo estádio de Heterodera glycines população PR extraídos de soja 'FT Cristalina'.

\begin{tabular}{|c|c|c|c|c|c|c|}
\hline Caracteres* & Min. & Max. & Média & E. P. Média & E.P. & C.V. $(\%)$ \\
\hline $\mathrm{L}$ & 386,60 & 451,03 & 421,91 & 15,88 & 19,05 & 4,52 \\
\hline bw & 20,10 & 23,71 & 21,47 & 0,88 & 1,05 & 4,88 \\
\hline stbw & 14,43 & 15,46 & 15,23 & 0,28 & 0,31 & 2,05 \\
\hline lcef & 3,09 & 4,12 & 3,32 & 0,30 & 0,35 & 10,64 \\
\hline wcef & 8,25 & 10,31 & 9,20 & 0,41 & 0,54 & 5,83 \\
\hline St & 20,10 & 23,20 & 21,70 & 0,63 & 0,88 & 4,07 \\
\hline $1 \mathrm{hbst}$ & 10,82 & 12,89 & 12,16 & 0,44 & 0,56 & 4,64 \\
\hline lbst & 2,06 & 3,09 & 2,45 & 0,27 & 0,33 & 13,45 \\
\hline wbst & 4,12 & 5,67 & 4,77 & 0,32 & 0,41 & 8,50 \\
\hline Ebst & 23,71 & 25,77 & 24,54 & 0,50 & 0,61 & 2,50 \\
\hline DGO & 3,09 & 6,19 & 4,20 & 0,86 & 0,99 & 23,64 \\
\hline Pbw & 16,49 & 19,07 & 18,04 & 0,46 & 0,67 & 3,71 \\
\hline EP & 89,69 & 105,67 & 95,88 & 3,25 & 3,93 & 4,10 \\
\hline $\mathrm{t}$ & 37,11 & 51,55 & 46,29 & 2,55 & 3,42 & 7,39 \\
\hline abw & 11,34 & 14,43 & 12,55 & 0,64 & 0,79 & 6,29 \\
\hline h & 22,68 & 30,41 & 26,60 & 1,45 & 1,96 & 7,37 \\
\hline wh & 6,70 & 8,25 & 7,55 & 0,49 & 0,56 & 7,44 \\
\hline a & 19,74 & 23,89 & 22,16 & 0,71 & 0,97 & 4,36 \\
\hline c & 8,45 & 11,46 & 9,16 & 0,49 & 0,77 & 8,41 \\
\hline$c^{\prime}$ & 3,27 & 4,00 & 3,69 & 0,18 & 0,22 & 5,87 \\
\hline $\mathrm{h} / \mathrm{wh}$ & 3,00 & 4,00 & 3,53 & 0,22 & 0,26 & 7,50 \\
\hline P & 21,78 & 24,27 & 22,74 & 0,40 & 0,58 & 2,55 \\
\hline lhbst/St & 50,00 & 61,54 & 56.11 & 2,26 & 2,87 & 5,11 \\
\hline
\end{tabular}

*Valores expressos em $\mu \mathrm{m}$, exceto os alométricos (números absolutos) e P e lhbst/St (expressos em porcentagem) 
Apêndice 08. Valores de morfometria de 20 juvenis de segundo estádio de Heterodera glycines população MG extraídos de soja 'FT Cristalina'.

\begin{tabular}{ccccccc}
\hline Caracteres* & Min. & Max. & Média & E. P. Média & E.P. & C.V. (\%) \\
\hline L & 381,44 & 438,14 & 403,48 & 9,55 & 12,89 & 3,19 \\
bw & 20,10 & 23,71 & 21,26 & 0,73 & 0,96 & 4,51 \\
stbw & 14,43 & 16,49 & 15,64 & 0,46 & 0,56 & 3,59 \\
Icef & 2,58 & 3,61 & 3,20 & 0,25 & 0,32 & 9,93 \\
wcef & 8,25 & 9,28 & 9,10 & 0,25 & 0,30 & 3,33 \\
St & 20,10 & 22,68 & 21,19 & 0,58 & 0,69 & 3,25 \\
l hbst & 11,34 & 12,89 & 12,14 & 0,31 & 0,35 & 2,91 \\
lbst & 1,55 & 3,09 & 2,40 & 0,32 & 0,38 & 16,02 \\
wbst & 4,12 & 5,15 & 4,64 & 0,15 & 0,29 & 6,24 \\
Ebst & 23,20 & 25,26 & 24,28 & 0,53 & 0,65 & 2,66 \\
DGO & 3,09 & 5,15 & 4,02 & 0,42 & 0,52 & 12,89 \\
Pbw & 17,53 & 19,07 & 17,99 & 0,37 & 0,47 & 2,61 \\
EP & 88,66 & 98,45 & 91,88 & 1,73 & 2,33 & 2,53 \\
t & 37,63 & 46,91 & 43,66 & 1,70 & 2,37 & 5,42 \\
abw & 11,34 & 13,40 & 12,50 & 0,46 & 0,60 & 4,80 \\
h & 17,01 & 25,77 & 23,56 & 1,26 & 1,92 & 8,16 \\
wh & 6,19 & 7,73 & 7,16 & 0,34 & 0,47 & 6,56 \\
a & 20,39 & 22,37 & 21,42 & 0,39 & 0,48 & 2,22 \\
c & 8,62 & 10,96 & 9,26 & 0,38 & 0,53 & 5,73 \\
c' & 3,17 & 3,82 & 3,50 & 0,16 & 0,19 & 5,43 \\
h/wh & 2,75 & 3,92 & 3,29 & 0,19 & 0,27 & 8,07 \\
P & 21,29 & 24,33 & 22,79 & 0,67 & 0,82 & 3,59 \\
lhbst/St & 53,49 & 60,00 & 57,33 & 1,15 & 1,64 & 2,86 \\
\hline
\end{tabular}

*Valores expressos em $\mu \mathrm{m}$, exceto os alométricos (números absolutos) e P e lhbst/St (expressos em porcentagem) 
Apêndice 09. Valores de morfometria de 20 machos de Heterodera glycines população MT extraídos de soja 'FT Cristalina'.

\begin{tabular}{ccccccc}
\hline Caracteres* & Min. & Max. & Média & E. P. Média & E.P. & C.V. (\%) \\
\hline L & 773,20 & 1523,20 & 1047,29 & 138,02 & 174,67 & 16,68 \\
bw & 27,84 & 30,93 & 29,30 & 0,59 & 0,81 & 2,75 \\
stbw & 15,46 & 19,59 & 16,91 & 0,93 & 1,15 & 6,82 \\
lcef & 4,12 & 5,67 & 4,79 & 0,30 & 0,38 & 7,88 \\
wcef & 9,28 & 11,34 & 10,23 & 0,31 & 0,45 & 4,41 \\
St & 23,20 & 26,80 & 25,31 & 1,08 & 1,28 & 5,07 \\
l hbst & 11,86 & 14,95 & 13,38 & 0,55 & 0,78 & 5,79 \\
lbst & 2,06 & 3,09 & 2,50 & 0,26 & 0,35 & 13,83 \\
wbst & 4,12 & 5,67 & 4,77 & 0,32 & 0,41 & 8,50 \\
Ebst & 25,77 & 30,41 & 28,20 & 0,65 & 0,95 & 3,36 \\
DGO & 3,09 & 4,64 & 3,79 & 0,51 & 0,59 & 15,47 \\
Pbw & 20,62 & 24,23 & 22,50 & 0,92 & 1,09 & 4,83 \\
EP & 119,59 & 163,40 & 138,92 & 9,05 & 11,91 & 8,57 \\
ltt & 417,53 & 804,12 & 595,36 & 58,76 & 83,07 & 13,95 \\
Oes' & 147,94 & 307,22 & 181,39 & 20,71 & 33,88 & 18,68 \\
a & 25,00 & 52,77 & 35,82 & 5,11 & 6,39 & 17,83 \\
b' & 3,89 & 7,99 & 5,84 & 0,59 & 0,87 & 14,82 \\
P & 9,58 & 16,84 & 13,51 & 1,49 & 1,87 & 13,83 \\
T & 34,86 & 72,67 & 57,70 & 6,14 & 8,50 & 14,74 \\
\hline
\end{tabular}

*Valores expressos em $\mu \mathrm{m}$, exceto os alométricos (números absolutos) e P e $\mathrm{T}$ (expressos em porcentagem) 
Apêndice 10. Valores de morfometria de 20 machos de Heterodera glycines população SP1 extraídos de soja 'FT Cristalina'.

\begin{tabular}{ccccccc}
\hline Caracteres $^{*}$ & Min. & Max. & Média & E. P. Média & E.P. & C.V. (\%) \\
\hline L & 785,71 & 1183,67 & 979,34 & 68,14 & 90,45 & 9,24 \\
bw & 27,84 & 30,93 & 29,15 & 0,55 & 0,78 & 2,66 \\
stbw & 15,46 & 18,04 & 17,06 & 0,66 & 0,78 & 4,59 \\
lcef & 4,12 & 5,67 & 5,03 & 0,36 & 0,44 & 8,73 \\
wcef & 9,28 & 11,34 & 10,03 & 0,41 & 0,51 & 5,13 \\
St & 22,16 & 26,80 & 24,54 & 1,11 & 1,33 & 5,43 \\
l hbst & 11,86 & 15,46 & 12,65 & 0,68 & 0,94 & 7,41 \\
lbst & 2,06 & 3,09 & 2,40 & 0,27 & 0,30 & 12,63 \\
wbst & 3,61 & 5,15 & 4,69 & 0,23 & 0,37 & 7,89 \\
Ebst & 25,77 & 29,38 & 27,47 & 0,77 & 0,99 & 3,61 \\
DGO & 3,09 & 4,64 & 4,05 & 0,27 & 0,38 & 9,49 \\
Pbw & 20,10 & 25,26 & 23,27 & 0,95 & 1,29 & 5,53 \\
EP & 114,95 & 154,12 & 136,88 & 10,36 & 12,41 & 9,06 \\
ltt & 515,46 & 747,42 & 588,14 & 44,69 & 58,17 & 9,89 \\
Oes' & 165,98 & 200,52 & 179,51 & 6,62 & 8,38 & 4,67 \\
a & 26,74 & 40,29 & 33,62 & 2,54 & 3,22 & 9,57 \\
b' & 4,42 & 6,02 & 5,45 & 0,25 & 0,36 & 6,57 \\
P & 11,89 & 18,04 & 14,05 & 1,17 & 1,51 & 10,71 \\
T & 48,68 & 70,43 & 60,28 & 4,55 & 5,58 & 9,25 \\
\hline
\end{tabular}

*Valores expressos em $\mu \mathrm{m}$, exceto os alométricos (números absolutos) e P e T (expressos em porcentagem) 
Apêndice 11. Valores de morfometria de 20 machos de Heterodera glycines população SP2 extraídos de soja 'FT Cristalina'.

\begin{tabular}{ccccccc}
\hline Caracteres* & Min. & Max. & Média & E. P. Média & E.P. & C.V. (\%) \\
\hline L & 795,92 & 1112,25 & 970,66 & 63,01 & 82,66 & 8,52 \\
bw & 27,84 & 30,93 & 29,25 & 0,53 & 0,69 & 2,35 \\
stbw & 15,46 & 18,56 & 17,22 & 0,59 & 0,77 & 4,49 \\
Icef & 4,64 & 5,67 & 5,18 & 0,15 & 0,26 & 5,08 \\
wcef & 9,28 & 11,34 & 10,36 & 0,34 & 0,50 & 4,82 \\
St & 20,62 & 27,32 & 24,74 & 1,29 & 1,68 & 6,79 \\
l hbst & 11,86 & 13,92 & 12,63 & 0,52 & 0,61 & 4,87 \\
lbst & 2,06 & 3,09 & 2,42 & 0,25 & 0,29 & 12,15 \\
wbst & 4,12 & 5,15 & 4,82 & 0,27 & 0,30 & 6,28 \\
Ebst & 24,74 & 28,87 & 27,40 & 0,70 & 0,96 & 3,52 \\
DGO & 3,09 & 4,12 & 3,40 & 0,31 & 0,35 & 10,31 \\
Pbw & 20,62 & 27,84 & 23,87 & 1,30 & 1,69 & 7,08 \\
EP & 119,07 & 143,30 & 129,95 & 4,79 & 6,36 & 4,90 \\
Itt & 389,18 & 662,37 & 512,76 & 57,59 & 76,18 & 14,86 \\
Oes' & 154,12 & 205,67 & 178,89 & 12,50 & 15,79 & 8,83 \\
a & 27,57 & 38,86 & 33,20 & 2,28 & 2,95 & 8,87 \\
b' & 4,80 & 6,17 & 5,44 & 0,37 & 0,44 & 8,03 \\
P & 11,31 & 15,43 & 13,46 & 0,80 & 1,03 & 7,67 \\
T & 38,14 & 63,66 & 52,85 & 4,80 & 6,37 & 12,05 \\
\hline
\end{tabular}

*Valores expressos em $\mu \mathrm{m}$, exceto os alométricos (números absolutos) e $\mathrm{P}$ e $\mathrm{T}$ (expressos em porcentagem) 
Apêndice 12. Valores de morfometria de 20 machos de Heterodera glycines população MS extraídos de soja 'FT Cristalina'.

\begin{tabular}{ccccccc}
\hline Caracteres* & Min. & Max. & Média & E. P. Média & E.P. & C.V. $(\%)$ \\
\hline L & 739,80 & 1209,18 & 993,88 & 96,63 & 122,85 & 12,36 \\
bw & 27,84 & 29,90 & 28,76 & 0,46 & 0,62 & 2,14 \\
stbw & 14,95 & 18,56 & 16,88 & 0,80 & 0,97 & 5,77 \\
lcef & 3,61 & 5,67 & 4,82 & 0,42 & 0,51 & 10,57 \\
wcef & 9,28 & 11,34 & 10,36 & 0,53 & 0,67 & 6,44 \\
St & 21,65 & 26,80 & 24,85 & 0,89 & 1,26 & 5,06 \\
l hbst & 11,34 & 14,43 & 12,73 & 0,55 & 0,73 & 5,74 \\
lbst & 2,06 & 3,09 & 2,53 & 0,14 & 0,23 & 9,13 \\
wbst & 4,12 & 5,67 & 4,74 & 0,30 & 0,40 & 8,35 \\
Ebst & 26,29 & 29,38 & 27,60 & 0,90 & 1,09 & 3,95 \\
DGO & 3,09 & 4,12 & 3,38 & 0,31 & 0,35 & 10,48 \\
Pbw & 21,13 & 25,77 & 23,32 & 1,25 & 1,48 & 6,33 \\
EP & 114,43 & 152,06 & 132,81 & 9,15 & 10,70 & 8,06 \\
ltt & 355,67 & 798,97 & 583,89 & 98,04 & 126,38 & 21,64 \\
Oes' & 163,40 & 205,67 & 184,97 & 8,83 & 11,67 & 6,31 \\
a & 25,18 & 43,44 & 34,58 & 3,35 & 4,41 & 12,75 \\
b' & 4,04 & 6,01 & 5,37 & 0,43 & 0,53 & 9,90 \\
P & 11,11 & 15,60 & 13,49 & 1,14 & 1,35 & 9,98 \\
T & 36,12 & 80,13 & 58,71 & 7,58 & 10,24 & 17,45 \\
\hline
\end{tabular}

*Valores expressos em $\mu \mathrm{m}$, exceto os alométricos (números absolutos) e $\mathrm{P}$ e $\mathrm{T}$ (expressos em porcentagem) 
Apêndice 13. Valores de morfometria de 20 machos de Heterodera glycines população GOl extraídos de soja 'FT Cristalina'.

\begin{tabular}{ccccccc}
\hline Caracteres* $^{*}$ & Min. & Max. & Média & E. P. Média & E.P. & C.V. (\%) \\
\hline L & 882,65 & 1234,69 & 1069,64 & 99,06 & 111,03 & 10,38 \\
bw & 27,84 & 29,90 & 29,05 & 0,40 & 0,54 & 1,85 \\
stbw & 15,46 & 18,56 & 16,98 & 0,76 & 0,92 & 5,44 \\
Icef & 4,12 & 6,19 & 5,03 & 0,40 & 0,50 & 9,91 \\
wcef & 9,28 & 11,34 & 10,26 & 0,52 & 0,65 & 6,29 \\
St & 22,68 & 27,84 & 25,03 & 0,85 & 1,13 & 4,51 \\
l hbst & 11,86 & 13,92 & 12,65 & 0,54 & 0,66 & 5,20 \\
lbst & 1,55 & 3,09 & 2,45 & 0,28 & 0,37 & 15,08 \\
wbst & 4,12 & 5,15 & 4,74 & 0,25 & 0,32 & 6,69 \\
Ebst & 25,77 & 29,90 & 27,84 & 0,77 & 1,04 & 3,75 \\
DGO & 3,09 & 4,64 & 3,51 & 0,41 & 0,52 & 14,78 \\
Pbw & 21,13 & 26,80 & 23,07 & 1,07 & 1,44 & 6,23 \\
EP & 113,40 & 152,58 & 134,82 & 9,15 & 11,57 & 8,58 \\
Itt & 487,11 & 737,11 & 632,47 & 68,97 & 78,70 & 12,44 \\
Oes' & 164,95 & 212,37 & 190,10 & 8,87 & 11,36 & 5,97 \\
a & 30,58 & 42,77 & 36,84 & 3,47 & 3,92 & 10,64 \\
b' & 5,07 & 6,77 & 5,62 & 0,32 & 0,41 & 7,37 \\
P & 10,76 & 14,95 & 12,68 & 0,94 & 1,18 & 9,32 \\
T & 54,12 & 66,56 & 59,06 & 2,38 & 3,15 & 5,33 \\
\hline
\end{tabular}

*Valores expressos em $\mu \mathrm{m}$, exceto os alométricos (números absolutos) e P e $\mathrm{T}$ (expressos em porcentagem) 
Apêndice 14. Valores de morfometria de 20 machos de Heterodera glycines população GO2 extraidos de soja 'FT Cristalina'.

\begin{tabular}{ccccccc}
\hline Caracteres* & Min. & Max. & Média & E. P. Média & E.P. & C.V. (\%) \\
\hline L & 744,90 & 1234,69 & 1009,69 & 103,62 & 130,28 & 12,90 \\
bw & 27,84 & 30,93 & 29,92 & 0,70 & 0,89 & 2,98 \\
stbw & 14,43 & 19,59 & 17,29 & 1,06 & 1,34 & 7,76 \\
Icef & 4,12 & 5,67 & 4,92 & 0,31 & 0,35 & 7,19 \\
wcef & 9,28 & 11,34 & 10,54 & 0,46 & 0,57 & 5,37 \\
St & 23,20 & 29,38 & 25,28 & 1,06 & 1,45 & 5,75 \\
I hbst & 11,34 & 14,95 & 13,09 & 0,62 & 0,81 & 6,18 \\
lbst & 2,06 & 3,09 & 2,50 & 0,26 & 0,35 & 13,83 \\
wbst & 4,12 & 5,15 & 4,69 & 0,32 & 0,41 & 8,66 \\
Ebst & 25,26 & 31,96 & 27,89 & 0,88 & 1,34 & 4,79 \\
DGO & 3,09 & 4,64 & 3,51 & 0,49 & 0,59 & 16,94 \\
Pbw & 21,65 & 29,90 & 25,05 & 2,14 & 2,52 & 10,09 \\
EP & 103,09 & 159,28 & 134,46 & 12,63 & 15,97 & 11,88 \\
Itt & 373,71 & 721,65 & 601,03 & 74,38 & 99,01 & 16,47 \\
Oes' & 160,31 & 228,87 & 183,97 & 13,76 & 17,99 & 9,78 \\
a & 25,07 & 44,36 & 33,80 & 3,63 & 4,70 & 13,90 \\
b' & 4,65 & 6,41 & 5,48 & 0,34 & 0,43 & 7,89 \\
P & 11,22 & 17,34 & 13,40 & 1,05 & 1,41 & 10,55 \\
T & 43,55 & 68,79 & 59,45 & 4,61 & 6,19 & 10,41 \\
\hline
\end{tabular}

*Valores expressos em $\mu \mathrm{m}$, exceto os alométricos (números absolutos) e P e T (expressos em porcentagem) 
Apêndice 15. Valores de morfometria de 20 machos de Heterodera glycines população PR extraídos de soja 'FT Cristalina'.

\begin{tabular}{ccccccc}
\hline Caracteres* & Min. & Max. & Média & E. P. Média & E.P. & C.V. (\%) \\
\hline L & 765,31 & 1132,65 & 985,71 & 83,67 & 101,39 & 10,29 \\
bw & 27,84 & 29,90 & 29,02 & 0,48 & 0,63 & 2,16 \\
stbw & 16,49 & 18,56 & 17,84 & 0,61 & 0,74 & 4,13 \\
Icef & 4,64 & 6,19 & 5,44 & 0,34 & 0,39 & 7,20 \\
wcef & 9,79 & 11,34 & 10,46 & 0,30 & 0,38 & 3,61 \\
St & 21,65 & 27,84 & 25,57 & 0,91 & 1,34 & 5,25 \\
l hbst & 11,34 & 14,43 & 12,68 & 0,65 & 0,83 & 6,51 \\
lbst & 2,06 & 3,09 & 2,55 & 0,20 & 0,31 & 12,22 \\
wbst & 4,12 & 5,67 & 4,85 & 0,30 & 0,35 & 7,24 \\
Ebst & 27,32 & 30,93 & 28,25 & 0,66 & 0,86 & 3,05 \\
DGO & 3,09 & 4,64 & 3,53 & 0,44 & 0,54 & 15,18 \\
Pbw & 21,65 & 26,29 & 24,20 & 0,70 & 0,97 & 4,00 \\
EP & 116,50 & 147,94 & 130,57 & 8,76 & 10,25 & 7,85 \\
Itt & 396,91 & 682,99 & 575,77 & 58,30 & 78,14 & 13,57 \\
Oes' & 151,03 & 193,81 & 168,22 & 9,27 & 11,62 & 6,91 \\
a & 26,51 & 39,24 & 33,99 & 2,93 & 3,62 & 10,65 \\
b' & 5,07 & 6,68 & 5,86 & 0,34 & 0,41 & 7,00 \\
P & 11,62 & 15,76 & 13,33 & 1,04 & 1,25 & 9,38 \\
T & 45,76 & 68,46 & 58,34 & 3,46 & 4,76 & 8,15 \\
\hline
\end{tabular}

*Valores expressos em $\mu \mathrm{m}$, exceto os alométricos (números absolutos) e P e T (expressos em porcentagem) 
Apêndice 16. Valores de morfometria de 20 machos de Heterodera glycines população MG extraídos de soja 'FT Cristalina'.

\begin{tabular}{ccccccc}
\hline Caracteres $^{*}$ & Min. & Max. & Média & E. P. Média & E.P. & C.V. (\%) \\
\hline L & 663,27 & 1086,74 & 874,74 & 93,06 & 117,93 & 13,48 \\
bw & 26,80 & 29,90 & 28,30 & 0,57 & 0,71 & 2,50 \\
stbw & 13,40 & 19,59 & 16,98 & 0,95 & 1,32 & 7,78 \\
lcef & 4,12 & 5,15 & 4,64 & 0,26 & 0,37 & 8,06 \\
wcef & 8,76 & 11,34 & 10,03 & 0,44 & 0,57 & 5,65 \\
St & 22,16 & 26,80 & 24,43 & 1,05 & 1,31 & 5,36 \\
l hbst & 10,82 & 15,46 & 12,78 & 0,77 & 1,03 & 8,02 \\
lbst & 2,06 & 3,09 & 2,45 & 0,27 & 0,33 & 13,45 \\
wbst & 3,09 & 5,15 & 4,36 & 0,36 & 0,46 & 10,50 \\
Ebst & 19,59 & 29,38 & 26,39 & 1,49 & 2,17 & 8,20 \\
DGO & 5,15 & 3,09 & 3,43 & 0,40 & 0,54 & 15,64 \\
Pbw & 19,07 & 25,26 & 22,55 & 1,33 & 1,69 & 7,49 \\
EP & 98,45 & 142,78 & 123,38 & 9,94 & 12,13 & 9,83 \\
ltt & 244,85 & 600,52 & 453,61 & 64,18 & 88,50 & 19,51 \\
Oes' & 138,66 & 188,14 & 164,56 & 12,77 & 14,88 & 9,04 \\
a & 22,98 & 37,65 & 30,92 & 3,35 & 4,15 & 13,41 \\
b' & 4,44 & 6,72 & 5,32 & 0,44 & 0,60 & 11,26 \\
P & 12,66 & 16,88 & 14,22 & 1,10 & 1,35 & 9,47 \\
T & 31,57 & 61,32 & 51,79 & 5,00 & 7,10 & 13,71 \\
\hline
\end{tabular}

*Valores expressos em $\mu \mathrm{m}$, exceto os alométricos (números absolutos) e P e T (expressos em porcentagem) 
Apêndice 17. Valores de morfometria de 12 cistos e 60 ovos de Heterodera glycines população MT extraídos de soja 'FT Cristalina'.

\begin{tabular}{|c|c|c|c|c|c|c|}
\hline Caracteres* & Min. & Max. & Média & E. P. Média & E.P. & C.V. $(\%)$ \\
\hline \multicolumn{7}{|l|}{ Cistos } \\
\hline $\mathrm{L}$ & 765,31 & 897,96 & 820,15 & 41,03 & 47,97 & 5,85 \\
\hline $\mathrm{Ls} / \mathrm{p}$ & 683,67 & 826,53 & 749,15 & 38,27 & 45,52 & 6,08 \\
\hline bw & 464,29 & 561,22 & 512,33 & 27,99 & 34,08 & 6,65 \\
\hline lc & 51,02 & 91,84 & 74,83 & 10,77 & 12,93 & 17,28 \\
\hline wc & 96,94 & 132,65 & 114,37 & 12,33 & 14,18 & 12,39 \\
\hline Ip & 51,02 & 76,53 & 61,65 & 7,30 & 9,09 & 14,74 \\
\hline wp & 51,02 & 91,84 & 74,40 & 12,19 & 14,83 & 19,93 \\
\hline lv & 37,62 & 49,50 & 44,31 & 2,56 & 3,35 & 7,57 \\
\hline wv & 5,94 & 11,88 & 7,59 & 1,16 & 1,65 & 21,78 \\
\hline Isf & 13,86 & 19,80 & 17,24 & 2,06 & 2,41 & 13,95 \\
\hline If & 39,60 & 47,52 & 43,98 & 1,97 & 2,41 & 5,47 \\
\hline a & 1,42 & 1,76 & 1,60 & 0,08 & 0,10 & 6,32 \\
\hline \multicolumn{7}{|l|}{ Ovos } \\
\hline 10 & 95,36 & 110,82 & 104,08 & 5,55 & 6,21 & 5,96 \\
\hline wo & 37,63 & 44,85 & 41,02 & 1,68 & 2,16 & 5,26 \\
\hline
\end{tabular}

*Valores expressos em $\mu \mathrm{m}$, exceto a (números absolutos). 
Apêndice 18. Valores de morfometria de 12 cistos e 60 ovos de Heterodera glycines população SPl extraídos de soja 'FT Cristalina'.

\begin{tabular}{ccccccc}
\hline Caracteres* & Min. & Max. & Média & E. P. Média & E.P. & C.V. (\%) \\
\hline Cistos & & & & & & \\
L & 637,76 & 918,37 & 755,95 & 62,78 & 80,90 & 10,70 \\
Ls/p & 525,51 & 826,53 & 678,57 & 56,97 & 76,39 & 11,26 \\
bw & 428,57 & 561,22 & 488,52 & 32,74 & 41,80 & 8,56 \\
Ic & 61,22 & 102,04 & 76,11 & 11,48 & 14,01 & 18,41 \\
wc & 86,73 & 158,16 & 122,87 & 16,65 & 21,80 & 17,75 \\
lp & 30,61 & 81,63 & 64,63 & 10,20 & 13,99 & 21,64 \\
wp & 45,92 & 102,04 & 76,96 & 15,73 & 18,77 & 24,39 \\
lv & 35,64 & 59,41 & 44,80 & 4,66 & 6,40 & 14,29 \\
wv & 4,95 & 11,88 & 6,77 & 1,76 & 2,34 & 34,65 \\
lsf & 12,87 & 19,80 & 17,57 & 1,94 & 2,43 & 13,83 \\
If & 39,60 & 47,52 & 43,07 & 1,82 & 2,37 & 5,50 \\
a & 1,35 & 1,67 & 1,55 & 0,06 & 0,09 & 5,56 \\
\hline Ovos & & & & & & \\
lo & 98,45 & 113,40 & 106,36 & 3,61 & 4,53 & 4,26 \\
wo & 37,63 & 42,78 & 41,07 & 1,17 & 1,62 & 3,95 \\
\hline
\end{tabular}

*Valores expressos em $\mu \mathrm{m}$, exceto a (número absoluto). 
Apêndice 19. Valores de morfometria de 12 cistos e 60 ovos de Heterodera glycines população SP2 extraídos de soja 'FT Cristalina'.

\begin{tabular}{ccccccc}
\hline Caracteres* & Min. & Max. & Média & E. P. Média & E.P. & C.V. (\%) \\
\hline Cistos & & & & & & \\
L & 734,69 & 846,94 & 792,94 & 32,38 & 36,89 & 4,65 \\
Ls/p & 673,47 & 765,31 & 719,39 & 28,91 & 33,07 & 4,60 \\
bw & 423,47 & 561,22 & 477,04 & 33,16 & 41,31 & 8,66 \\
lc & 61,22 & 91,84 & 77,81 & 6,59 & 8,46 & 10,87 \\
wc & 91,84 & 142,86 & 108,84 & 12,47 & 15,89 & 14,60 \\
lp & 51,02 & 81,63 & 69,73 & 8,22 & 10,28 & 14,74 \\
wp & 61,22 & 91,84 & 74,83 & 5,67 & 7,94 & 10,62 \\
lv & 37,62 & 47,52 & 41,67 & 1,75 & 2,55 & 6,12 \\
wp & 4,95 & 7,92 & 6,19 & 0,78 & 0,96 & 15,44 \\
lsf & 13,86 & 19,80 & 15,92 & 1,73 & 2,04 & 12,84 \\
If & 39,60 & 47,52 & 43,56 & 2,15 & 2,70 & 6,21 \\
a & 1,50 & 1,93 & 1,67 & 0,08 & 0,12 & 7,11 \\
\hline Ovos & & & & & & \\
lo & 101,55 & 108,24 & 104,08 & 1,91 & 2,39 & 2,30 \\
wo & 40,72 & 43,81 & 41,71 & 0,56 & 0,81 & 1,93 \\
\hline
\end{tabular}

*Valores expressos em $\mu \mathrm{m}$, exceto a (número absoluto). 
Apêndice 20. Valores de morfometria de 12 cistos e 60 ovos de Heterodera glycines população MS extraídos de soja 'FT Cristalina'.

\begin{tabular}{ccccccc}
\hline Caracteres* & Min. & Max. & Média & E. P. Média & E.P. & C.V. (\%) \\
\hline Cistos & & & & & & \\
L & 698,98 & 908,16 & 784,44 & 45,71 & 60,92 & 7,77 \\
Ls/p & 617,35 & 831,63 & 709,61 & 50,60 & 63,22 & 8,91 \\
bw & 438,76 & 627,55 & 535,29 & 48,12 & 57,91 & 10,82 \\
lc & 61,22 & 91,84 & 76,53 & 8,50 & 9,97 & 13,03 \\
wc & 91,84 & 158,16 & 119,47 & 20,69 & 24,07 & 20,15 \\
Ip & 56,12 & 86,73 & 68,45 & 8,43 & 10,08 & 14,72 \\
wp & 51,02 & 91,84 & 75,26 & 12,33 & 14,12 & 18,76 \\
lv & 37,62 & 49,50 & 43,73 & 3,30 & 3,96 & 9,05 \\
wp & 4,95 & 8,91 & 6,35 & 1,05 & 1,30 & 20,44 \\
lsf & 13,86 & 19,80 & 17,49 & 1,54 & 1,95 & 11,15 \\
If & 39,60 & 47,52 & 43,56 & 2,81 & 3,22 & 7,38 \\
a & 1,23 & 1,68 & 1,47 & 0,11 & 0,13 & 8,69 \\
\hline Ovos & & & & & & \\
lo & 94,85 & 116,49 & 101,20 & 4,32 & 5,89 & 5,82 \\
wo & 42,78 & 45,36 & 43,99 & 0,77 & 0,94 & 2,14 \\
\hline
\end{tabular}

*Valores expressos em $\mu \mathrm{m}$, exceto a (número absoluto). 
Apêndice 21. Valores de morfometria de 12 cistos e 60 ovos de Heterodera glycines população GO1 extraídos de soja 'FT Cristalina'.

\begin{tabular}{ccccccc}
\hline Caracteres* & Min. & Max. & Média & E. P. Média & E.P. & C.V. (\%) \\
\hline Cistos & & & & & & \\
L & 755,10 & 928,57 & 828,23 & 39,97 & 50,94 & 6,15 \\
Ls/p & 678,57 & 857,14 & 750,00 & 43,37 & 52,57 & 7,01 \\
bw & 479,59 & 602,04 & 536,56 & 33,30 & 40,22 & 7,50 \\
lc & 61,22 & 86,73 & 74,40 & 4,68 & 6,33 & 8,50 \\
wc & 96,94 & 153,06 & 113,10 & 11,48 & 15,96 & 14,11 \\
lp & 40,82 & 81,63 & 63,78 & 14,46 & 16,50 & 25,87 \\
wp & 40,82 & 91,84 & 72,28 & 14,31 & 16,54 & 22,89 \\
lv & 37,62 & 51,49 & 45,54 & 3,63 & 4,43 & 9,72 \\
wp & 4,95 & 11,88 & 8,17 & 1,53 & 2,12 & 25,91 \\
lsf & 13,86 & 19,80 & 17,16 & 1,98 & 2,29 & 13,32 \\
lf & 39,60 & 48,51 & 44,97 & 2,82 & 3,23 & 7,18 \\
a & 1,35 & 1,68 & 1,55 & 0,10 & 0,11 & 7,34 \\
\hline Ovos & & & & & & \\
lo & 97,94 & 115,98 & 106,74 & 3,83 & 5,05 & 4,73 \\
wo & 37,11 & 42,78 & 41,45 & 1,04 & 1,58 & 3,80 \\
\hline
\end{tabular}

*Valores expressos em $\mu \mathrm{m}$, exceto a (número absoluto). 
Apêndice 22. Valores de morfometria de 12 cistos e 60 ovos de Heterodera glycines população GO2 extraídos de soja 'FT Cristalina'.

\begin{tabular}{ccccccc}
\hline Caracteres* & Min. & Max. & Média & E. P. Média & E.P. & C.V. (\%) \\
\hline Cistos & & & & & & \\
L & 658,16 & 892,86 & 793,37 & 40,39 & 61,46 & 7,75 \\
Ls/p & 602,04 & 836,73 & 725,34 & 38,55 & 57,35 & 7,91 \\
bw & 464,29 & 602,04 & 502,13 & 23,74 & 36,37 & 7,24 \\
Ic & 71,43 & 91,84 & 78,23 & 7,37 & 8,52 & 10,89 \\
wc & 86,73 & 132,65 & 104,59 & 10,63 & 13,67 & 13,07 \\
Ip & 51,02 & 86,73 & 65,90 & 8,15 & 10,31 & 15,64 \\
wp & 51,02 & 91,84 & 70,58 & 12,90 & 15,20 & 21,54 \\
lv & 38,61 & 47,52 & 44,39 & 1,98 & 2,53 & 5,69 \\
wp & 4,95 & 9,90 & 6,68 & 1,57 & 1,80 & 26,89 \\
lsf & 13,86 & 21,78 & 18,40 & 1,47 & 2,00 & 10,87 \\
If & 39,60 & 47,52 & 44,14 & 1,99 & 2,48 & 5,61 \\
a & 1,42 & 1,72 & 1,58 & 0,07 & 0,09 & 5,61 \\
\hline Ovos & & & & & & 4,63 \\
lo & 94,33 & 111,86 & 102,62 & 3,55 & 4,51 \\
wo & 38,66 & 46,39 & 43,13 & 1,58 & 2,05 & 4,76 \\
\hline
\end{tabular}

*Valores expressos em $\mu \mathrm{m}$, exceto a (número absoluto). 
Apêndice 23. Valores de morfometria de 12 cistos e 60 ovos de Heterodera glycines população PR extraídos de soja 'FT Cristalina'.

\begin{tabular}{ccccccc}
\hline Caracteres* & Min. & Max. & Média & E. P. Média & E.P. & C.V. (\%) \\
\hline Cistos & & & & & & \\
L & 750,00 & 928,57 & 832,06 & 47,26 & 58,72 & 7,06 \\
Ls/p & 647,96 & 867,35 & 760,63 & 44,64 & 60,50 & 7,95 \\
bw & 464,29 & 530,61 & 502,98 & 16,94 & 20,35 & 4,04 \\
Ic & 61,22 & 86,73 & 76,53 & 8,50 & 9,73 & 12,71 \\
wc & 96,94 & 153,06 & 127,98 & 12,26 & 16,78 & 13,11 \\
lp & 51,02 & 76,53 & 64,20 & 7,58 & 9,09 & 14,16 \\
wp & 40,82 & 122,45 & 75,26 & 19,98 & 25,20 & 33,48 \\
Iv & 37,62 & 54,46 & 44,55 & 4,29 & 5,17 & 11,61 \\
wp & 4,95 & 11,88 & 7,76 & 1,84 & 2,23 & 28,71 \\
Isf & 13,86 & 19,80 & 17,33 & 1,82 & 2,13 & 12,30 \\
If & 38,61 & 49,50 & 42,74 & 2,50 & 3,18 & 7,45 \\
a & 1,52 & 1,88 & 1,66 & 0,09 & 0,12 & 6,97 \\
\hline Ovos & & & & & & \\
lo & 99,48 & 114,95 & 106,70 & 4,12 & 5,12 & 4,80 \\
wo & 39,69 & 44,85 & 41,62 & 1,12 & 1,44 & 3,47 \\
\hline
\end{tabular}

*Valores expressos em $\mu \mathrm{m}$, exceto a (número absoluto). 
Apêndice 24. Valores de morfometria de 12 cistos e 60 ovos de Heterodera glycines população MG extraídos de soja 'FT Cristalina'.

\begin{tabular}{ccccccc}
\hline Caracteres* & Min. & Max. & Média & E. P. Média & E.P. & C.V. (\%) \\
\hline Cistos & & & & & & \\
L & 744,90 & 887,76 & 822,28 & 29,62 & 38,97 & 4,74 \\
Ls/p & 678,57 & 780,61 & 730,87 & 24,45 & 32,28 & 4,42 \\
bw & 459,18 & 540,82 & 498,30 & 26,64 & 29,70 & 5,96 \\
Ic & 61,22 & 86,73 & 73,98 & 6,38 & 7,69 & 10,40 \\
wc & 96,94 & 153,06 & 127,98 & 12,26 & 16,78 & 13,11 \\
lp & 45,92 & 81,63 & 60,37 & 8,50 & 10,40 & 17,22 \\
wp & 45,92 & 112,24 & 78,66 & 15,38 & 20,46 & 26,01 \\
lv & 39,60 & 51,49 & 43,89 & 3,08 & 3,83 & 8,72 \\
wp & 4,95 & 9,90 & 7,26 & 0,99 & 1,29 & 17,76 \\
Isf & 12,87 & 19,80 & 15,92 & 1,73 & 2,04 & 12,84 \\
If & 39,60 & 49,50 & 43,32 & 2,39 & 3,05 & 7,04 \\
a & 1,45 & 1,88 & 1,66 & 0,10 & 0,13 & 7,75 \\
\hline Ovos & & & & & & 3,88 \\
lo & 103,09 & 114,43 & 106,06 & 3,29 & 3,88 \\
wo & 37,63 & 42,27 & 41,11 & 0,73 & 1,25 & 3,03 \\
\hline
\end{tabular}

*Valores expressos em $\mu \mathrm{m}$, exceto a (número absoluto). 
Apêndice 25. Valores de morfometria de 20 juvenis de segundo estádio de Heterodera glycines população SP2 extraídos de soja 'FT Cristalina'.

\begin{tabular}{|c|c|c|c|c|c|c|}
\hline Caracteres* & Min. & Max. & Média & E. P. Média & E.P. & C.V. $(\%)$ \\
\hline $\mathrm{L}$ & 371,13 & 463,92 & 434,54 & 17,89 & 23,19 & 5,34 \\
\hline bw & 20,10 & 24,74 & 22,42 & 1,19 & 1,52 & 6,77 \\
\hline stbw & 14,95 & 16,49 & 15,64 & 0,30 & 0,38 & 2,46 \\
\hline Icef & 3,09 & 4,12 & 3,51 & 0,37 & 0,43 & 12,26 \\
\hline wcef & 8,25 & 9,79 & 9,36 & 0,35 & 0,45 & 4,82 \\
\hline St & 20,62 & 23,71 & 22,24 & 0,70 & 0,86 & 3,85 \\
\hline $1 \mathrm{hbst}$ & 11,86 & 13,40 & 12,42 & 0,28 & 0,41 & 3,27 \\
\hline lbst & 2,06 & 3,09 & 2,55 & 0,10 & 0,20 & 7,96 \\
\hline wbst & 4,12 & 5,15 & 4,92 & 0,30 & 0,35 & 7,19 \\
\hline Ebst & 24,23 & 26,29 & 25,15 & 0,47 & 0,57 & 2,26 \\
\hline DGO & 3,09 & 4,12 & 3,69 & 0,18 & 0,25 & 6,84 \\
\hline Pbw & 17,53 & 18,56 & 18,27 & 0,28 & 0,31 & 1,71 \\
\hline EP & 94,33 & 106,70 & 98,66 & 2,47 & 3,19 & 3,24 \\
\hline $\mathrm{t}$ & 41,75 & 51,55 & 46,65 & 2,53 & 3,03 & 6,49 \\
\hline$a b w$ & 11,86 & 13,40 & 12,65 & 0,41 & 0,49 & 3,85 \\
\hline $\mathrm{h}$ & 21,13 & 28,87 & 25,75 & 1,38 & 2,01 & 7,81 \\
\hline wh & 6,19 & 8,25 & 7,29 & 0,51 & 0,65 & 8,96 \\
\hline a & 16,46 & 22,44 & 19,45 & 1,11 & 1,49 & 7,65 \\
\hline c & 8,49 & 10,06 & 9,33 & 0,42 & 0,49 & 5,26 \\
\hline$c^{\prime}$ & 3,27 & 4,17 & 3,69 & 0,24 & 0,28 & 7,55 \\
\hline $\mathrm{h} / \mathrm{wh}$ & 3,13 & 4,17 & 3,54 & 0,24 & 0,30 & 8,39 \\
\hline$P$ & 21,44 & 25,56 & 22,74 & 0,68 & 0,94 & 4,11 \\
\hline lhbst/St & 53,33 & 59,52 & 55.90 & 1,69 & 1.99 & 3,56 \\
\hline
\end{tabular}

*Valores expressos em $\mu \mathrm{m}$, exceto os alométricos (números absolutos) e P e lhbst/St (expressos em porcentagem) 
Apêndice 26. Valores de morfometria de 20 juvenis de segundo estádio de Heterodera glycines população SP2 extraídos de feijão comum 'IAC Carioca'.

\begin{tabular}{|c|c|c|c|c|c|c|}
\hline Caracteres* & Min. & Max. & Média & E. P. Média & E.P. & C.V. (\%) \\
\hline $\mathrm{L}$ & 381,44 & 474,23 & 436,60 & 19,48 & 23,97 & 5,49 \\
\hline bw & 19,59 & 22,68 & 20,85 & 0,79 & 0,98 & 4,71 \\
\hline stbw & 14,95 & 16,49 & 15,49 & 0,30 & 0,43 & 2,75 \\
\hline Icef & 3,09 & 4,12 & 3,58 & 0,34 & 0,43 & 11,88 \\
\hline wcef & 8,25 & 9,79 & 9,18 & 0,34 & 0,43 & 4,68 \\
\hline St & 21,13 & 23,71 & 22,42 & 0,70 & 0,84 & 3,77 \\
\hline $1 \mathrm{hbst}$ & 11,34 & 13,40 & 12,16 & 0,41 & 0,51 & 4,21 \\
\hline lbst & 2,06 & 3,09 & 2,58 & 0,21 & 0,33 & 12,98 \\
\hline wbst & 4,12 & 5,15 & 4,87 & 0,28 & 0,31 & 6,40 \\
\hline Ebst & 23,71 & 26,29 & 24,92 & 0,44 & 0,59 & 2,35 \\
\hline DGO & 3,09 & 4,12 & 3,45 & 0,32 & 0,38 & 10,94 \\
\hline $\mathrm{Pbw}$ & 17,53 & 19,07 & 18,20 & 0,43 & 0,50 & 2,77 \\
\hline EP & 91,24 & 111,34 & 100,21 & 3,74 & 5,07 & 5,06 \\
\hline $\mathrm{t}$ & 36,60 & 51,03 & 47,22 & 2,56 & 3,46 & 7,32 \\
\hline abw & 10,82 & 12,89 & 12,14 & 0,56 & 0,66 & 0,42 \\
\hline $\mathrm{h}$ & 23,20 & 30,93 & 27,24 & 1,89 & 2,28 & 8,38 \\
\hline wh & 6,19 & 8,25 & 7,14 & 0,40 & 0,51 & 7,13 \\
\hline a & 16,82 & 23,33 & 20,99 & 1,26 & 1,64 & 7,83 \\
\hline c & 8,51 & 11,20 & 9,27 & 0,34 & 0,54 & 5,81 \\
\hline$c^{\prime}$ & 2,84 & 4,36 & 3,90 & 0,25 & 0,34 & 8,83 \\
\hline $\mathrm{h} / \mathrm{wh}$ & 3,21 & 4,15 & 3,82 & 0,20 & 0,26 & 6,73 \\
\hline $\mathrm{P}$ & 22,16 & 24,05 & 22,97 & 0,56 & 0,64 & 2,79 \\
\hline lhbst/St & 50,00 & 57,14 & 54,29 & 2,02 & 2,32 & 4,27 \\
\hline
\end{tabular}

*Valores expressos em $\mu \mathrm{m}$, exceto os alométricos (números absolutos) e $\mathrm{P}$ e lhbst/St (expressos em porcentagem) 
Apêndice 27. Valores de morfometria de juvenis de segundo estádio de Heterodera glycines população SP2 extraídos de crotalária cv. IAC 1-2 e chícharo.

\begin{tabular}{ccc}
\hline Caracteres* $^{*}$ & \multicolumn{2}{c}{ Juvenis de segundo estádio } \\
\cline { 2 - 3 } & Crotalária & Chícharo \\
\hline L $=2 * *$ & $n=1$ \\
\hline bw & 398,20 & 368,56 \\
stbw & 19,07 & 18,56 \\
lcef & 15,46 & 15,46 \\
wcef & 3,61 & 3,09 \\
St & 8,76 & 8,25 \\
l hbst & 21,65 & 20,62 \\
lbst & 12,11 & 11,34 \\
wbst & 2,58 & 2,58 \\
Ebst & 4,90 & 4,64 \\
DGO & 24,48 & 23,20 \\
Pbw & 3,62 & 3,50 \\
EP & 18,04 & 18,04 \\
t & 95,88 & 86,08 \\
abw & 39,69 & 49,48 \\
h & 11,86 & 13,40 \\
wh & 22,42 & 19,59 \\
a & 6,70 & 6,70 \\
c & 20,88 & 19,86 \\
c' & 10,03 & 23,45 \\
h/wh & 3,35 & 55,00 \\
Phbst/St & 3,35 & 2,92 \\
\hline
\end{tabular}

*Valores expressos em $\mu \mathrm{m}$, exceto os alométricos (números absolutos) e $\mathrm{P}$ e lhbst/St (expressos em porcentagem)

* *Número de exemplares examinados. 
Apêndice 28. Valores de morfometria de 20 juvenis de segundo estádio de Heterodera glycines população SP2 extraídos de feijão azuki vermelho 'AL-9'.

\begin{tabular}{|c|c|c|c|c|c|c|}
\hline Caracteres* & Min. & Max. & Média & E. P. Média & E.P. & C.V. $(\%)$ \\
\hline $\mathrm{L}$ & 394,33 & 484,54 & 448,97 & 20,31 & 25,22 & 5,62 \\
\hline bw & 19,59 & 21,65 & 20,75 & 0,39 & 0,53 & 2,53 \\
\hline stbw & 14,95 & 16,49 & 15,62 & 0,30 & 0,38 & 2,42 \\
\hline lcef & 3,09 & 4,12 & 3,61 & 0,26 & 0,37 & 10,36 \\
\hline wcef & 8,25 & 10,31 & 9,20 & 0,41 & 0,54 & 5,82 \\
\hline St & 20,62 & 23,71 & 22,45 & 0,67 & 0,84 & 3,76 \\
\hline 1 hbst & 11,34 & 13,40 & 12,45 & 0,49 & 0,61 & 4,89 \\
\hline lbst & 2,06 & 3,09 & 2,55 & 0,20 & 0,31 & 12,22 \\
\hline wbst & 4,64 & 5,15 & 4,95 & 0,25 & 0,26 & 5,24 \\
\hline Ebst & 23,20 & 26,29 & 25,05 & 0,64 & 0,79 & 3,16 \\
\hline DGO & 3,09 & 4,12 & 3,45 & 0,29 & 0,34 & 9,81 \\
\hline Pbw & 17,01 & 19,07 & 18,12 & 0,36 & 0,48 & 2,66 \\
\hline EP & 93,81 & 110,31 & 102,53 & 3,45 & 4,23 & 4,13 \\
\hline$t$ & 41,24 & 54,64 & 47,94 & 3,09 & 3,64 & 7,60 \\
\hline abw & 10,31 & 13,40 & 12,35 & 0,60 & 0,83 & 6,70 \\
\hline $\mathrm{h}$ & 22,16 & 31,96 & 27,24 & 1,79 & 2,51 & 9,21 \\
\hline wh & 6,19 & 7,73 & 7,24 & 0,29 & 0,46 & 6,31 \\
\hline a & 19,13 & 23,50 & 21,66 & 1,11 & 1,37 & 6,31 \\
\hline c & 8,35 & 10,24 & 9,39 & 0,45 & 0,53 & 5,63 \\
\hline$c^{\prime}$ & 3,32 & 4,45 & 3,89 & 0,27 & 0,33 & 8,55 \\
\hline $\mathrm{h} / \mathrm{wh}$ & 3,07 & 4,43 & 3,77 & 0,28 & 0,35 & 9,24 \\
\hline $\mathbf{P}$ & 21,60 & 24,15 & 22,86 & 0,52 & 0,65 & 8,86 \\
\hline lhbst/St & 48,89 & 59,52 & 55,51 & 2,24 & 3,03 & 5,46 \\
\hline
\end{tabular}

*Valores expressos em $\mu \mathrm{m}$, exceto os alométricos (números absolutos) e $\mathrm{P}$ e lhbst/St (expressos em porcentagem) 
Apêndice 29. Valores de morfometria de 20 juvenis de segundo estádio de Heterodera glycines população SP2 extraídos de feijão mungo 'M-80'.

\begin{tabular}{|c|c|c|c|c|c|c|}
\hline Caracteres* & Min. & Max. & Média & E. P. Média & E.P. & C.V. $(\%)$ \\
\hline $\mathrm{L}$ & 376,27 & 474,23 & 433,25 & 19,07 & 24,46 & 5,65 \\
\hline bw & 20,10 & 24,74 & 21,21 & 0,98 & 1,27 & 5,97 \\
\hline stbw & 14,95 & 15,98 & 15,52 & 0,19 & 0,28 & 1,84 \\
\hline lcef & 3,09 & 4,12 & 3,58 & 0,34 & 0,43 & 11,88 \\
\hline wcef & 8,25 & 9,79 & 9,07 & 0,30 & 0,35 & 3,87 \\
\hline St & 20,62 & 23,20 & 22,09 & 0,81 & 0,94 & 4,23 \\
\hline $1 \mathrm{hbst}$ & 11,34 & 12,89 & 11,96 & 0,48 & 0,57 & 4,76 \\
\hline lbst & 2,06 & 2,58 & 2,50 & 0,13 & 0,19 & 7,55 \\
\hline wbst & 4,64 & 5,67 & 4,92 & 0,28 & 0,31 & 6,33 \\
\hline Ebst & 23,71 & 25,77 & 24,66 & 0,46 & 0,59 & 2,38 \\
\hline DGO & 3,09 & 5,15 & 3,71 & 0,35 & 0,49 & 13,21 \\
\hline $\mathrm{Pbw}$ & 17,01 & 18,56 & 18,09 & 0,37 & 0,50 & 2,76 \\
\hline EP & 91,75 & 106,70 & 100,57 & 3,13 & 4,31 & 4,28 \\
\hline $\mathrm{t}$ & 36,08 & 53,09 & 45,05 & 3,07 & 4,03 & 8,95 \\
\hline abw & 11,34 & 13,40 & 12,47 & 0,47 & 0,59 & 4,76 \\
\hline $\mathrm{h}$ & 19,07 & 29,90 & 25,03 & 2,40 & 3,00 & 11,98 \\
\hline wh & 6,19 & 7,73 & 7,16 & 0,34 & 0,47 & 6,56 \\
\hline a & 17,17 & 23,00 & 20,51 & 1,46 & 1,81 & 8,84 \\
\hline c & 8,45 & 11,29 & 9,67 & 0,66 & 0,79 & 8,21 \\
\hline$c^{\prime}$ & 3,13 & 4,23 & 3,61 & 0,24 & 0,31 & 8,71 \\
\hline $\mathrm{h} / \mathrm{wh}$ & 2,47 & 4,46 & 3,51 & 0,42 & 0,51 & 14,51 \\
\hline$P$ & 21,96 & 24,66 & 23,24 & 0,56 & 0,71 & 3,04 \\
\hline lhbst/St & 48,89 & 62,50 & 54,23 & 2,42 & 3,35 & 6,17 \\
\hline
\end{tabular}

*Valores expressos em $\mu \mathrm{m}$, exceto os alométricos (números absolutos) e P e lhbst/St (expressos em porcentagem) 
Apêndice 30. Valores de morfométricos de 20 juvenis de segundo estádio de Heterodera glycines população SP2 extraídos de tremoço branco.

\begin{tabular}{|c|c|c|c|c|c|c|}
\hline Caracteres* & Min. & Max. & Média & E. P. Média & E.P. & C.V. $(\%)$ \\
\hline $\mathrm{L}$ & 407,22 & 484,54 & 434,41 & 17,54 & 21,24 & 4,89 \\
\hline bw & 20,10 & 25,77 & 21,86 & 1,09 & 1,47 & 6,73 \\
\hline stbw & 14,43 & 17,53 & 15,70 & 0,51 & 0,72 & 4,58 \\
\hline lcef & 3,09 & 4,12 & 3,61 & 0,26 & 0,37 & 10,36 \\
\hline wcef & 8,25 & 9,79 & 9,25 & 0,25 & 0,39 & 4,23 \\
\hline St & 20,62 & 24,74 & 22,01 & 0,79 & 1,03 & 4,69 \\
\hline I hbst & 10,82 & 12,89 & 12,04 & 0,45 & 0,54 & 4,45 \\
\hline lbst & 2,06 & 3,09 & 2,58 & 0,21 & 0,33 & 12,98 \\
\hline wbst & 4,64 & 5,67 & 4,95 & 0,28 & 0,31 & 6,23 \\
\hline Ebst & 23,71 & 25,77 & 24,80 & 0,48 & 0,60 & 2,42 \\
\hline DGO & 3,09 & 4,64 & 3,43 & 0,34 & 0,42 & 12,22 \\
\hline Pbw & 17,01 & 19,07 & 18,02 & 0,49 & 0,59 & 3,28 \\
\hline EP & 87,63 & 107,73 & 98,40 & 4,28 & 5,19 & 5,27 \\
\hline$t$ & 40,21 & 53,61 & 47,53 & 2,46 & 3,22 & 6,77 \\
\hline$a b w$ & 10,82 & 12,89 & 12,14 & 0,64 & 0,72 & 5,92 \\
\hline $\mathrm{h}$ & 22,68 & 32,47 & 26,60 & 1,99 & 2,68 & 10,07 \\
\hline wh & 6,19 & 7,73 & 7,09 & 0,41 & 0,50 & 7,03 \\
\hline a & 16,20 & 23,50 & 19,96 & 1,06 & 1,60 & 8,02 \\
\hline c & 8,17 & 10,64 & 9,16 & 0,31 & 0,48 & 5,25 \\
\hline$c^{\prime}$ & 3,50 & 4,45 & 3,92 & 0,24 & 0,29 & 7,37 \\
\hline $\mathrm{h} / \mathrm{wh}$ & 3,13 & 4,67 & 3,77 & 0,42 & 0,49 & 13,01 \\
\hline$P$ & 21,26 & 25,22 & 22,66 & 0,68 & 0,93 & 4,11 \\
\hline lhbst/St & 51,16 & 60,00 & 54,74 & 1,90 & 2,46 & 4,50 \\
\hline
\end{tabular}

*Valores expressos em $\mu \mathrm{m}$, exceto os alométricos (números absolutos) e P e lhbst/St (expressos em porcentagem) 
Apêndice 31. Valores de morfometria de 20 machos de Heterodera glycines população SP2 extraídos de soja 'FT Cristalina'.

\begin{tabular}{ccccccc}
\hline Caracteres* & Min. & Max. & Média & E. P. Média & E.P. & $\begin{array}{c}\text { C.V. } \\
(\%)\end{array}$ \\
\hline L & 1020,41 & 1326,53 & 1171,94 & 56,79 & 74,20 & 6,33 \\
bw & 24,23 & 32,47 & 26,73 & 1,35 & 1,89 & 7,09 \\
stbw & 16,49 & 19,07 & 17,86 & 0,71 & 0,84 & 4,71 \\
lcef & 4,12 & 6,19 & 5,21 & 0,28 & 0,44 & 8,44 \\
wcef & 9,79 & 11,34 & 10,64 & 0,44 & 0,51 & 4,78 \\
St & 23,71 & 29,38 & 26,34 & 1,14 & 1,38 & 5,23 \\
I hbst & 12,37 & 13,92 & 12,86 & 0,39 & 0,49 & 3,79 \\
lbst & 2,06 & 2,58 & 2,42 & 0,22 & 0,24 & 10,00 \\
wbst & 4,64 & 5,15 & 5,05 & 0,16 & 0,21 & 4,19 \\
Ebst & 26,80 & 30,41 & 28,56 & 0,72 & 0,91 & 3,18 \\
DGo & 3,09 & 4,12 & 3,45 & 0,32 & 0,38 & 10,94 \\
Pbw & 22,68 & 28,87 & 25,23 & 1,26 & 1,62 & 6,41 \\
EP & 121,13 & 156,19 & 139,56 & 8,76 & 10,51 & 7,53 \\
Itt & 335,05 & 757,73 & 603,99 & 88,44 & 113,42 & 18,79 \\
Oes' & 172,68 & 205,15 & 189,90 & 7,60 & 9,42 & 4,96 \\
a & 36,14 & 50,46 & 43,98 & 2,42 & 3,27 & 7,43 \\
b' & 5,20 & 7,07 & 6,18 & 0,33 & 0,46 & 7,39 \\
P & 10,27 & 13,36 & 11,93 & 0,70 & 0,89 & 7,43 \\
T & 32,89 & 62,81 & 51,53 & 7,17 & 9,08 & 17,61 \\
\hline
\end{tabular}

*Valores expressos em $\mu \mathrm{m}$, exceto os alométricos (números absolutos) e P e $\mathrm{T}$ (expressos em porcentagem) 
Apêndice 32. Valores de morfometria de 20 machos de Heterodera glycines população SP2 extraídos de feijão comum 'IAC Carioca'.

\begin{tabular}{ccccccc}
\hline Caracteres* & Min. & Max. & Média & E. P. Média & E.P. & C.V. (\%) \\
\hline L & 867,35 & 1275,51 & 1088,78 & 101,84 & 121,13 & 11,12 \\
bw & 22,16 & 26,80 & 24,61 & 1,19 & 1,48 & 6,00 \\
stbw & 14,95 & 18,56 & 17,42 & 0,74 & 0,95 & 5,48 \\
lcef & 4,64 & 6,19 & 5,28 & 0,24 & 0,33 & 6,23 \\
wcef & 8,76 & 11,34 & 10,28 & 0,35 & 0,57 & 5,51 \\
St & 21,65 & 26,80 & 25,57 & 0,84 & 1,21 & 4,74 \\
I hbst & 12,37 & 14,43 & 12,94 & 0,44 & 0,60 & 4,64 \\
lbst & 2,06 & 3,09 & 2,42 & 0,29 & 0,34 & 13,98 \\
wbst & 4,12 & 5,67 & 4,97 & 0,29 & 0,35 & 6,95 \\
Ebst & 26,80 & 29,90 & 28,25 & 0,55 & 0,72 & 2,55 \\
DGO & 3,09 & 4,12 & 3,40 & 0,28 & 0,31 & 9,06 \\
Pbw & 21,65 & 25,77 & 23,58 & 1,06 & 1,32 & 5,58 \\
EP & 127,32 & 169,07 & 143,20 & 8,97 & 11,56 & 8,07 \\
ltt & 404,64 & 737,11 & 594,97 & 73,70 & 90,71 & 15,25 \\
Oes' & 169,07 & 209,79 & 186,88 & 8,51 & 11,12 & 5,95 \\
a & 37,61 & 47,63 & 44,16 & 2,73 & 3,21 & 7,27 \\
b' & 5,13 & 6,74 & 5,82 & 0,41 & 0,49 & 8,34 \\
P & 11,32 & 16,23 & 13,26 & 1,11 & 1,37 & 10,34 \\
T & 45,06 & 65,08 & 54,65 & 4,80 & 6,18 & 11,31 \\
\hline
\end{tabular}

*Valores expressos em $\mu \mathrm{m}$, exceto os alométricos (números absolutos) e P e T (expressos em porcentagem) 
Apêndice 33. Valores de morfometria de 20 machos de Heterodera glycines população SP2 extraídos de feijão azuki vermelho 'AL-9'.

\begin{tabular}{ccccccc}
\hline Caracteres* & Min. & Max. & Média & E. P. Média & E.P. & C.V. (\%) \\
\hline L & 765,31 & 1265,31 & 1140,82 & 73,06 & 110,97 & 9,73 \\
bw & 21,13 & 29,90 & 25,52 & 1,08 & 1,74 & 6,83 \\
stbw & 15,46 & 19,59 & 17,14 & 0,88 & 1,10 & 6,39 \\
Icef & 4,64 & 6,19 & 5,23 & 0,27 & 0,38 & 7,34 \\
wcef & 9,79 & 10,82 & 10,36 & 0,19 & 0,28 & 2,75 \\
St & 23,71 & 27,84 & 25,82 & 0,85 & 1,19 & 4,62 \\
l hbst & 11,34 & 15,46 & 12,94 & 0,63 & 0,88 & 6,83 \\
lbst & 2,06 & 3,09 & 2,60 & 0,24 & 0,35 & 13,59 \\
wbst & 3,61 & 5,67 & 4,97 & 0,36 & 0,48 & 9,67 \\
Ebst & 25,77 & 29,90 & 28,17 & 0,82 & 0,99 & 3,53 \\
DGO & 3,09 & 3,61 & 3,25 & 0,22 & 0,24 & 7,46 \\
Pbw & 20,62 & 28,87 & 24,46 & 1,01 & 1,62 & 6,61 \\
EP & 118,56 & 163,40 & 144,87 & 7,19 & 9,74 & 6,72 \\
Itt & 402,06 & 809,28 & 641,88 & 72,31 & 94,82 & 14,77 \\
Oes' & 158,76 & 207,73 & 188,48 & 7,67 & 10,86 & 5,76 \\
a & 36,21 & 50,10 & 44,73 & 2,90 & 3,69 & 8,25 \\
b' & 4,82 & 6,51 & 6,04 & 0,28 & 0,39 & 6,44 \\
P & 11,02 & 15,49 & 12,78 & 0,70 & 1,03 & 8,04 \\
T & 49,16 & 69,57 & 56,15 & 4,24 & 5,21 & 9,28 \\
\hline
\end{tabular}

*Valores expressos em $\mu \mathrm{m}$, exceto os alométricos (números absolutos) e $\mathrm{P}$ e T (expressos em porcentagem) 
Apêndice 34. Valores de morfometria de 20 machos de Heterodera glycines população SP2 extraídos de feijão mungo 'M-80'.

\begin{tabular}{ccccccc}
\hline Caracteres* $^{*}$ & Min. & Max. & Média & E. P. Média & E.P. & C.V. (\%) \\
\hline L & 959,18 & 1265,31 & 1111,22 & 70,61 & 86,51 & 7,79 \\
bw & 23,20 & 28,87 & 25,15 & 0,79 & 1,18 & 4,68 \\
stbw & 15,98 & 18,56 & 17,19 & 0,56 & 0,67 & 3,92 \\
Icef & 4,12 & 6,19 & 5,05 & 0,35 & 0,49 & 9,71 \\
wcef & 9,28 & 11,34 & 10,21 & 0,40 & 0,54 & 5,33 \\
St & 23,20 & 26,29 & 25,39 & 0,59 & 0,78 & 3,08 \\
l hbst & 11,34 & 14,95 & 12,53 & 0,65 & 0,87 & 6,95 \\
lbst & 2,06 & 2,58 & 2,27 & 0,25 & 0,26 & 11,42 \\
wbst & 4,12 & 5,67 & 4,95 & 0,32 & 0,39 & 7,85 \\
Ebst & 26,29 & 28,87 & 27,73 & 0,55 & 0,70 & 2,53 \\
DGO & 3,09 & 5,15 & 3,63 & 0,50 & 0,66 & 18,10 \\
Pbw & 22,68 & 28,35 & 24,18 & 0,82 & 1,26 & 5,22 \\
EP & 121,65 & 169,59 & 145,31 & 10,10 & 12,43 & 8,55 \\
Itt & 502,58 & 824,74 & 618,17 & 52,96 & 75,23 & 12,17 \\
Oes' & 170,10 & 207,22 & 187,99 & 9,35 & 11,69 & 6,22 \\
a & 37,98 & 49,09 & 44,22 & 2,94 & 3,37 & 7,63 \\
b' & 5,10 & 6,60 & 5,92 & 0,35 & 0,42 & 7,12 \\
P & 11,74 & 15,10 & 13,09 & 0,59 & 0,79 & 6,01 \\
T & 47,68 & 69,08 & 55,66 & 4,15 & 5,50 & 9,88 \\
\hline
\end{tabular}

*Valores expressos em $\mu \mathrm{m}$, exceto os alométricos (números absolutos) e P e T (expressos em porcentagem) 
Apêndice 35. Valores de morfometria de 20 machos de Heterodera glycines população SP2 extraídos de tremoço branco.

\begin{tabular}{ccccccc}
\hline Caracteres* & Min. & Max. & Média & E. P. Média & E.P. & C.V. (\%) \\
\hline L & 908,16 & 1142,86 & 1031,12 & 53,62 & 67,36 & 6,53 \\
bw & 23,20 & 26,80 & 25,77 & 0,72 & 1,00 & 3,89 \\
stbw & 11,86 & 19,07 & 17,47 & 1,05 & 1,57 & 8,97 \\
Icef & 4,12 & 5,67 & 5,13 & 0,20 & 0,35 & 6,90 \\
wcef & 9,79 & 11,34 & 10,39 & 0,40 & 0,48 & 4,63 \\
St & 23,71 & 27,84 & 25,70 & 0,92 & 1,13 & 4,38 \\
l hbst & 11,34 & 13,92 & 12,55 & 0,54 & 0,65 & 5,21 \\
lbst & 1,55 & 3,09 & 2,50 & 0,18 & 0,30 & 12,11 \\
wbst & 4,64 & 5,67 & 4,87 & 0,28 & 0,31 & 6,40 \\
Ebst & 25,77 & 29,38 & 27,78 & 0,63 & 0,87 & 3,12 \\
DGO & 3,09 & 5,15 & 3,84 & 0,43 & 0,54 & 14,09 \\
Pbw & 21,65 & 26,29 & 24,56 & 1,00 & 1,29 & 5,24 \\
EP & 118,56 & 174,23 & 140,52 & 6,63 & 10,87 & 7,74 \\
ltt & 412,37 & 695,88 & 529,25 & 66,11 & 78,88 & 14,90 \\
Oes' & 133,51 & 203,61 & 175,54 & 12,42 & 16,52 & 9,41 \\
a & 35,96 & 44,65 & 40,02 & 1,93 & 2,40 & 6,00 \\
b' & 5,28 & 8,10 & 5,92 & 0,48 & 0,67 & 11,28 \\
P & 10,98 & 17,07 & 13,68 & 1,05 & 1,38 & 10,12 \\
T & 36,98 & 62,95 & 51,33 & 5,69 & 6,74 & 13,14 \\
\hline
\end{tabular}

*Valores expressos em $\mu \mathrm{m}$, exceto os alométricos (números absolutos) e $\mathrm{P} \mathrm{e} \mathrm{T}$ (expressos em porcentagem) 
Apêndice 36. Valores de morfometria de 12 cistos e 60 ovos de Heterodera glycines população SP2 extraídos de soja 'FT Cristalina'.

\begin{tabular}{ccccccc}
\hline Caracteres* & Min. & Max. & Média & E. P. Média & E.P. & C.V. (\%) \\
\hline Cistos & & & & & & \\
L & 755,10 & 867,35 & 830,61 & 30,20 & 44,39 & 5,34 \\
Ls/p & 663,27 & 760,20 & 732,65 & 27,76 & 39,62 & 5,41 \\
bw & 454,08 & 510,20 & 488,78 & 13,88 & 21,16 & 4,33 \\
Ic & 76,53 & 91,84 & 86,73 & 6,12 & 7,22 & 8,32 \\
wc & 91,84 & 153,06 & 130,61 & 18,78 & 25,41 & 19,45 \\
lp & 91,84 & 112,25 & 97,96 & 5,71 & 8,38 & 8,56 \\
wp & 66,33 & 91,84 & 80,61 & 5,71 & 9,13 & 11,32 \\
lv & 35,64 & 57,43 & 47,85 & 4,57 & 6,02 & 12,58 \\
wv & 5,94 & 11,88 & 8,00 & 1,11 & 1,61 & 20,06 \\
Isf & 15,84 & 19,80 & 17,74 & 1,57 & 1,71 & 9,66 \\
If & 38,61 & 43,56 & 40,92 & 1,43 & 1,71 & 4,17 \\
a & 1,48 & 1,91 & 1,70 & 0,11 & 0,16 & 9,12 \\
\hline Ovos & & & & & & \\
lo & 103,09 & 118,56 & 108,68 & 3,22 & 4,64 & 4,27 \\
wo & 38,66 & 46,39 & 41,88 & 1,72 & 2,23 & 5,33 \\
\hline
\end{tabular}

*Valores expressos em $\mu \mathrm{m}$, exceto a (número absoluto). 
Apêndice 37. Valores de morfometria de 12 cistos e 60 ovos de Heterodera glycines população SP2 extraídos de feijão comum 'IAC Carioca'.

\begin{tabular}{ccccccc}
\hline Caracteres* & Min. & Max. & Média & E. P. Média & E.P. & C.V. (\%) \\
\hline Cistos & & & & & & \\
L & 755,10 & 938,78 & 875,51 & 61,63 & 77,26 & 8,82 \\
Ls/p & 663,27 & 852,04 & 779,59 & 58,37 & 74,76 & 9,59 \\
bw & 454,08 & 510,20 & 488,78 & 13,88 & 21,16 & 4,33 \\
lc & 76,53 & 91,84 & 86,73 & 6,12 & 7,22 & 8,32 \\
wc & 91,84 & 153,06 & 130,61 & 18,78 & 25,41 & 19,45 \\
lp & 91,84 & 112,25 & 97,96 & 5,71 & 8,38 & 8,56 \\
wp & 66,33 & 91,84 & 80,61 & 5,71 & 9,13 & 11,32 \\
lv & 39,60 & 58,42 & 47,77 & 5,40 & 6,42 & 13,44 \\
wv & 4,95 & 11,88 & 7,59 & 1,54 & 2,04 & 26,87 \\
lsf & 12,87 & 18,81 & 16,67 & 1,71 & 2,15 & 12,87 \\
If & 35,64 & 43,56 & 39,85 & 1,53 & 2,20 & 5,52 \\
a & 1,74 & 2,04 & 1,87 & 0,09 & 0,12 & 6,51 \\
\hline Ovos & & & & & & \\
lo & 97,94 & 118,56 & 105,67 & 4,30 & 5,60 & 5,30 \\
wo & 38,66 & 46,39 & 42,31 & 1,93 & 2,32 & 5,48 \\
\hline
\end{tabular}

*Valores expressos em $\mu \mathrm{m}$, exceto a (número absoluto). 
Apêndice 38. Valores de morfometria de 7 cistos de Heterodera glycines população SP2 extraídos de chícharo.

\begin{tabular}{ccccccc}
\hline Caracteres* $^{*}$ & Min. & Max. & Média & E. P. Média & E.P. & C.V. (\%) \\
\hline L & 612,24 & 857,14 & 694,90 & 80,82 & 102,32 & 14,73 \\
Ls/p & 515,31 & 698,98 & 589,80 & 60,82 & 75,47 & 12,80 \\
bw & 306,12 & 408,16 & 348,98 & 24,90 & 37,60 & 10,77 \\
Ic & 61,22 & 96,94 & 78,57 & 9,80 & 13,30 & 16,93 \\
wc & 117,35 & 142,86 & 132,65 & 8,16 & 10,20 & 7,69 \\
lp & 66,33 & 158,16 & 105,10 & 21,22 & 33,18 & 31,57 \\
wp & 61,22 & 91,84 & 74,49 & 8,57 & 11,75 & 15,77 \\
a & 1,74 & 2,12 & 1,99 & 0,13 & 0,16 & 8,21 \\
\hline
\end{tabular}

*Valores expressos em $\mu \mathrm{m}$, exceto a (número absoluto). 
Apêndice 39. Valores de morfometria de 12 cistos e 60 ovos de Heterodera glycines população SP2 extraídos de feijão azuki vermelho 'AL-9'.

\begin{tabular}{ccccccc}
\hline Caracteres* & Min. & Max. & Média & E. P. Média & E.P. & C.V. (\%) \\
\hline Cistos & & & & & & \\
L & 673,47 & 867,35 & 759,18 & 57,96 & 74,50 & 9,81 \\
Ls/p & 561,22 & 765,31 & 659,18 & 64,49 & 81,19 & 12,32 \\
bw & 408,16 & 479,59 & 442,86 & 23,67 & 29,40 & 6,64 \\
Ic & 76,53 & 81,63 & 78,57 & 2,45 & 2,79 & 3,56 \\
wc & 122,45 & 153,06 & 135,71 & 9,80 & 12,29 & 9,05 \\
lp & 81,63 & 112,24 & 100,00 & 10,61 & 13,30 & 13,30 \\
wp & 81,63 & 102,04 & 91,84 & 4,08 & 7,22 & 7,86 \\
lv & 37,62 & 55,45 & 46,04 & 3,38 & 4,71 & 10,23 \\
wv & 5,94 & 9,90 & 7,51 & 1,07 & 1,30 & 17,29 \\
Isf & 14,85 & 19,80 & 17,66 & 1,35 & 1,68 & 9,51 \\
lf & 36,63 & 41,58 & 39,36 & 0,95 & 1,28 & 3,24 \\
a & 1,51 & 1,89 & 1,72 & 0,12 & 0,15 & 8,91 \\
\hline Ovos & & & & & & \\
lo & 95,36 & 113,40 & 103,74 & 3,11 & 4,68 & 4,51 \\
wo & 43,81 & 46,39 & 44,24 & 0,72 & 1,00 & 2,26 \\
\hline
\end{tabular}

*Valores expressos em $\mu \mathrm{m}$, exceto a (número absoluto). 
Apêndice 40. Valores de morfometria de 12 cistos e 60 ovos de Heterodera glycines população SP2 extraídos de feijão mungo 'M-80'.

\begin{tabular}{ccccccc}
\hline Caracteres* & Min. & Max. & Média & E. P. Média & E.P. & C.V. (\%) \\
\hline Cistos & & & & & & \\
L & 673,47 & 903,06 & 783,67 & 91,43 & 108,63 & 13,86 \\
Ls/p & 581,63 & 846,94 & 710,20 & 97,14 & 118,69 & 16,71 \\
bw & 469,39 & 510,20 & 497,96 & 14,69 & 18,25 & 3,67 \\
lc & 71,43 & 112,24 & 87,76 & 15,51 & 18,54 & 21,12 \\
wc & 122,45 & 147,96 & 134,69 & 6,53 & 9,27 & 6,88 \\
lp & 56,12 & 91,84 & 73,47 & 11,84 & 14,70 & 20,01 \\
wp & 40,82 & 112,24 & 74,49 & 22,86 & 29,22 & 39,23 \\
lv & 37,62 & 51,49 & 46,78 & 3,67 & 4,43 & 9,47 \\
wv & 4,95 & 11,88 & 8,42 & 1,57 & 2,05 & 24,32 \\
lsf & 13,86 & 19,80 & 17,49 & 1,65 & 2,04 & 11,66 \\
If & 36,63 & 43,56 & 39,60 & 1,65 & 2,27 & 5,74 \\
a & 1,36 & 1,84 & 1,57 & 0,18 & 0,21 & 13,40 \\
\hline Ovos & & & & & & \\
lo & 92,78 & 108,25 & 102,88 & 3,33 & 4,72 & 4,59 \\
wo & 38,66 & 43,81 & 41,02 & 0,79 & 1,33 & 3,24 \\
\hline
\end{tabular}

*Valores expressos em $\mu \mathrm{m}$, exceto a (número absoluto). 
Apêndice 41. Valores de morfometria de 12 cistos e 60 ovos de Heterodera glycines população SP2 extraídos de tremoço branco.

\begin{tabular}{ccccccc}
\hline Caracteres* & Min. & Max. & Média & E. P. Média & E.P. & C.V. (\%) \\
\hline Cistos & & & & & & \\
L & 602,04 & 816,33 & 726,53 & 75,10 & 90,60 & 12,47 \\
Ls/p & 556,12 & 734,69 & 652,04 & 62,45 & 76,90 & 11,79 \\
bw & 392,86 & 469,39 & 435,71 & 28,16 & 33,38 & 7,66 \\
lc & 76,53 & 102,04 & 90,82 & 8,98 & 11,06 & 12,18 \\
wc & 132,65 & 153,06 & 138,78 & 7,35 & 9,13 & 6,58 \\
lp & 45,92 & 96,94 & 74,49 & 12,65 & 18,61 & 24,98 \\
wp & 51,02 & 102,04 & 80,61 & 17,14 & 21,77 & 27,00 \\
lv & 37,62 & 56,44 & 44,06 & 5,36 & 6,47 & 14,67 \\
wv & 6,93 & 11,88 & 8,33 & 1,31 & 1,61 & 19,26 \\
lsf & 13,86 & 19,80 & 17,33 & 1,82 & 2,13 & 12,30 \\
If & 36,63 & 41,58 & 39,11 & 1,24 & 1,61 & 4,11 \\
a & 1,48 & 1,74 & 1,66 & 0,08 & 0,11 & 6,46 \\
\hline Ovos & & & & & & \\
lo & 95,36 & 113,40 & 103,09 & 3,87 & 5,38 & 5,22 \\
wo & 38,66 & 43,81 & 40,81 & 1,07 & 1,49 & 3,65 \\
\hline
\end{tabular}

*Valores expressos em $\mu \mathrm{m}$, exceto a (número absoluto). 